RAFAEL COUTO RODRIGUES DE OLIVEIRA

MODELAGEM E SIMULAÇÃO DE SISTEMA DE EMBALAGEM E PESAGEM DE MATERIAL PARTICULADO EM PÓ

São Paulo

2014 
RAFAEL COUTO RODRIGUES DE OLIVEIRA

\title{
MODELAGEM E SIMULAÇÃO DE SISTEMA DE EMBALAGEM E PESAGEM DE MATERIAL PARTICULADO EM PÓ
}

\author{
Dissertação apresentada à Escola \\ Politécnica da Universidade de São Paulo \\ para a obtenção do título de Mestre em \\ Engenharia \\ Área de concentração: \\ Engenharia de Sistemas \\ Orientador: \\ Prof. Dr. Claudio Garcia
}

São Paulo 
Este exemplar foi revisado e corrigido em relação à versão original, sob responsabilidade única do autor e com a anuência de seu orientador.

São Paulo, 13 de setembro de 2014.

Assinatura do autor

Assinatura do orientador

Catalogação-na-publicação

Oliveira, Rafael Couto Rodrigues de

Modelagem e simulação de sistema de embalagem e pesagem de material particulado em pó / R.C.R. de Oliveira. -- versão corr. -- São Paulo, 2014.

$94 \mathrm{p.}$

Dissertação (Mestrado) - Escola Politécnica da Universidade de São Paulo. Departamento de Engenharia de Telecomunicações e Controle.

1.Automação industrial (Controle) I.Universidade de São Paulo. Escola Politécnica. Departamento de Engenharia de Telecomunicações e Controle Il.t. 


\section{DEDICATÓRIA}

Esse trabalho é dedicado com todo meu carinho, aos meus pais Bazílio e Regina, ao meu irmão Daniel e a minha querida esposa Kátia. 


\section{AGRADECIMENTOS}

Ao meu orientador, Claudio Garcia, pela liderança, profissionalismo e dedicação com que conduziu as orientações dadas a este trabalho e com que conduz a pesquisa científica dentro da universidade. Por ir além do lado acadêmico, tendo a preocupação de motivar seus alunos e de fazer o máximo para a conciliação do trabalho acadêmico e o profissional dos mesmos.

Aos demais professores Baccalá e Trintinália da Escola Politécnica, pelos ensinamentos passados, que contribuíram, não somente para o desenvolvimento deste trabalho, mas também para a minha formação acadêmica e profissional.

À minha mãe Regina Fátima Couto de Oliveira e ao meu pai Bazílio Rodrigues de Oliveira Filho, por terem proporcionado, sem medir esforços, a melhor formação escolar e pessoal possível, com valores que fazem a diferença nos dias de hoje.

A minha esposa, Kátia Zanelato, por sempre me dar força e servir de exemplo para a conclusão do mestrado.

Ao meu irmão, Daniel Couto Rodrigues de Oliveira, por todo amor que temos um pelo outro.

As pessoas que fizeram a diferença na empresa que trabalhava para termos sucesso na construção dessa dissertação. 


\section{EPÍGRAFE}

"Se você quer ser bem sucedido, precisa ter dedicação total, buscar seu último limite e dar o melhor de si".

(Ayrton Senna)

"Há um grande desejo em mim de sempre melhorar. Melhorar, é o que me faz feliz. E sempre que sinto que estou aprendendo menos, que a curva de aprendizado está nivelando, ou seja o que for, então não fico muito contente. $E$ isso se aplica não só profissionalmente, como piloto, mas como pessoa".

(Ayrton Senna)

"É engraçado. Quando acho que cheguei ao ponto máximo, descubro que é possível superá-lo".

(Ayrton Senna) 


\section{RESUMO}

Esse trabalho é dedicado ao desenvolvimento de um simulador para sistema de pesagem e embalagem de produto em pó granulado. Tal simulador reproduz a variabilidade de peso dos cartuchos observados em um sistema de embalagem real. Para esse desenvolvimento foram aplicadas técnicas de Identificação de Sistemas para obter o modelo determinístico do processo e conceitos de Processos Estocásticos para reproduzir as perturbações. O simulador tem como objetivo a avaliação de propostas de melhorias nesse sistema de pesagem, visando reduzir o sobrepeso médio e a quantidade de cartuchos rejeitados por subpeso, denominados de scraps, diminuindo consequentemente as perdas monetárias do processo industrial de embalagem de produtos granulados, com grande potencial de reaplicação para outros tipos de produtos industrializados e sistemas de pesagem. $O$ desempenho do simulador é muito bom, uma vez que as oscilações observadas nos pesos dos cartuchos, devido à variação de densidade, são bem reproduzidas. Portanto as principais contribuições desse trabalho são: 1) o uso de uma abordagem estatística e inovadora para modelar as perturbações, evitando o estudo profundo de suas causas, alcançando um modelo preciso, que simula resultados de sobrepeso e número de cartuchos rejeitados bem próximo da realidade; 2) identificação e quantificação de melhorias no sistema de pesagem e embalagem, sem a necessidade de altos investimentos, dando a opção de decisão de quais melhorias realmente serão implementadas; 3) sobrepeso e scrap normalmente estão entre as três principais perdas monetárias das indústrias que produzem produtos embalados por peso e esse simulador representa uma forma de redução significativa dessas perdas, trazendo uma grande vantagem competitiva em um mercado cada vez mais acirrado.

Palavras-chaves: sistema de pesagem, sistema de embalagem, simulador de peso, pó granulado, sobrepeso, scrap, subpeso. 


\begin{abstract}
This work describes the development of a simulator for a packing and weighing system of granulated powder. This simulator reproduces the weight variability of observed cartons in a real packing system. In this development, System Identification techniques were used to obtain the deterministic part of the model and Stochastic Processes to reproduce disturbances. Its objective is to evaluate proposed improvements in the packing and weighing system, aiming at reducing the overweight average and the quantity of rejected cartons by underweight, denominated scraps, cutting down consequently the monetary losses of the granulated product packing process in the industry, with great reapplication potential to other kind of industry products and weighing systems. The simulator performance is very satisfactory, once the oscillations observed in the carton weights, due to powder density variability, are well reproduced. Hence, the main contributions of this work are: 1) use of a statistical and innovative approach to model the disturbances, avoiding a deep study of their causes, achieving a model that provided precise simulated overpacking and scrap results when compared to reality; 2) identification and quantification improvements of the weighing and packing system, with no large investment, giving the option of decision of which improvement will be actually implemented; 3) overweight and scrap are among the three main monetary losses in the industries that make products packed in weight and so this simulator of a packing and weighing system of granulated powder represents a way of reducing significantly these losses, bringing a big competitive advantage in a demanding market.
\end{abstract}

Keywords: weighing system, packing system, weighing simulator, granulated powder, overweight, scraps, underweight. 


\section{LISTA DE ILUSTRAÇÕES}

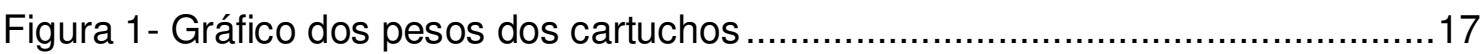

Figura 2- Diferença estatística entre o processo amostrado e o processo real.........18

Figura 3 - Representação da planta de detergente em pó. .......................................23

Figura 4- Diagrama de malha fechada do sistema de pesagem. ...........................24

Figura 5- llustração do conjunto de canecas......................................................24

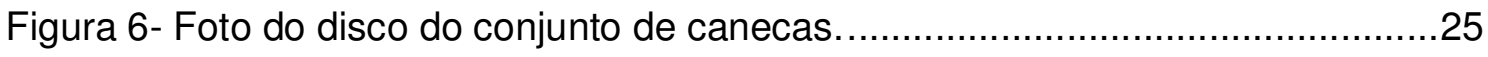

Figura 7- Foto do raspador da cabeça dosadora. .............................................25

Figura 8 - Foto da checkweigher - a) em funcionamento, b) parada........................26

Figura 9- Estrutura principal do simulador - três grandes blocos.............................29

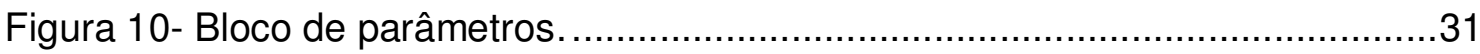

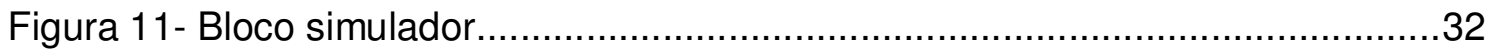

Figura 12- Tensão de saída da célula de carga da checkweigher. ............................34

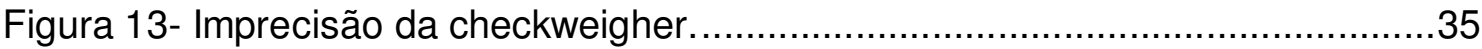

Figura 14- Diagrama em blocos do modelo da checkweigher..................................35

Figura 15- Autocorrelação normalizada do sinal de entrada..................................36

Figura 16- Comparação entre os pesos de saída total w(k) e de saída da função de

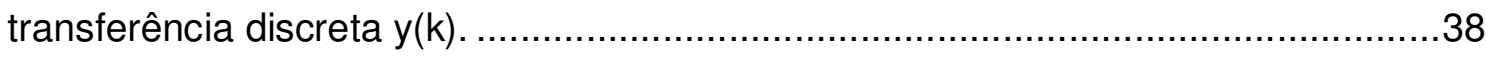

Figura 17- Histograma da imprecisão da checkweigher - passo de 1,5g ...............39

Figura 18 - Comparação da autocorrelação do ruído da checkweigher com um RGB.

Figura 19- Diagrama do modelo da checkweigher no Simulink ................................41

Figura 20- Gráfico comparando o peso com e sem variação das canecas................43

Figura 21- Histograma da distribuição das diferenças de pesos locais do teste de

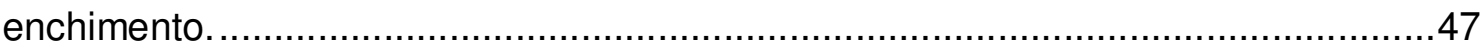

Figura 22- Diagrama em blocos do conjunto de canecas......................................48

Figura 23- Modelo do conjunto de canecas.........................................................

Figura 24- Modelo de uma caneca....................................................................... 49

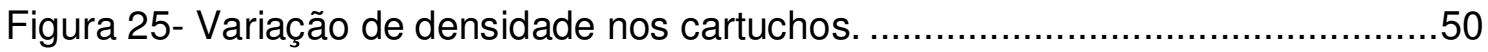

Figura 26- Gráfico de variação de densidade de curto prazo.....................................53

Figura 27 - Histograma da variação da densidade de curto prazo - passo de $1 \mathrm{~g}$...53

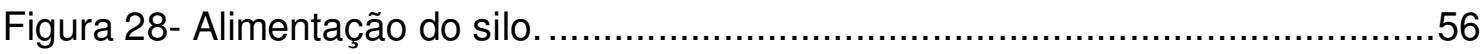


Figura 29- Histograma da densidade dos buggies - passo de $2 \mathrm{~g}$. .58

Figura 30- Parte dos dados de pesos coletados - eixo x em amostras e eixo y em $\mathrm{g}$.

Figura 31- Autocorrelação de trinta mil pesos - ampliação à direita. 62

Figura 32 - Gráficos das correlações cruzadas normalizadas das formas de oscilação encontradas. 63

Figura 33 - Autocorrelação das oscilações de seno curto. ...................................64

Figura 34- Autocorrelação das oscilações de seno longo / triangular. .......................65

Figura 35 - Autocorrelação das oscilações de rampa lenta....................................65

Figura 36- Autocorrelação das oscilações de rampa brusca....................................65

Figura 37- Modelo do bloco gerador de densidade...........................................

Figura 38- Gerador de densidade no Simulink ......................................................

Figura 39- Gerador de densidade média dos buggies. .......................................

Figura 40- Gerador de densidade de médio prazo..............................................

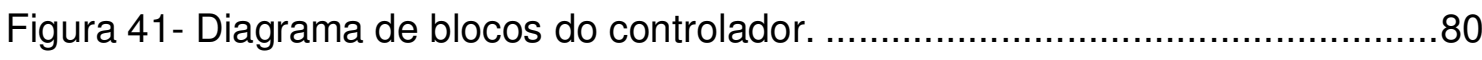

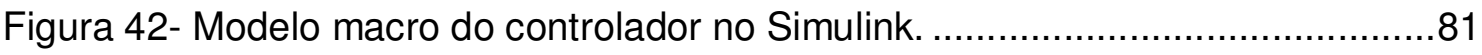

Figura 43- Modelo da parte do controlador e partes físicas que controlam a altura

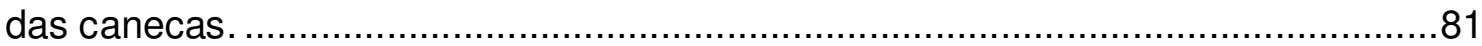

Figura 44- Bloco de cálculo de perdas monetárias. ............................................

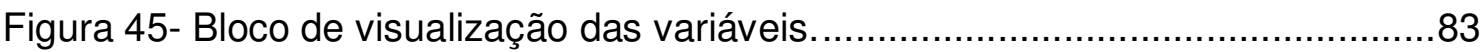

Figura 46- Gráfico dos pesos e das atuações do controlador gerados pelo simulador.

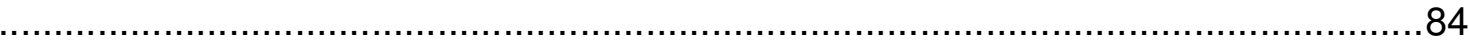

Figura 47- Gráfico de pesos e densidade da simulação de 6 horas..........................85

Figura 48- Comparação de pesos reais e simulados. ..........................................

Figura 49- DEP (baseada em FFT unilateral) para os pesos simulados e reais com

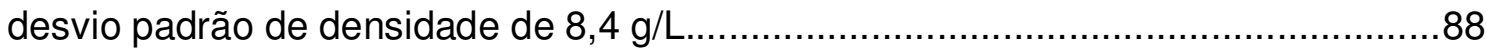

Figura 50- Ampliação em DEP (baseada em FFT Unilateral) de pesos reais e simulados para desvio padrão de densidade de $8,4 \mathrm{~g} / \mathrm{L}$ .89

Figura 51- Ampliação em DEP (baseada em FFT Unilateral) de pesos reais e simulados para desvio padrão de densidade de $8,4 \mathrm{~g} / \mathrm{L}$. 


\section{LISTA DE TABELAS}

Tabela 1 - Pesos mínimos para faixa de valores nominais. ......................................14

Tabela 2- Média estabelecida para amostragem de produtos................................15

Tabela 3- Diferença de peso média entre as canecas. ...........................................42

Tabela 4- Resultado da análise estatística das formas de onda.............................69

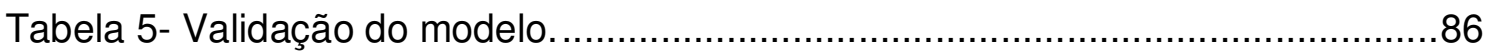




\section{LISTA DE ABREVIATURAS E SIGLAS}

DEP Densidade Espectral de Potência

INMETRO Instituto Nacional de Metrologia, Normalização e Qualidade Industrial

IIS Interferência Inter-Simbólica

ISI Identificador de Situação Indesejada

PLC Programmable Logic Controller

RGB Ruído Gaussiano Branco 


\section{SUMÁRIO}

CATALOGAÇÃO-NA-PUBLICAÇÃO

1. INTRODUÇÃO..........................................................................14

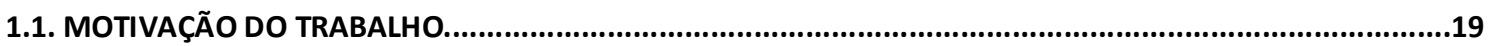

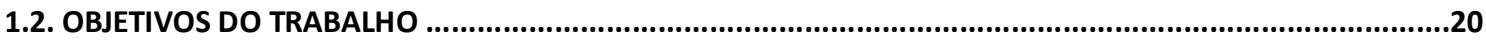

1.3. REVISÃO RESUMIDA DA LITERATURA E LEVANTAMENTO DE DADOS E INFORMAÇÕES............................21

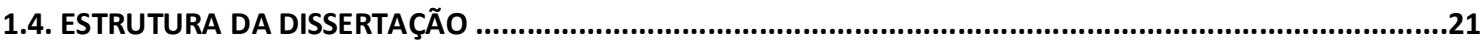

\section{DESCRIÇÃO DO PROBLEMA E DOS SISTEMAS ENVOLVIDOS ..23}

2.1. DESCRIÇÃO DA PLANTA E DO SISTEMA DE CONTROLE .................................................................................

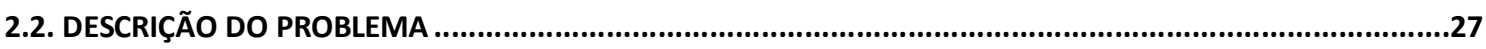

3. DESENVOLVIMENTO DO SIMULADOR ......................................28

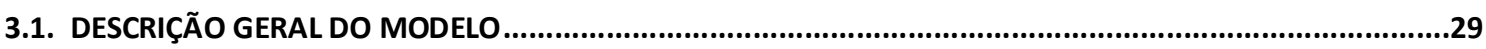

3.2. BLOCO DE PARÂMETROS DO SISTEMA .....................................................................................................30

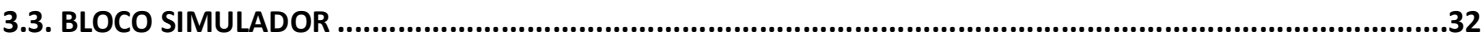

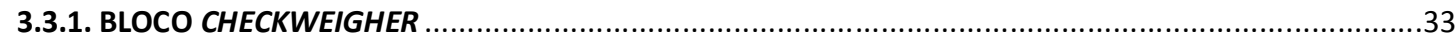

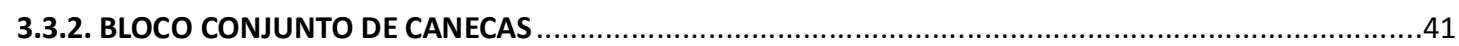

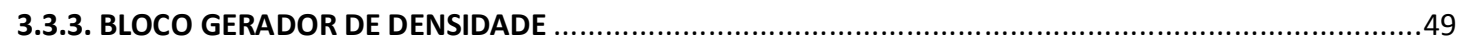

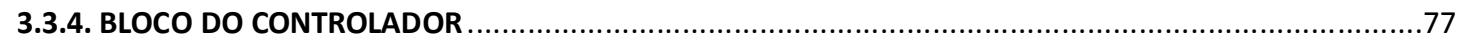

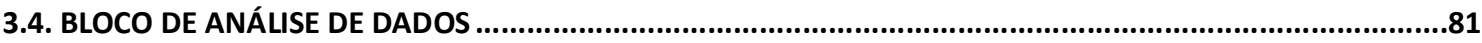

4. VALIDAÇÃO DO SIMULADOR ........................................................

5. CONCLUSÕES E AVALIAÇÃO DE REAPLICAÇÃO........................90

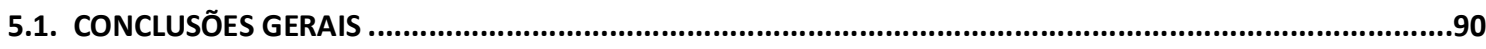

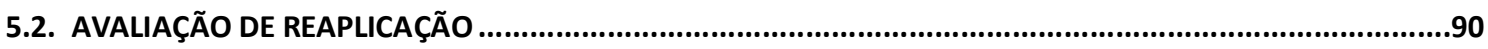

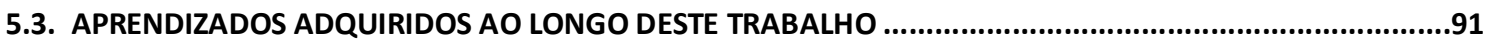

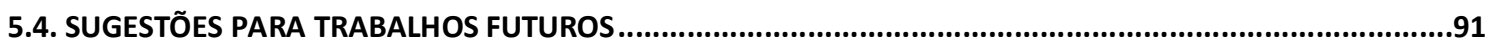




\section{INTRODUÇÃO}

A lei brasileira do Código de Defesa do Consumidor estabelece valores de média e de peso mínimo, para os produtos vendidos por peso ou volume em embalagens padrão (ref. Lei № 5966 e Lei № 9933 da portaria № 096 do Ministério do Desenvolvimento, Indústria e Comércio exterior). Por exemplo, para embalagens de $1000 \mathrm{~g}$, o peso ${ }^{1}$ mínimo é $985 \mathrm{~g}$ (15g a menos que o valor nominal), como mostrado na Tabela 1.

Tabela 1 - Pesos mínimos para faixa de valores nominais.

\begin{tabular}{|c|c|c|}
\hline & \multicolumn{2}{|c|}{ Tolerância Individual $T$} \\
\hline $\begin{array}{c}\text { Conteúdo nominal } Q n \text { (g ou } \\
\mathrm{ml})\end{array}$ & Percentual de $Q n$ & $\mathrm{~g}$ ou ml \\
\hline 5 a 50 & 9 & - \\
\hline 50 a 100 & - & 4,5 \\
\hline 100 a 200 & 4,5 & - \\
\hline 200 a 300 & - & 9 \\
\hline 300 a 500 & 3 & - \\
\hline 500 a 1000 & - & 15 \\
\hline 1000 a 10000 & 1,5 & - \\
\hline 10000 a 15000 & - & 150 \\
\hline 15000 a 25000 & 1 & - \\
\hline
\end{tabular}

Obs.: 1 - Valores de T para Qn, menor ou igual a $1000 \mathrm{~g}$ ou $\mathrm{ml}$, devem ser arredondados em $0,1 \mathrm{~g}$ ou $\mathrm{ml}$ para mais.

2- Valores de Tpara Qn maior que 1000g ou ml, devem ser arredondados para o inteiro superior em gou $\quad \mathrm{ml}$.

A Tabela 2 mostra a fórmula utilizada para a média, levando em conta o desvio padrão da amostra feita pelo Instituto Nacional de Metrologia, Normalização e Qualidade Industrial (INMETRO).

\footnotetext{
${ }^{1}$ Durante todo o texto é usada a unidade de medida gramas para quantificar o peso dos cartuchos. Isso é feito para facilitar o entendimento e não complicar os cálculos, uma vez que se deveria multiplicar a massa por $9,8 \mathrm{~m} / \mathrm{s}^{2}$ para obter-se o peso.
} 
Tabela 2- Média estabelecida para amostragem de produtos.

\begin{tabular}{|c|c|c|}
\hline Lote & Amostra do lote & $\begin{array}{c}\text { Critério de aceitação para a } \\
\text { média }\end{array}$ \\
\hline 5 & 5 & $\bar{x} \geq Q n-2,059 s$ \\
\hline 6 & 6 & $\bar{x} \geq Q n-1,646 s$ \\
\hline 7 & 7 & $\bar{x} \geq Q n-1,401 s$ \\
\hline 8 & 8 & $\bar{x} \geq Q n-1,237 s$ \\
\hline 9 & 9 & $\bar{x} \geq Q n-1,118 s$ \\
\hline 10 & 10 & $\bar{x} \geq Q n-1,028 s$ \\
\hline 11 & 11 & $\bar{x} \geq Q n-0,995 s$ \\
\hline 12 & 12 & $\bar{x} \geq Q n-0,897 s$ \\
\hline 13 & 13 & $\bar{x} \geq Q n-0,847 s$ \\
\hline 14 a 49 & 14 & $\bar{x} \geq Q n-0,805 s$ \\
\hline
\end{tabular}

$\bar{x}=$ a média da amostra

$Q n=0$ conteúdo nominal do produto

$s=0$ desvio padrão da amostra

O processo de inspeção realizado pelo INMETRO para verificar as duas regulamentações é feito através de uma amostragem de produtos retirados da prateleira de um supermercado qualquer. Essa amostragem pode variar de 5 a 14 amostras, de acordo com o número de produtos encontrados na prateleira (ver Tabela 2).

O peso líquido individual de cada amostra é medido e a média é calculada em função de tais pesos. As condições para a amostragem ser aprovada são: nenhum peso individual pode estar abaixo do peso mínimo e a média da amostragem deve satisfazer à respectiva inequação da Tabela 2 . Se a amostragem não satisfaz a inequação, temse $99,5 \%$ de certeza que a média da produção inteira está abaixo do valor nominal do pacote. Isso ocorre, pois o teste de hipóteses que determina a inequação é feito considerando uma distribuição $t$ de student (Leon-Garcia, 1994), a qual é uma distribuição de probabilidade muito semelhante e derivada da curva normal padrão, porém com caudas mais largas, uma vez que sua variável aleatória é dividida pelo desvio padrão amostrado e não pelo real da população. A distribuição $t$ de student só é obtida quando a população amostrada tem distribuição normal. O único parâmetro que a define e caracteriza a sua forma é o número de graus de liberdade, e quanto maior for esse parâmetro, mais próxima da normal ela será.

Caso uma das duas condições não seja verdadeira, a amostragem é reprovada, e a respectiva empresa é notificada com uma multa que vai aumentando 
exponencialmente, de acordo com o número de notificações no período de um ano. Em 2013, as mesmas iniciavam com valores em torno de $\mathrm{R} \$ 1.000,00$ podendo chegar a $\mathrm{R} \$ 500.000,00$, além da exposição negativa na mídia.

Não existe uma regra determinada pelo INMETRO de quantas amostragens serão feitas para cada produto no período de 1 ano, mas sabe-se que o número de amostragens é aumentado significativamente (100 - 500\%) caso seja encontrada uma amostragem que não cumpra com as duas condições.

Portanto, a existência de sobrepeso e de embalagens rejeitadas por estarem abaixo do peso mínimo estabelecido (conhecidas como scraps) em máquinas embaladoras de grande velocidade, para materiais particulados em pó é um problema presente em grandes empresas que se utilizam desse sistema. O sobrepeso é o quanto a média do peso dos pacotes embalados está acima do valor nominal do pacote.

A Figura 1 mostra como esse sobrepeso e scrap ocorrem. Devido principalmente à variabilidade da densidade do material particulado em pó e algumas imprecisões no processo de enchimento e de medida, existe uma grande variabilidade do peso dos pacotes no tempo (em azul). Essa variabilidade ocorre em diferentes velocidades, como a rápida de cartucho a cartucho, as médias entre 200 e 1200 cartuchos e as lentas para mais de 1500 cartuchos. Para reduzir o número de pacotes rejeitados (abaixo da linha vermelha) é necessário encher os pacotes em média com valores superiores ao valor nominal (linha verde), colocando um set point no controlador (linha rosa) acima desse valor nominal. As linhas amarela e azul claro representam a zona morta do controlador que são explicadas em detalhe mais adiante. 


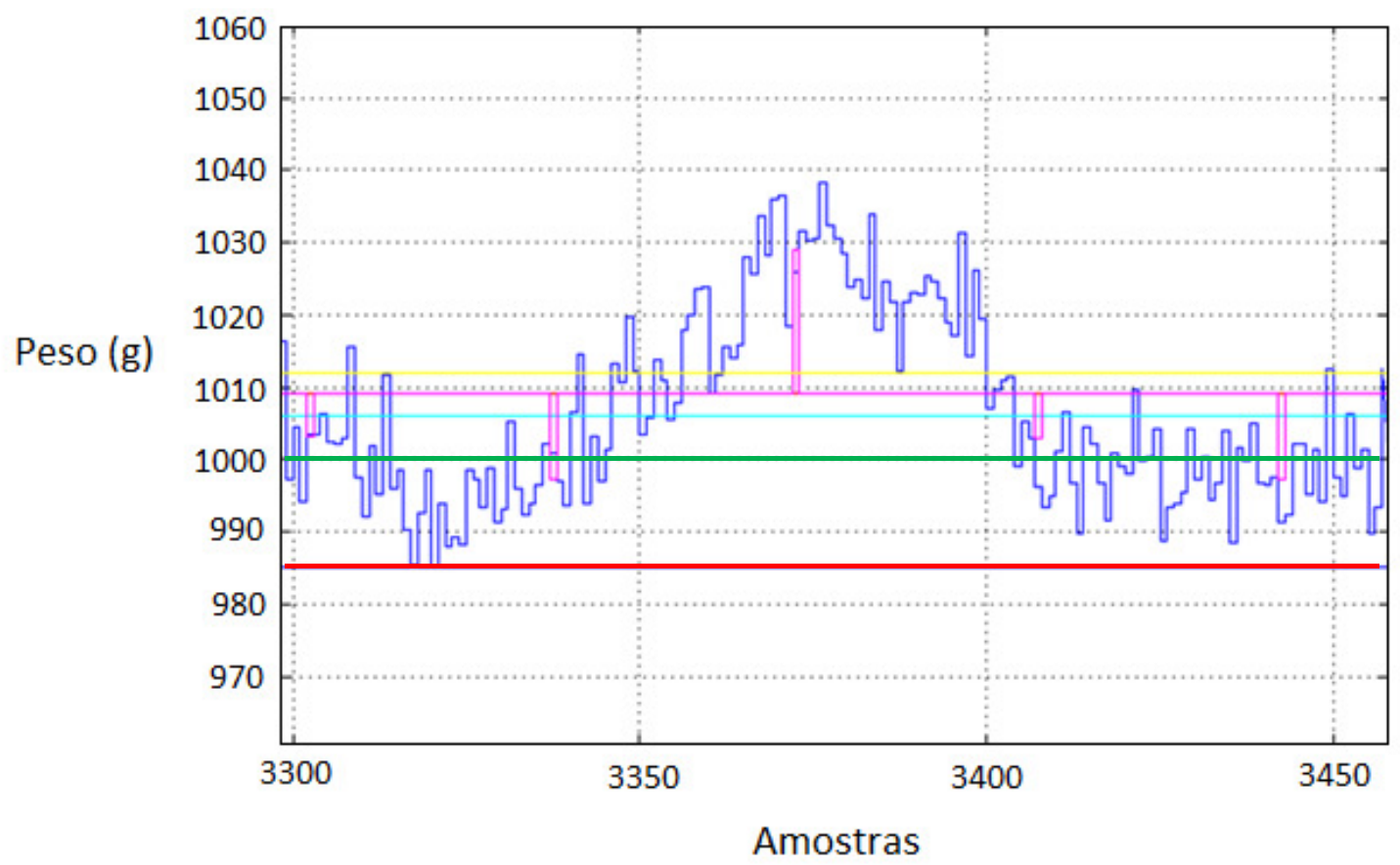

Figura 1- Gráfico dos pesos dos cartuchos

O sobrepeso e scrap estão na grande maioria das vezes entre as três principais perdas monetárias de uma fábrica que fornece produtos embalados por peso, e em muitas é a principal. Essa perda normalmente está entre 0,5 e $3 \%$ do faturamento total das indústrias e pode representar até $30 \%$ do lucro (informação verbal) $)^{2}$.

Esse problema é intensificado, uma vez que o INMETRO usa um critério estatístico considerando uma produção não correlacionada, isto é, uma produção em que o peso do pacote atual não depende do peso do pacote anterior, sendo um processo estocástico independente, o que não é verdade na prática, como mostra a Figura 2, pois o controle do processo é volumétrico, uma vez que ele visa manter o peso dos pacotes no valor desejado (referência do sistema de controle) através da variação do volume do material que preenche os pacotes, com o objetivo de compensar a variação de densidade que é correlacionada. Além disso, algumas das imprecisões do sistema de enchimento também são correlacionadas, aumentando a imprecisão do sistema usado pelo INMETRO.

\footnotetext{
${ }^{2}$ Essa informação é baseada em conhecimento do autor, por trabalhar no ramo industrial na área de embalagem e pesagem, e também pelos donos de empresas fabricantes de máquinas de embalagem industriais como a Masipack, Packform e ACMA.
} 

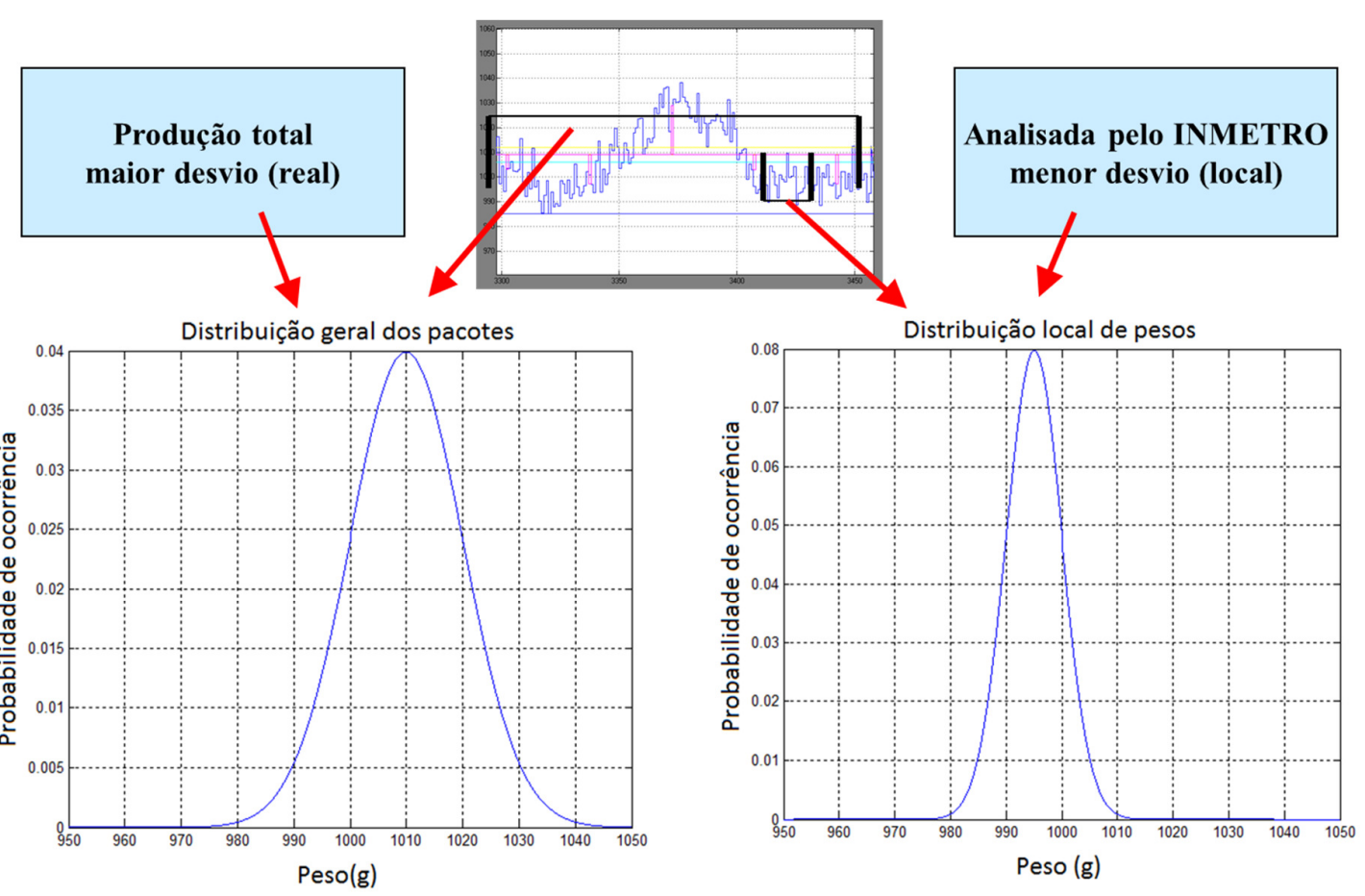

Figura 2- Diferença estatística entre o processo amostrado e o processo real.

Dessa forma, o desvio padrão da amostragem mencionado anteriormente é referente na maioria dos casos, a uma sequência pequena da produção e, consequentemente tem um valor muito menor que o valor do desvio padrão real de toda a produção, o que faz com que seja ainda mais difícil de satisfazer as inequações da Tabela 2. A consequência é se ter mais sobrepeso ainda para poder satisfazer tal condição.

Estes problemas são extremamente difíceis de serem resolvidos na prática, pois para a implementação de qualquer tentativa prática de melhoria do sistema de embalagem ou de fabricação seria necessário um investimento consideravelmente alto, além de não se saber se a tentativa reduziria as perdas, ou mesmo, não se saber o quanto traria de redução de perdas, o que poderia não justificar o investimento.

Portanto, a ideia de se desenvolver um simulador capaz de representar a fabricação, a pesagem e a embalagem do material, é uma saída bastante adequada, pois nele pode-se identificar e quantificar melhorias capazes de reduzir o sobrepeso e scrap, reduzindo desta forma as perdas monetárias, sem a necessidade de altos investimentos, muitas vezes na ordem de milhões de reais. 
O modelo desenvolvido engloba a fabricação do material, uma máquina para pesar e embalar, e um sistema de controle para controlar o peso dos pacotes embalados. Tal sistema reflete a realidade de uma grande indústria de bens de consumo, na qual o projeto foi desenvolvido e implementado com sucesso.

\subsection{MOTIVAÇÃO DO TRABALHO}

A maioria das companhias que embalam produtos granulados em pó usam o mesmo sistema de enchimento e os problemas de sobrepeso e scrap estão sempre entre as principais perdas monetárias, na faixa de $0,5 \%$ a $3 \%$ do total das vendas. Para detergente em pó, que tem um mercado de aproximadamente $\mathrm{R} \$ 2$ bilhões no Brasil, a perda total de sobrepeso e scrap está estimada na ordem de $\mathrm{R} \$ 50$ milhões. $\mathrm{O}$ potencial de redução é ainda muito maior, se esse conceito for aplicado globalmente para outros tipos de produtos granulados, ou mesmo outros tipos de produtos como líquidos e comida (Cronin,1999), (Cronin et al., 2003). Portanto, esse modelo de sistema de pesagem e embalagem de produto granulado em pó representa uma chance de grande economia para esse tipo de indústria (Oliveira; Garcia, 2013).

Nesse tipo de problema, com muitas variáveis de impacto, mudanças são normalmente muito caras e algumas vezes, por mais que se saiba que elas vão melhorar o processo, não se sabe quanto. Então, uma abordagem inovadora é proposta para essa aplicação industrial, através de um simulador capaz de detectar as causas das perdas monetárias, devido ao grande número de scraps e do elevado sobrepeso, e consequentemente, identificar e quantificar melhorias para o sistema em questão, fazendo com que o fabricante possa decidir implementar ou não tais modificações, baseado em uma análise de custo benefício, que é o principal objetivo do trabalho (Carrasco; Dormido, 2006).

É conhecido nesse caso, que a modelagem da perturbação do sistema, que é a variação de densidade, tem muitas causas primárias e desconhecidas, sendo um desafio a criação de um modelo preciso. Com isso, tentar fazer o modelo através do estudo das causas primárias seria algo que tomaria um tempo incompatível com os objetivos do trabalho, ou mesmo, seria impossível com as ferramentas conhecidas 
hoje em dia. Portanto, a visão de conseguir fazer tal modelagem através de uma abordagem estocástica, alcançando alto grau de precisão e que possa ser utilizada em trabalhos futuros, foi uma importante motivação do trabalho.

$\mathrm{Na}$ segunda etapa deste trabalho, a qual será uma tese de Doutorado, serão mostradas melhorias testadas e implementadas de todas as espécies, como alterações físicas na máquina de embalagem, alterações no processo de fabricação do material, alterações no sistema de controle utilizado, além de alguns novos algoritmos, sendo alguns deles inovadores, tendo ajuste automático de set point do sistema de controle, de forma a minimizar as perdas.

Como mencionado anteriormente, foi utilizado como estudo de caso, uma fábrica de sabão em pó, sem perda de generalidade, pois o tipo de máquina que foi utilizado para o modelo é usado para embalar muitos tipos de materiais particulados em pó e ainda, qualquer pequena diferença entre máquinas embaladoras é facilmente adaptável no simulador.

\subsection{OBJETIVOS DO TRABALHO}

Os objetivos do trabalho são três e estão bem alinhados com a motivação do mesmo.

a. Produzir uma ferramenta chave que possa ser usada para fazer a diferença na redução de sobrepeso e rejeitos por peso baixo na indústria, uma vez que o atual conhecimento do tema e recursos disponíveis para resolver o problema são limitados, razões pelas quais os resultados obtidos na maioria das indústrias são muito ruins;

b. Desenvolver um simulador capaz de identificar e quantificar melhorias do sistema em questão, evitando testes caros ou impossíveis; e

c. Criar um modelo preciso de perturbação baseado em um estudo estocástico e não pelos princípios primários ou testes forçados. 


\subsection{REVISÃO RESUMIDA DA LITERATURA E LEVANTAMENTO DE DADOS E INFORMAÇÕES}

$\mathrm{Na}$ pesquisa realizada em busca de informações para realizar esse trabalho, não foram encontrados nem artigos técnicos descrevendo simuladores de sistema de embalagem ou pesagem e nem qualquer documentação que minimamente se assemelhe ao modelo e simulação aqui presentes. Por essa razão, nenhuma outra referência deste tipo de simulador foi mencionada, e todas as ideias apresentadas aqui para a modelagem e simulação de sistema de embalagem e pesagem foram criadas pelo autor. Essa originalidade é a principal novidade desse trabalho.

A primeira etapa da pesquisa foi o levantamento de dados e informações necessárias para poder entender o sistema em questão e então partir para a criação do modelo. Esse levantamento foi elaborado com base em quatro fontes principais de informação:

- Coleta intensiva de dados do sistema de controle de peso na fábrica em questão. Foram realizados inúmeros testes e conversas com pessoas-chave no processo de embalagem e enchimento do material particulado em pó.

- Leitura dos manuais de todos os equipamentos usados no sistema de embalagem e pesagem.

- Leitura de livros de modelagem e controle, estatística e processos estocásticos.

- Leitura das leis normativas do sistema de pesos e medidas determinadas pelo INMETRO.

\subsection{ESTRUTURA DA DISSERTAÇÃO}

Esta dissertação está estruturada da seguinte forma:

1. Capítulo 2 - Descrição do problema e dos sistemas envolvidos, fazendo-se uma explicação mais detalhada do problema de sobrepeso e scrap, da planta e do sistema de controle em questão.

2. Capítulo 3 - Desenvolvimento do Simulador. Neste capítulo é feita uma descrição detalhada de como o simulador foi construído, explicando-se cada 
um dos blocos com suas respectivas técnicas de identificação das partes determinísticas e estocásticas, bem como o processo de validação utilizado.

3. Capítulo 4 - Validação do Simulador. O simulador é validado através de três métodos: comparação visual dos gráficos de pesos, comparação dos resultados de saída (sobrepeso e scrap) para dadas variabilidades de densidade, medidas a partir do desvio padrão e através da análise de frequência dos dados de peso.

4. Capítulo 5-Conclusões e Avaliação de Reaplicação. Para terminar, o trabalho descreve as conclusões do processo de criar um simulador como forma de viabilizar economicamente projetos de redução de custo, o resultado desse simulador e o potencial de reaplicação do conceito e desse simulador a outros casos da indústria. 


\section{DESCRIÇÃO DO PROBLEMA E DOS SISTEMAS ENVOLVIDOS}

\subsection{DESCRIÇÃO DA PLANTA E DO SISTEMA DE CONTROLE}

Para melhor compreensão do sistema, é necessária uma descrição geral da planta. O material particulado em pó é fabricado na própria planta e armazenado em silos móveis (buggies), organizados em um grande galpão localizado no andar acima do sistema de embalagem. No caso em questão, o produto fabricado é detergente em pó.

O material contido nesses silos é despejado frequentemente em um silo fixo, localizado na parte de cima do andar inferior. Deste silo fixo, o material é despejado na cabeça dosadora da máquina embaladora e posteriormente ele é transferido para os pacotes que são vendidos no mercado. O esquema descrito é mostrado na Figura 3.

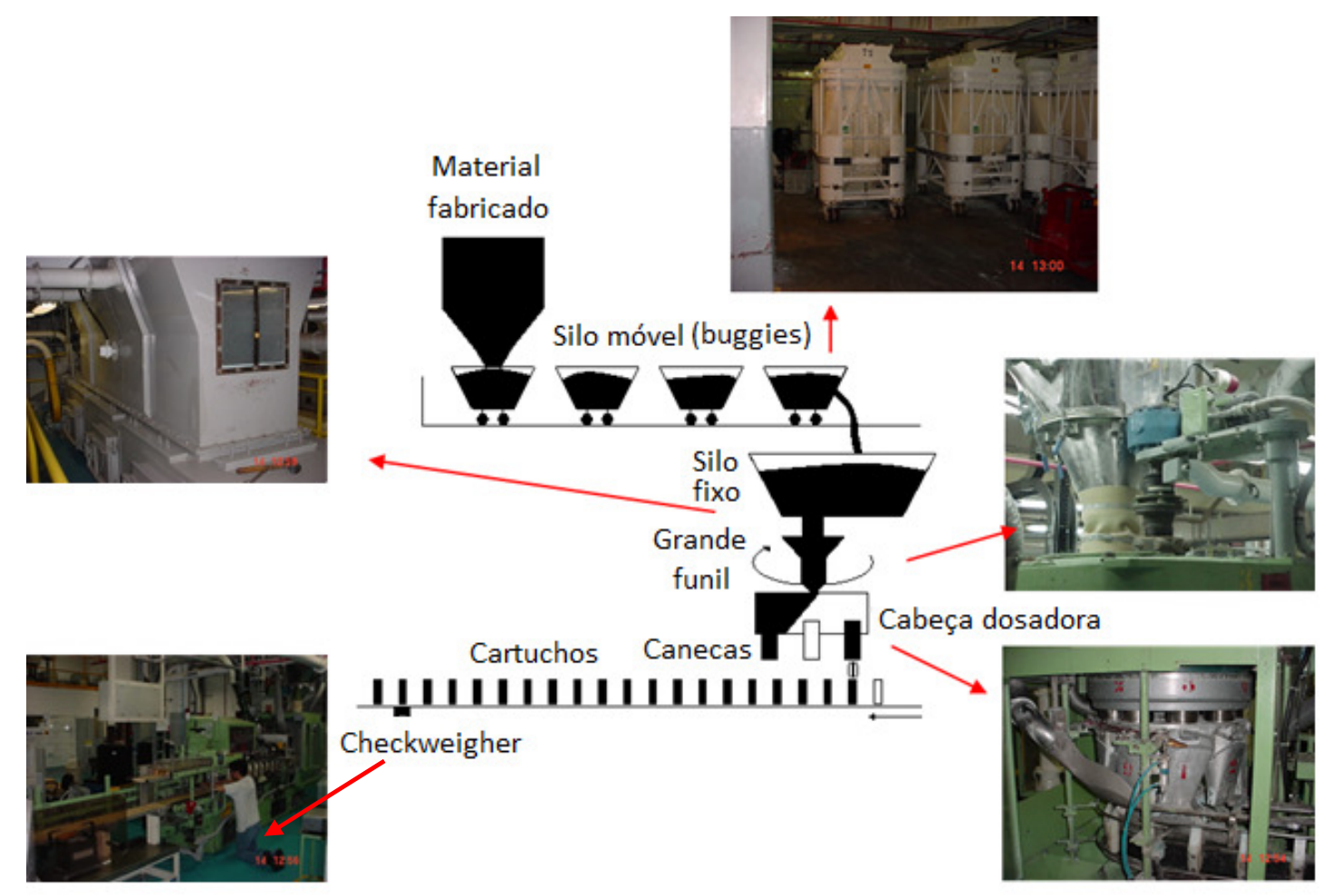

Figura 3 - Representação da planta de detergente em pó. 
Na Figura 4 é mostrado o diagrama da malha fechada do sistema de controle de peso.

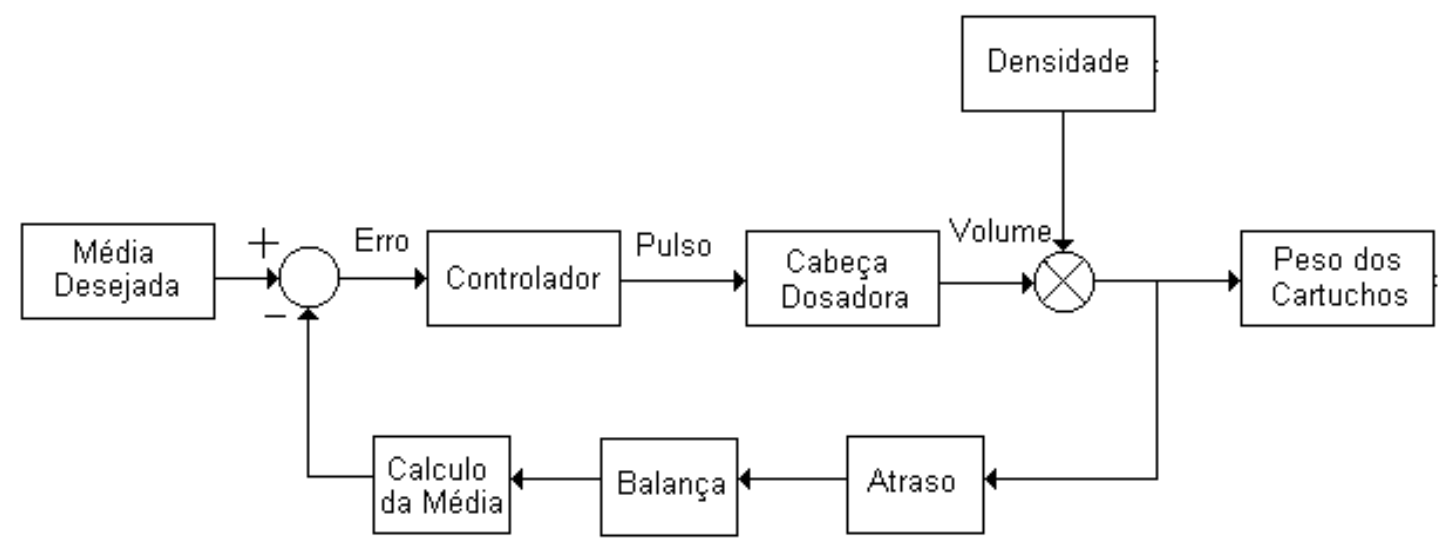

Figura 4- Diagrama de malha fechada do sistema de pesagem.

Na máquina embaladora existe uma cabeça dosadora de material particulado em pó.

Ela é constituída de duas partes: cabeça propriamente dita (disco superior) e um conjunto de nove canecas, onde se dosa o material antes de ser empacotado. Através do movimento vertical acionado por um motor e uma rosca sem fim, se controla a altura das canecas, alterando assim o volume de material que será entregue aos pacotes. O controle de altura é possível, pois a cabeça desliza sobre as canecas. Nas Figura 5 e 6 pode-se observar um esquema do conjunto.

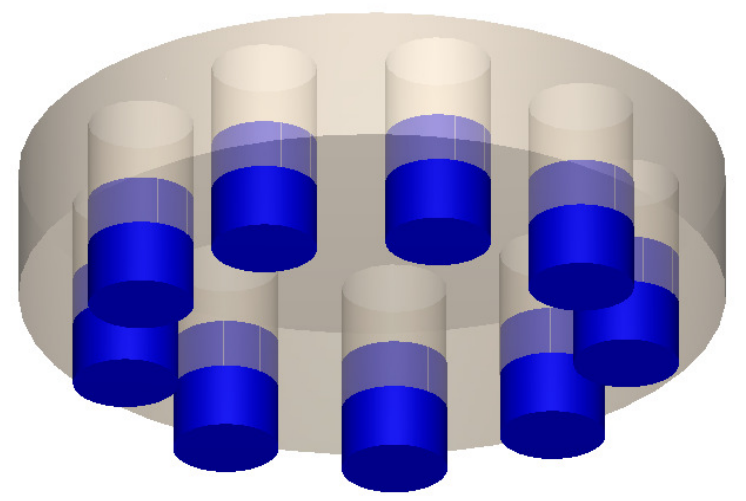

Figura 5- llustração do conjunto de canecas. 


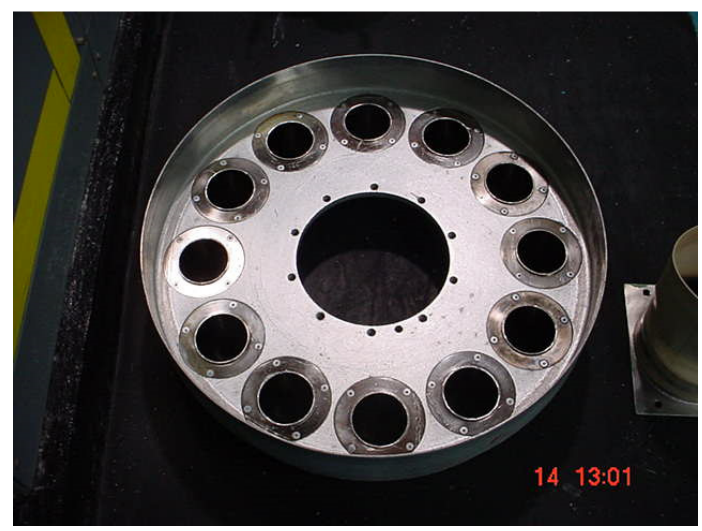

Figura 6- Foto do disco do conjunto de canecas.

Os cilindros inferiores (canecas) têm um diâmetro ligeiramente menor $(0,1 \mathrm{~mm})$ que 0 diâmetro dos cilindros superiores, que são fixos no disco da cabeça dosadora. $\mathrm{O}$ motor, que faz o disco subir e descer, é acionado por um pulso de tempo determinado, que é calculado pelo sistema de controle.

A cabeça dosadora ainda tem um raspador localizado $0,5 \mathrm{~mm}$ acima do disco superior, para garantir que o topo dos cilindros tenha uma camada uniforme de produto, diminuindo a variação de enchimento, como mostra a Figura 7.

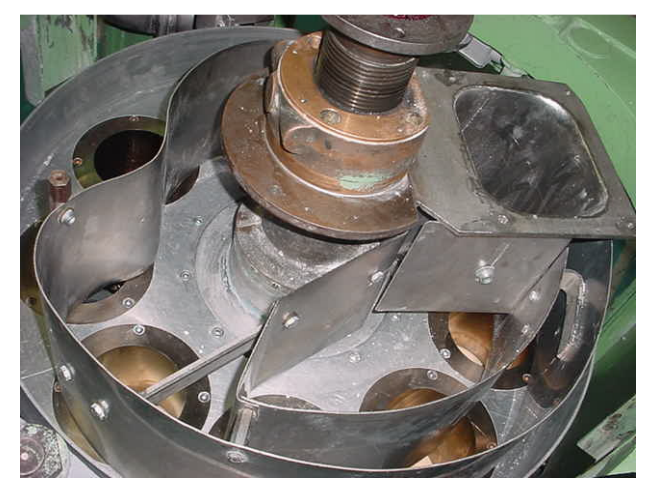

Figura 7- Foto do raspador da cabeça dosadora.

Como se pode observar na Figura 3, a cabeça dosadora permanece girando, sendo que em uma região as canecas são enchidas pelo topo e em outra região elas são esvaziadas, através da abertura de uma tampa inferior. O volume total das canecas é de cerca de 2 litros, uma vez que a massa específica média é em torno de $500 \mathrm{~g} / \mathrm{l}$ e o peso nominal é $1000 \mathrm{~g}$. 
A checkweigher (célula de carga dinâmica) é um dispositivo capaz de efetuar a pesagem dos pacotes a uma grande velocidade e enviar os dados para o controlador. A velocidade da máquina pode chegar a quatro cartuchos e meio por segundo, quando os mesmos são de $500 \mathrm{~g}$ e três cartuchos por segundo, quando eles são de $1 \mathrm{~kg}$. A Figura 8 mostra a foto de uma checkweigher. Pode-se verificar do lado esquerdo da Figura 8b o carrinho onde são armazenados os cartuchos rejeitados, que depois são reprocessados, perdendo-se a embalagem dos mesmos.

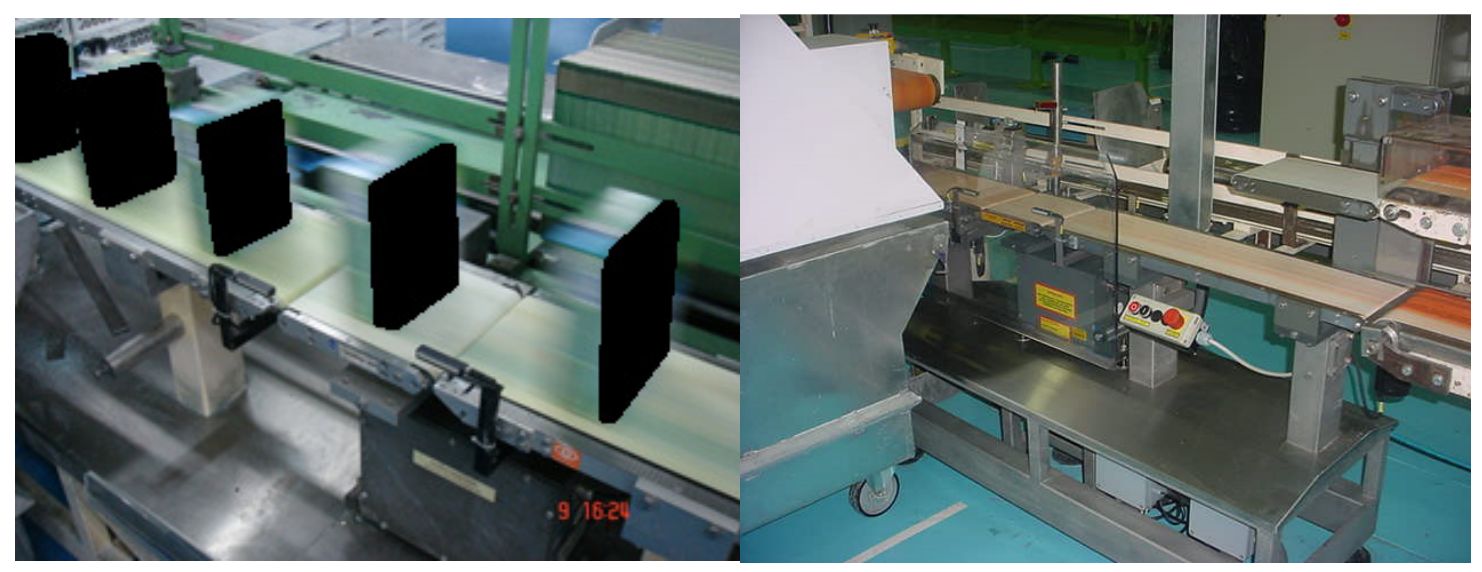

Figura 8 - Foto da checkweigher - a) em funcionamento, b) parada.

A balança é localizada a uma distância de vinte e oito pacotes, contados a partir do local onde as canecas foram totalmente enchidas. Na Figura 3 tem-se uma ilustração do atraso. Este atraso existe, pois logo que os cartuchos são enchidos, eles são fechados através da colagem de suas abas e para realizar tal colagem, é necessário um trecho de esteira de movimento contínuo, o qual causa esse atraso.

Para controlar o peso dos pacotes, o controlador envia um comando pulsado para o motor, de forma a ajustar a altura e, consequentemente, o volume das canecas, tentando assim compensar principalmente as variações da densidade do produto. $A$ lógica de controle, que é explicada no capítulo 3, é executada pela própria checkweigher, através do circuito eletrônico da mesma. Os parâmetros desse controlador são ajustados através da tela de interface da checkweigher com o usuário e podem ser armazenados na forma de receitas para cada tamanho de pacote produzido. 


\subsection{DESCRIÇÃO DO PROBLEMA}

Os principais problemas encontrados no sistema de pesagem estudado são:

1. O atraso entre a cabeça dosadora e a checkweigher, o qual é conhecido como tempo morto;

2. A grande e rápida variabilidade de densidade do produto particulado.

Além desses dois principais problemas, existem outros. Dentre eles, a imprecisão da checkweigher, que devido à sua alta velocidade, tem efeito residual do peso de um cartucho no seguinte e outras imprecisões dinâmicas, como oscilação do cartucho na esteira. Existem também imprecisões consideráveis de enchimento das canecas, por questões de variação de dimensão física das mesmas e problemas para conseguir um enchimento uniforme, os quais são descritos no capítulo 3 .

Com a intenção de estudar esses efeitos e propor melhorias para o sistema, sem o investimento de capital, um simulador foi desenvolvido, como descrito no próximo capítulo. Tal simulador torna possível entender esses principais fenômenos da planta, bem como avaliar o impacto de modificações na planta, no sistema de controle e nas perturbações de densidade, visando identificar e quantificar benefícios antes da implementação real. 


\section{DESENVOLVIMENTO DO SIMULADOR}

O simulador foi desenvolvido utilizando os programas Simulink 4.0 e Matlab 6.0. Ele é constituído de três blocos principais, sendo que cada bloco tem sub-blocos internos. Os três blocos são: um bloco das variáveis do sistema (bloco de parâmetros), um bloco que constitui a modelagem do sistema em questão (bloco do simulador) e um bloco de análises de dados.

O bloco das variáveis do sistema foi utilizado para que nas simulações se possa alterar os valores das mesmas e quantificar essas mudanças, como por exemplo, alterar a média desejada dos pesos dos pacotes no controlador. A alteração desse parâmetro afeta as perdas, pois quanto maior esse valor, menor o número de rejeitados (scraps), mas maior o sobrepeso, ou seja, se ganha de um lado e se perde do outro.

O bloco de modelagem do sistema é formado pelo controlador, pela máquina embaladora, pela balança (checkweigher), por um bloco que simula a densidade do detergente em pó produzido, ou seja, todo o sistema de embalagem e pesagem.

No bloco de análise de dados existem gráficos que mostram, dentre algumas variáveis do controlador, os pesos dos pacotes, número de rejeitados, valor de sobrepeso e perda em dinheiro. Além disso, os mostradores exibem os valores correntes dessas variáveis e o valor final da simulação, os quais são usados para avaliar as melhorias no sistema.

Para elaboração do simulador foram utilizadas técnicas de Identificação de Sistemas, técnicas de modelagem, aplicação de processos estocásticos, aplicação de Processamento Digital de Sinais, aplicação de cálculo numérico, além do estudo detalhado do funcionamento do controlador de peso e da planta. A Figura 9 mostra a estrutura principal do simulador. 


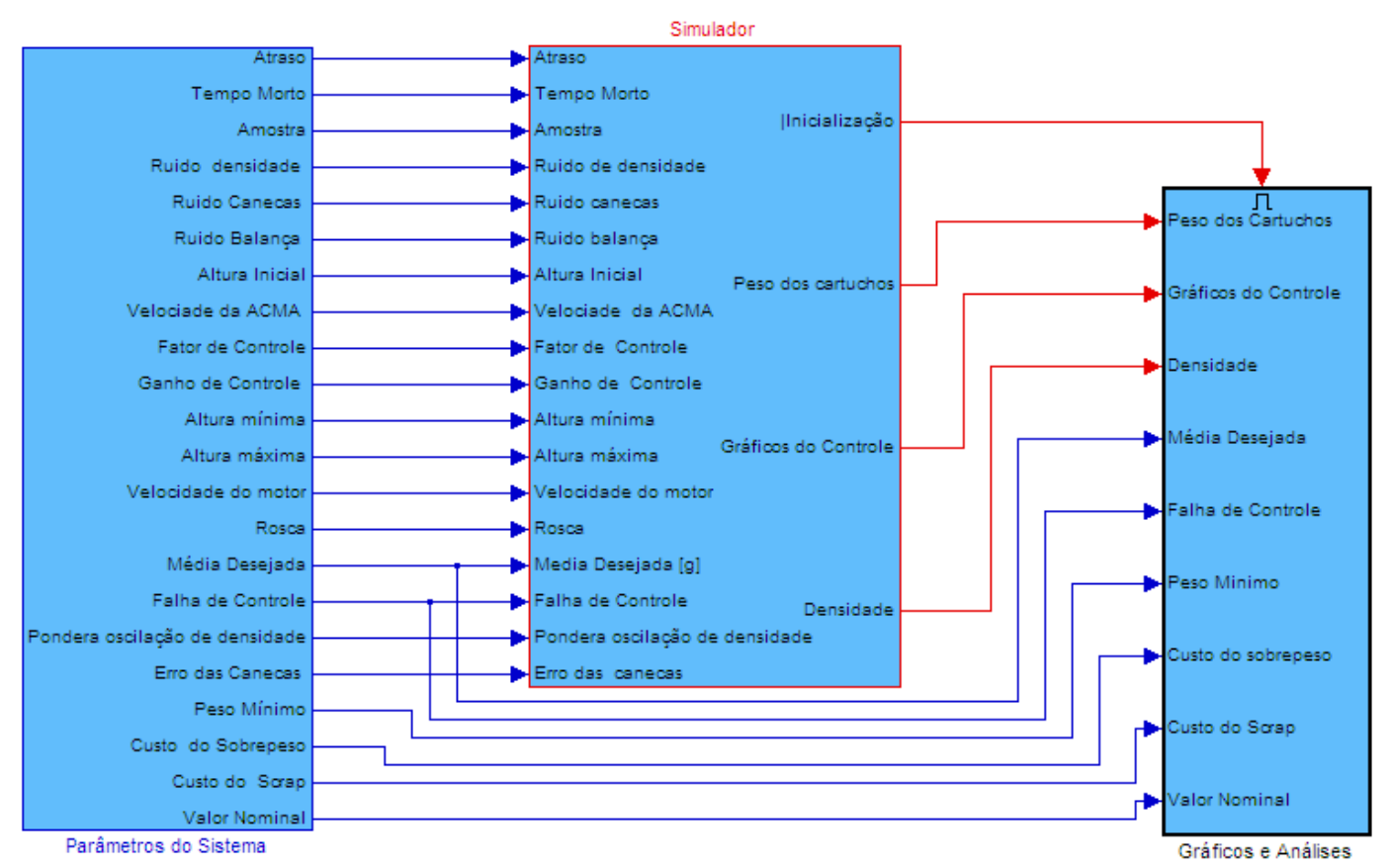

Figura 9- Estrutura principal do simulador - três grandes blocos.

A seguir é descrito como foram desenvolvidos os blocos e sub-blocos.

\subsection{DESCRIÇÃO GERAL DO MODELO}

O diagrama em blocos do sistema foi mostrado na Figura 4. Ele é constituído pelas seguintes partes principais: a cabeça dosadora, o gerador de densidade de detergente em pó, a balança (checkweigher) e o controlador. Comparando os elementos da Figura 4 com um sistema de controle tradicional de malha fechada, é possível chegar às seguintes correlações entre eles: a cabeça dosadora corresponde ao processo, o gerador de densidade corresponde às perturbações, a checkweigher corresponde ao elemento de realimentação, o controle de pesagem ao controlador e a média de peso desejada ao set point.

No modelo, as partes determinísticas e estocásticas do processo foram separadas. $O$ modelo da parte determinística foi obtido de forma relativamente simples, embora criativo, empregando técnicas de Identificação de Sistemas. Por outro lado, para o modelo da variabilidade do processo, os gráficos dos pesos dos cartuchos (sem atuação do controlador) foram analisados profundamente, tendo sido detectadas as 
presenças de variações de alta, média e baixa frequência. Além disso, as propriedades estatísticas dessas ondas foram exaustivamente analisadas e, consequentemente, esses pontos foram incorporados no modelo de perturbação do simulador, criando oscilações e perturbações nos pesos dos cartuchos, que como é apresentado mais adiante, são bem próximas da realidade.

Como mencionado no capítulo 13 de (Aström, Wittenmark, 2000), "modelos de perturbações podem, contudo, somente raramente ser determinados pelos princípios primários. Portanto experimentos são frequentemente a única maneira de conseguir os modelos para as perturbações". Isso significa que raramente é possível determinar modelos de perturbação pelos fenômenos físicos e/ou químicos e, normalmente, coleta de dados através de experimentos é a única maneira de descrevê-los. O que foi feito nesse trabalho foi criar o modelo de perturbações, nem com os princípios primários e nem diretamente através de experimentos, mas sim com a observação e análise das características estocásticas das perturbações.

É importante notar que este é um sistema híbrido (Sanchez et al., 2003), tendo parte do processo em tempo contínuo (motor e saída do controlador) e parte em tempo discreto (checkweigher, conjunto de canecas e a perturbação). Esta é uma situação normal que ocorre nas aplicações industriais.

\subsection{BLOCO DE PARÂMETROS DO SISTEMA}

Foi desenvolvido um bloco de parâmetros do sistema para facilitar as simulações, conforme mostrado na Figura 10. Desta forma, é possível somente alterar parâmetros neste bloco e depois da simulação, ver os resultados no bloco de análises, sem preocupações de alteração no bloco do simulador em si. 


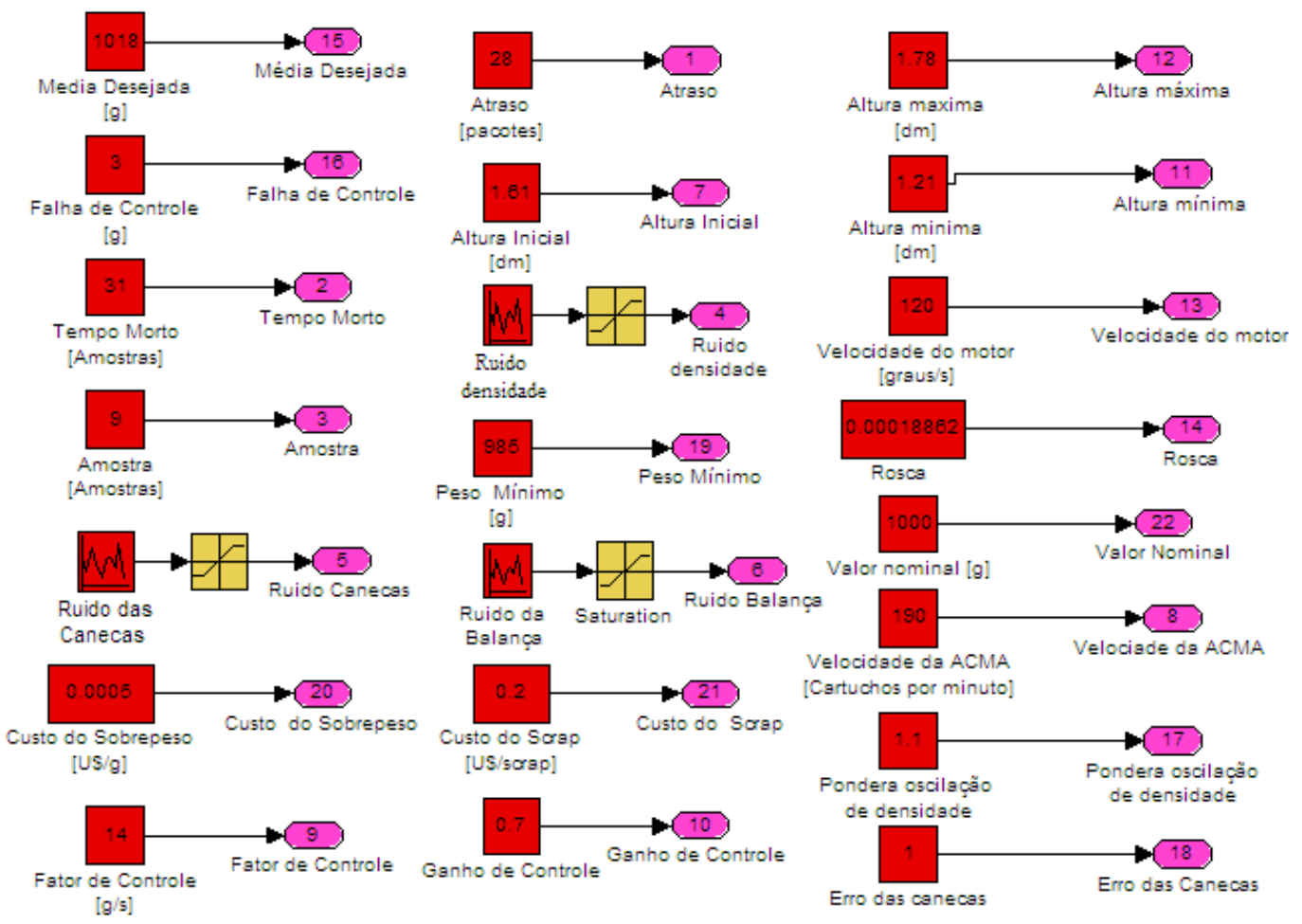

Figura 10- Bloco de parâmetros.

Os parâmetros disponíveis são descritos a seguir e são explicados em mais detalhe nas seções seguintes.

- Média de peso desejado (em g)

- Falha de controle (zona morta) (em g)

- Tempo morto (para cálculo do controlador) (em amostras)

- Número de amostras

- Fator de controle (ganho do controlador em g/s)

- Ganho de controle (adimensional)

- Atraso (distância física em número de cartuchos)

- Ruído de densidade - perturbação de densidade cartucho a cartucho (em gramas/l)

- Ruído das canecas - perturbação de enchimento não uniforme

- Peso mínimo (em g)

- Ruído da checkweigher - devido à imprecisão da balança

- Custo do sobrepeso (em $\mathrm{R} \$ / \mathrm{g}$ )

- Custo do cartucho rejeitado (em $\mathrm{R} \$$ /cartucho) 
- Altura inicial das canecas (em dm)

- Máxima altura das canecas (em dm)

- Mínima altura das canecas (em dm)

- Velocidade do motor (em graus/s)

- Passo da rosca (em mm/passo)

- Valor nominal de peso (g)

- Velocidade da máquina (em cartuchos por minuto)

- Ganho de densidade (adimensional) - fator usado para aumentar ou diminuir as oscilações de densidade

- Erro de canecas - fator para ponderar as variações das canecas

\subsection{BLOCO SIMULADOR}

A Figura 11 mostra os sub-blocos deste bloco. Há o conjunto de canecas (cabeça dosadora), a checkweigher (a balança), o gerador de densidade (perturbação), o controlador e o bloco inicializador.

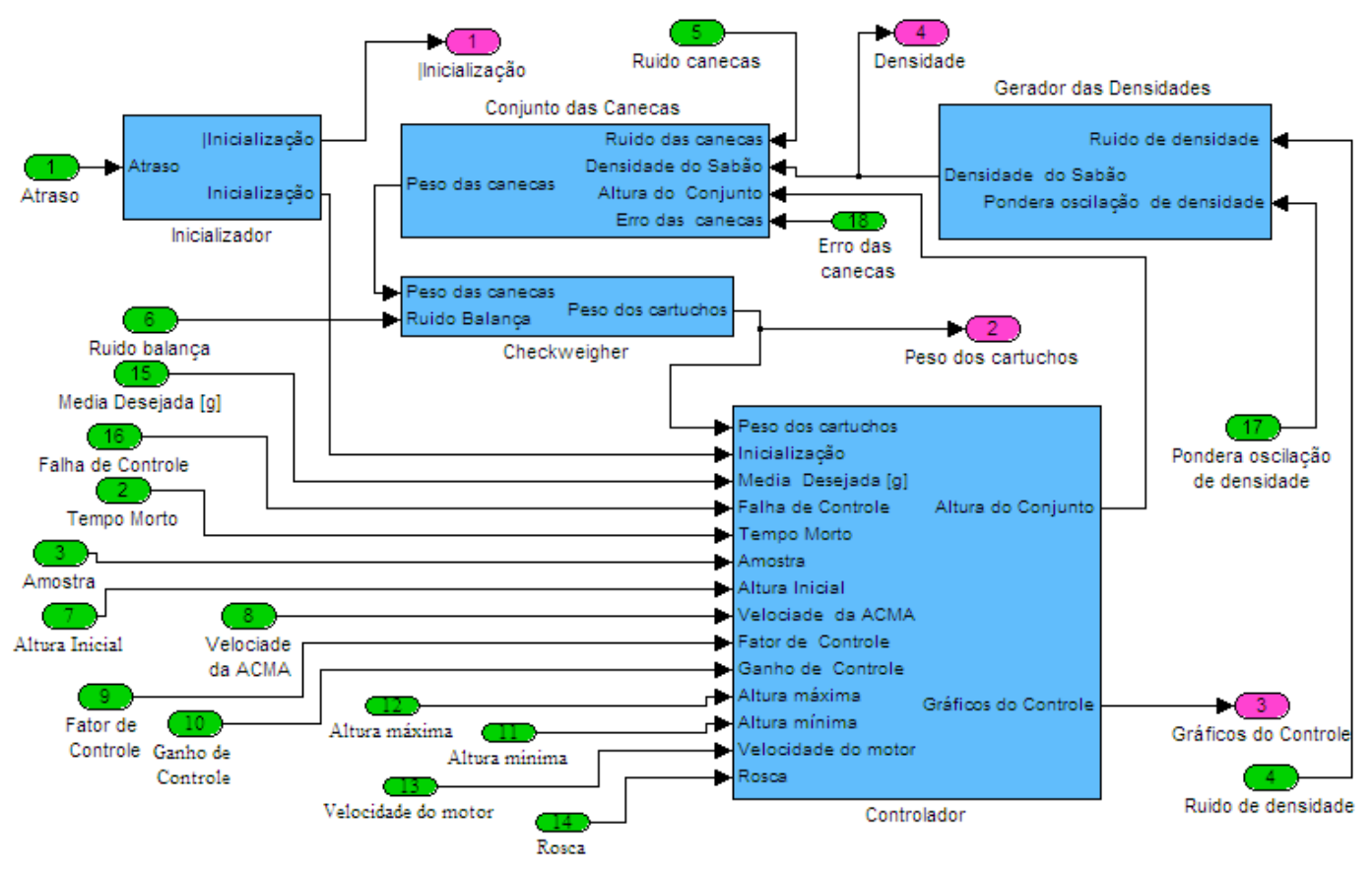

Figura 11- Bloco simulador.

O bloco inicializador existe somente para que o simulador possa compensar no início da simulação o atraso entre encher e pesar os pacotes. Caso contrário, o modelo 
consideraria os primeiros 28 pacotes como tendo peso zero gramas, o que levaria a uma série de erros, como no cálculo do desvio padrão de pesos, no cálculo da média da produção e existiria uma correção de pesos, levando as canecas ao seu limite máximo.

\subsubsection{BLOCO CHECKWEIGHER}

Como já mencionado, a checkweigher é uma balança utilizada como medidor para que o controlador possa receber os dados e atuar. Ela é localizada a uma distância de vinte e oito pacotes, contados a partir do local onde as canecas foram totalmente enchidas.

Existem dois fatores que influenciam o valor da pesagem da checkweigher: a Interferência Inter-Simbólica (IIS) (Lathi, 1998), um termo consagrado usado em Telecomunicações e a imprecisão da balança, sendo essa uma variação aleatória vinda da parte dinâmica e estática da pesagem, que funciona como um ruído adicional ao peso. Os dois fatores são bastante influenciados pelo fato de que a pesagem é feita dinamicamente.

O primeiro é devido ao transitório que ocorre na tensão fornecida pelo sensor de peso. A Figura 12 ilustra o que acontece com a tensão de saída da célula de carga da checkweigher em duas situações distintas: cartuchos distantes (primeiro gráfico) e sequência rápida de cartuchos (segundo gráfico). 


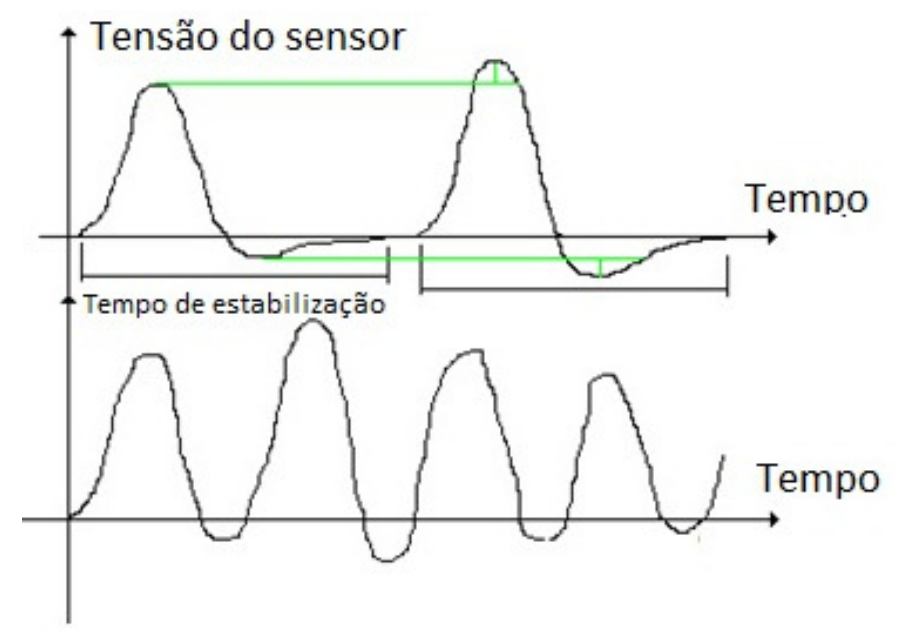

Figura 12- Tensão de saída da célula de carga da checkweigher.

Pode-se facilmente notar no segundo gráfico da Figura 12 que não existe tempo suficiente de estabilização da tensão para a célula de carga. Portanto, o resultado de uma medida afeta a próxima, representando uma interferência inter-simbólica. Quanto maior o pico de tensão, mais ele vai afetar o peso do próximo cartucho e, como consequência, o próximo pico tem um impacto negativo, reduzindo o valor que ele alcançaria caso não existisse a pesagem anterior. Para representar esse efeito foi aplicada uma técnica de Identificação de Sistemas, discutida a seguir.

O segundo efeito é devido às seguintes causas: ruído na tensão de alimentação da célula de carga, vibração de partes mecânicas como rolamentos e roletes, oscilação vertical dos cartuchos devido à instabilidade do transporte, que resulta em oscilação na tensão de saída da célula de carga e os cartuchos um pouco inclinados em relação à esteira de transporte (não completamente perpendiculares à direção do movimento). Essas razões podem ser vistas na Figura 13. 


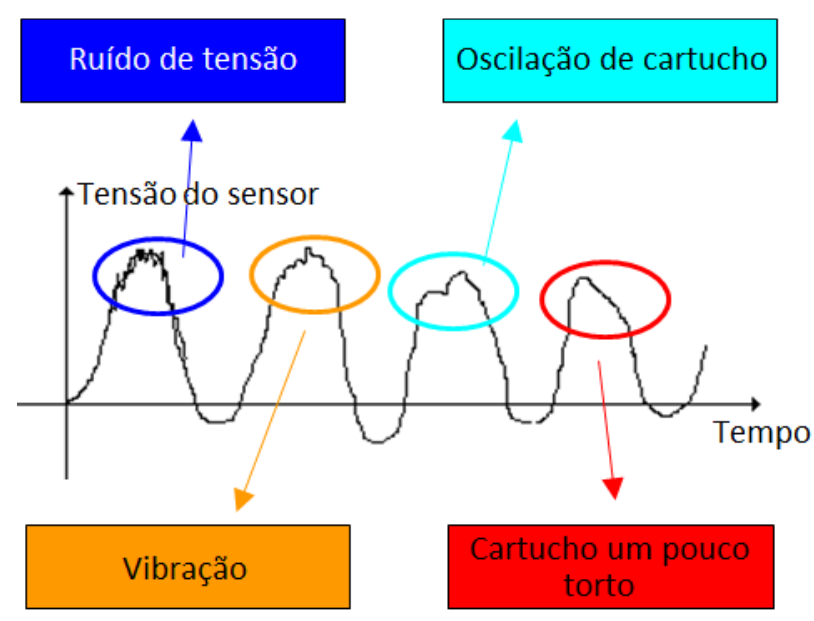

Figura 13- Imprecisão da checkweigher.

A partir desses fatos, modelou-se a checkweigher como mostrado na Figura 14.

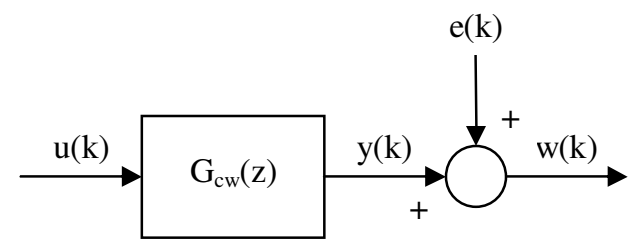

Figura 14- Diagrama em blocos do modelo da checkweigher.

Inicialmente, para se determinar a função de transferência, tentou-se calcular a correlação entre o sinal de entrada e de saída. Para isso, um teste foi realizado com o controlador desligado, isto é, sem correções para compensar a variação de densidade do produto. Neste teste foram numerados 171 cartuchos (19 ciclos do sistema de canecas) e colocados em ordem na máquina embaladora. Estes cartuchos, depois de pesados pela checkweigher, foram retirados da linha de produção, numerados e pesados em uma balança com precisão de 0,05 gramas. Desta forma, pode-se ter os valores de entrada do modelo da checkweigher (pesos fornecidos pela balança de precisão) e os valores de saída (os próprios valores pesados pela checkweigher).

Com os dados do teste, calculou-se a autocorrelação do sinal de entrada, percebendose que ele não era branco e, portanto, não se poderia determinar a função de transferência dinâmica através da correlação cruzada entre entrada e saída. A autocorrelação normalizada é mostrada na Figura 15. 


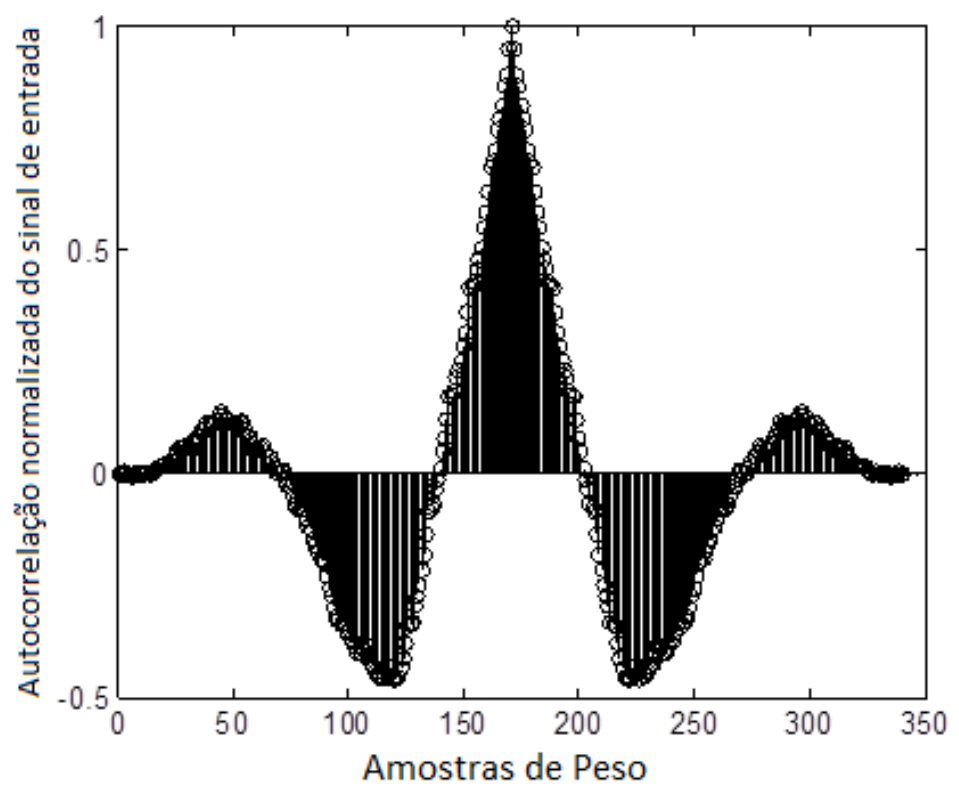

Figura 15- Autocorrelação normalizada do sinal de entrada.

Assim, partiu-se para o método de Identificação de Sistemas, usando a estrutura de modelo do tipo OE. Como mostrado na Figura 14, o modelo da checkweigher é dividido em duas partes: determinística e estocástica. Para estimar a parte determinística, o modelo de interferência inter-simbólica (IIS) foi considerado de acordo com a Equação (1).

$$
y(k)=a \cdot y(k-1)+b \cdot u(k-28)
$$

em que $y(k)$ é a saída do bloco de interferência inter-simbólica e $u(k)$ é a entrada (valor preciso de peso), a qual tem um atraso de 28 cartuchos, considerando que a taxa de amostragem corresponde ao tempo médio para pesar um cartucho.

Transformando-se a Equação (1) para o domínio z (Ogata, 1995), a função de transferência discreta é mostrada na Equação (2) a seguir:

$$
G_{c w}(z)=\frac{Y(z)}{U(z)}=z^{-28} \frac{b z}{z-a}
$$

Para caracterizar a parte estocástica do modelo, o efeito do ruído correspondendo às perturbações mostradas na Figura 14 foi considerado. Então a Equação (3) é aplicada

$$
\begin{aligned}
& w(k)=y(k)+e(k) \\
& w(k)=a \cdot y(k-1)+b \cdot u(k-28)+e(k)
\end{aligned}
$$


em que $w(k)$ é a saída do módulo da checkweigher e $e(k)$ é o ruído.

Para determinar os coeficientes da equação (2), se utilizou a função OE do Matlab, que usa o método do mínimo erro quadrático médio (Ljung, 1999). Essa função monta um sistema com muito mais equações do que incógnitas (171 equações neste caso e duas incógnitas), e minimizando o erro quadrático médio ela fornece os valores dos coeficientes da função de transferência. Desta forma, tudo que for ruído (imprecisão da balança) acaba automaticamente desaparecendo na saída do bloco de IIS, ou seja, se for gerada a saída deste bloco com os mesmos dados de entrada, não se têm os mesmos dados de saída, mas sim os dados de saída menos o ruído. Os valores obtidos dos coeficientes da função de transferência foram:

$a=-0,02047$ e $b=1,0206$

Como esperado, o valor de "a" foi negativo e próximo de zero e o valor de " $b$ " foi positivo e próximo de um. A Figura 16 mostra em azul os pesos fornecidos pela checkweigher no teste, e em vermelho os valores de peso da saída da função de transferência da IIS, gerados a partir de uma simulação livre com dados de entrada medidos pela balança de precisão durante o teste. Como se pode perceber, a diferença existente é devida à imprecisão da balança (ruído), que desaparece ao se usar a função $O E$, já que seu processo de modelagem só leva em conta as partes correlacionadas dos sinais. 


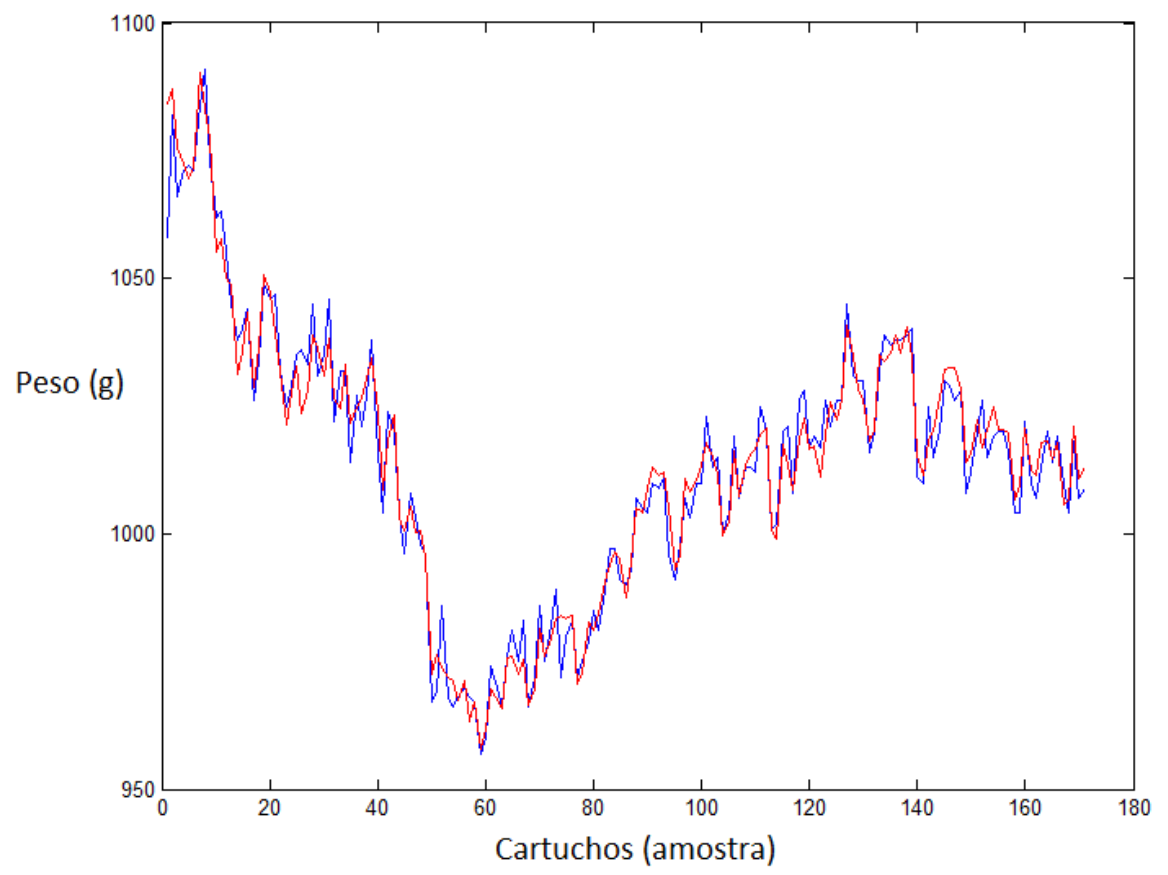

Figura 16- Comparação entre os pesos de saída total $w(k)$ e de saída da função de transferência discreta $y(k)$.

Portanto, para se determinar o ruído, geraram-se com os mesmos dados de entrada os valores de saída da função de transferência, e depois se subtraíram os valores pesados pela checkweigher, dos valores de saída da função de transferência (gráficos vermelho e azul, respectivamente, na Figura 16). Desta forma, determinou-se a parte do sinal que é descorrelacionada. A partir desses valores determinou-se a função de densidade de probabilidade (histograma), o desvio padrão do ruído e sua média. A função é mostrada na Figura 17 e o desvio e a média valem respectivamente:

$\sigma_{\text {checkweigler }}=1,8 \mathrm{~g}$ e $\mu_{\text {checkweigler }}=0,0055 \mathrm{~g}$ 


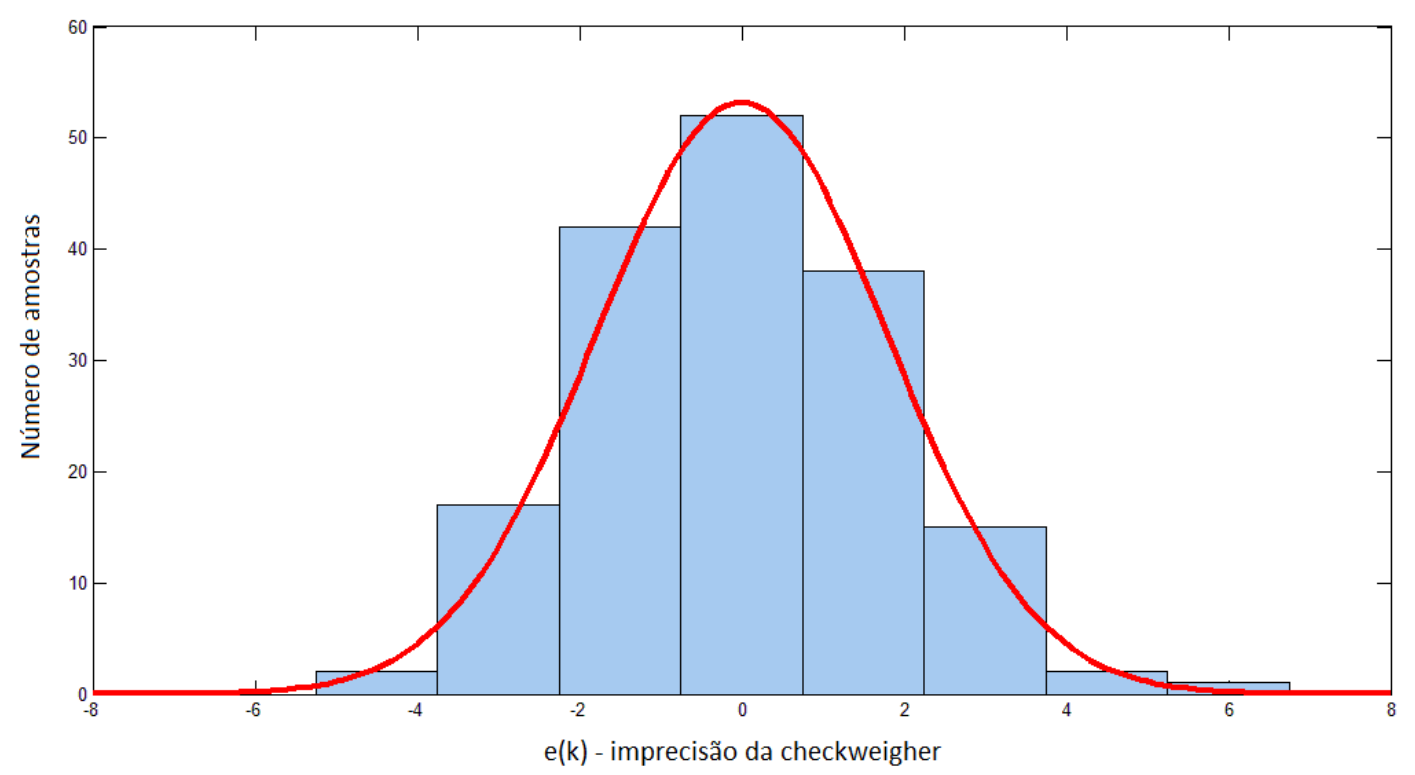

Figura 17- Histograma da imprecisão da checkweigher-passo de 1,5g.

Como esperado, a média foi de aproximadamente zero. A função densidade de probabilidade (Leon-Garcia, 1994) foi aproximada por uma normal, por ser a que mais se aproxima do histograma obtido. Considerou-se que o ruído é branco uma vez que sua autocorrelação tem praticamente somente a raia no ponto zero. Os resíduos que ainda existem no gráfico de auto correlação são devidos à amostragem ter um número não muito grande de pesos, assim como um Ruído Gaussiano Branco (RGB) com o mesmo número de amostras gera uma autocorrelação muito similar, como mostrado na Figura 18. Quanto maior o tamanho da amostragem menores são esses resíduos, até o momento que ele desaparece, para um número de amostras tendendo ao infinito. 

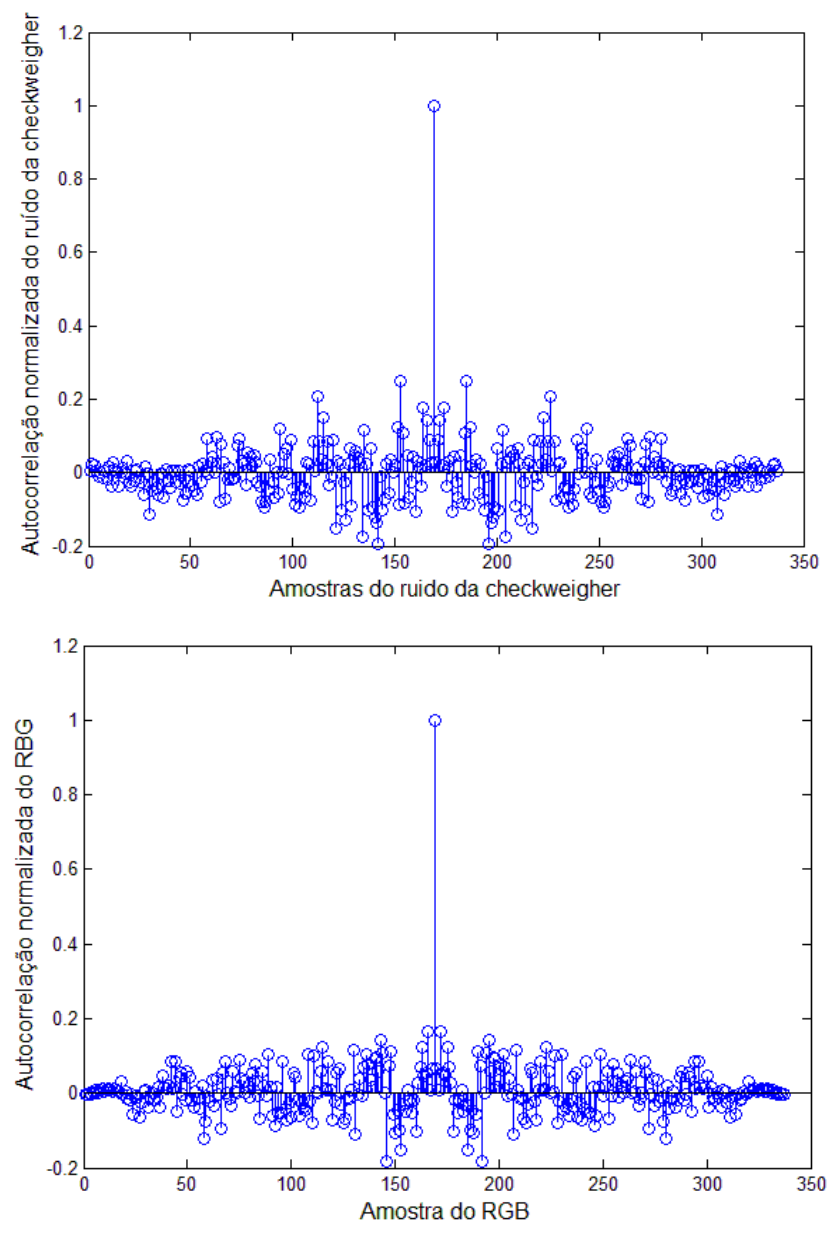

Figura 18 - Comparação da autocorrelação do ruído da checkweigher com um RGB.

Uma forma utilizada para conferir o resultado foi através de somas de variáveis aleatórias. Sabe-se, neste caso, que o erro dos pesos fornecidos pela checkweigher em relação aos pesos corretos é igual à soma dos erros fornecidos pela função de transferência da IIS e pela imprecisão da balança, por serem variáveis independentes. Portanto, o desvio padrão do erro total é igual à raiz quadrada da soma dos quadrados de cada um dos dois erros. Calculando-se os três erros verificou-se a igualdade, como pode ser observado a seguir.

$$
\sigma_{\text {total }}=1,81 \mathrm{~g} \quad \sigma_{\text {transfer_function }}=0,22 \mathrm{~g} \quad 1,81=\sqrt{0,22^{2}+1,8^{2}}
$$

Portanto, a Figura 19 mostra o modelo da checkweigher implementado no Simulink, no qual o ruído tem desvio $1,8 \mathrm{~g}$, média zero e é uma curva gaussiana. Vale a ressalva de que se o número de cartuchos por minuto ou a velocidade da esteira mudar, eles 
impactam no modelo dinâmico da checkweigher. O impacto não é muito relevante se a mudança for pequena, da ordem de $5 \%$, mas pode ser significativo se a alteração começa a ser maior do que esse nível.

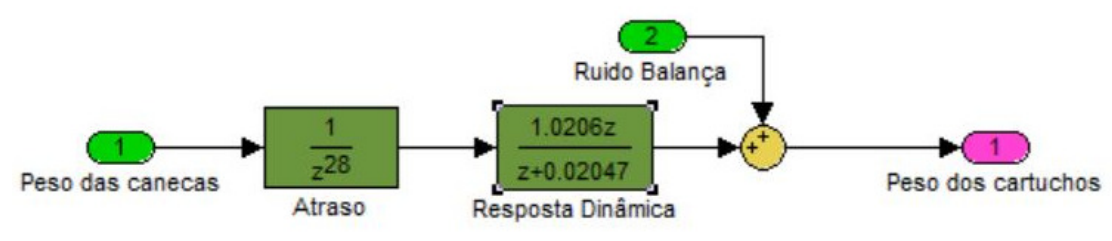

Figura 19- Diagrama do modelo da checkweigher no Simulink.

\subsubsection{BLOCO CONJUNTO DE CANECAS}

Na máquina de embalagem existe o conjunto de canecas ou cabeça dosadora, usada para definir o volume de detergente em pó que é colocado dentro de cada cartucho, como previamente descrito no capítulo 2.

Teoricamente, para a mesma densidade e a mesma altura do raspador, as canecas deveriam fornecer o mesmo peso, mas foi verificado através de medidas da cabeça dosadora e de análise do peso dos cartuchos, que isso não acontece, devido a diferenças físicas entre elas. Essas diferenças aparecem porque as canecas não têm a mesma posição em relação ao raspador; em outras palavras, elas não são perfeitamente alinhadas.

Além disso, existem problemas de diferenças físicas na montagem e fabricação das canecas, dentre eles: eixo ligeiramente torto, algumas tampas das canecas sem revestimento, gerando $0,5 \mathrm{~mm}$ a mais de altura, bico dosador entre caneca e cartucho torto, dosando um pouco de pó fora do mesmo, diferenças mecânicas de fabricação das tampas, gerando diferenças de fechamento, dentre outros.

Outro fato observado é que o diâmetro das canecas foi medido e suas diferenças podem ser certamente ignoradas, uma vez que as diferenças causadas por esse motivo não passam de $0,1 \mathrm{~g}$. Como o diâmetro de cada caneca é $D_{\text {caneca }}=0,1256 \mathrm{~m}$ e a densidade do detergente em pó é, em média, $500 \mathrm{~g} / \mathrm{L}$, para cada milímetro de diferença de altura, existe uma diferença média de peso de $7,5 \mathrm{~g}$. 
Essa diferença entre as canecas é constante, porque é um conjunto de características que sempre acontece da mesma forma em cada caneca, em todos os ciclos de funcionamento da máquina; em outras palavras, é uma variação periódica no volume liberado por cada caneca.

Para quantificar essa diferença de peso para cada caneca, foram utilizados os dados de peso do mesmo teste de 171 cartuchos descrito na subseção 3.3.1, para identificar o modelo da checkweigher. Foram calculados então os pesos médios para cada conjunto de nove canecas (um ciclo da cabeça dosadora), usando os dados obtidos com a balança de precisão, que eliminam a influência da checkweigher, gerando com isso dezenove valores de média de peso.

Então, a diferença de peso médio para cada caneca foi calculada, fazendo-se primeiramente a diferença entre o peso medido de cada caneca e o peso médio do respectivo conjunto de nove canecas (um ciclo) para cada uma das dezenove médias, gerando dezenove diferenças para cada caneca, e posteriormente foi calculada a média aritmética dessas dezenove diferenças, gerando assim a diferença de peso médio para cada caneca. As fórmulas usadas para esses cálculos são apresentadas nas Equações (4) a (6).

$$
\begin{aligned}
& \mu_{\text {peso, rotaça } 0}(j)=\frac{\sum_{a=1}^{9} \operatorname{peso}(j, a)}{9} \quad j=1 \text { a } 19 \\
& \operatorname{peso}_{d i f}(j, i)=\operatorname{peso}(j, i)-\mu_{\text {pess, }, \text { rotą åo }}(j) \quad j=1 \text { a } 19, i=1 \text { a } 9 \text { (cada caneca) } \\
& \mu_{\text {pess, dif }}(i)=\frac{\sum_{j=1}^{19} \operatorname{peso}_{d i f}(j, i)}{19} \quad i=1 \text { a } 9 \text { (cada caneca) }
\end{aligned}
$$

Desses cálculos foram derivadas as nove médias de diferenças de peso, cada uma para cada caneca, que são mostradas na Tabela 3.

Tabela 3- Diferença de peso média entre as canecas.

\begin{tabular}{|c|c|c|c|c|c|c|c|c|c|}
\hline$i$ & 1 & 2 & 3 & 4 & 5 & 6 & 7 & 8 & 9 \\
\hline$\mu_{\text {pess, dif }}(i)(\mathrm{g})$ & 5,3 & 6,6 & 4,2 & 2,5 & $-9,7$ & $-7,1$ & 2,7 & $-3,1$ & $-1,4$ \\
\hline
\end{tabular}


O desvio padrão das médias de diferença de peso das canecas, que é chamado daqui em diante de desvio padrão das canecas, foi calculado através dos nove valores anteriores de $\mu_{\text {pesodif }}(i), i=1$ a 9 e é mostrado a seguir.

$\sigma_{\text {caneca }}=5,65 \mathrm{~g}$

Esse desvio padrão é a contribuição para a variabilidade total vinda do conjunto de canecas. A Figura 20 mostra a diferença entre considerar ou não a variação de peso, devida às canecas com os pesos obtidos pela balança de precisão. Pode-se notar que o gráfico vermelho com a influência das canecas tem uma variabilidade maior que o gráfico azul, que teve eliminada a influência das canecas, somente considerando as outras causas de variabilidade do processo.

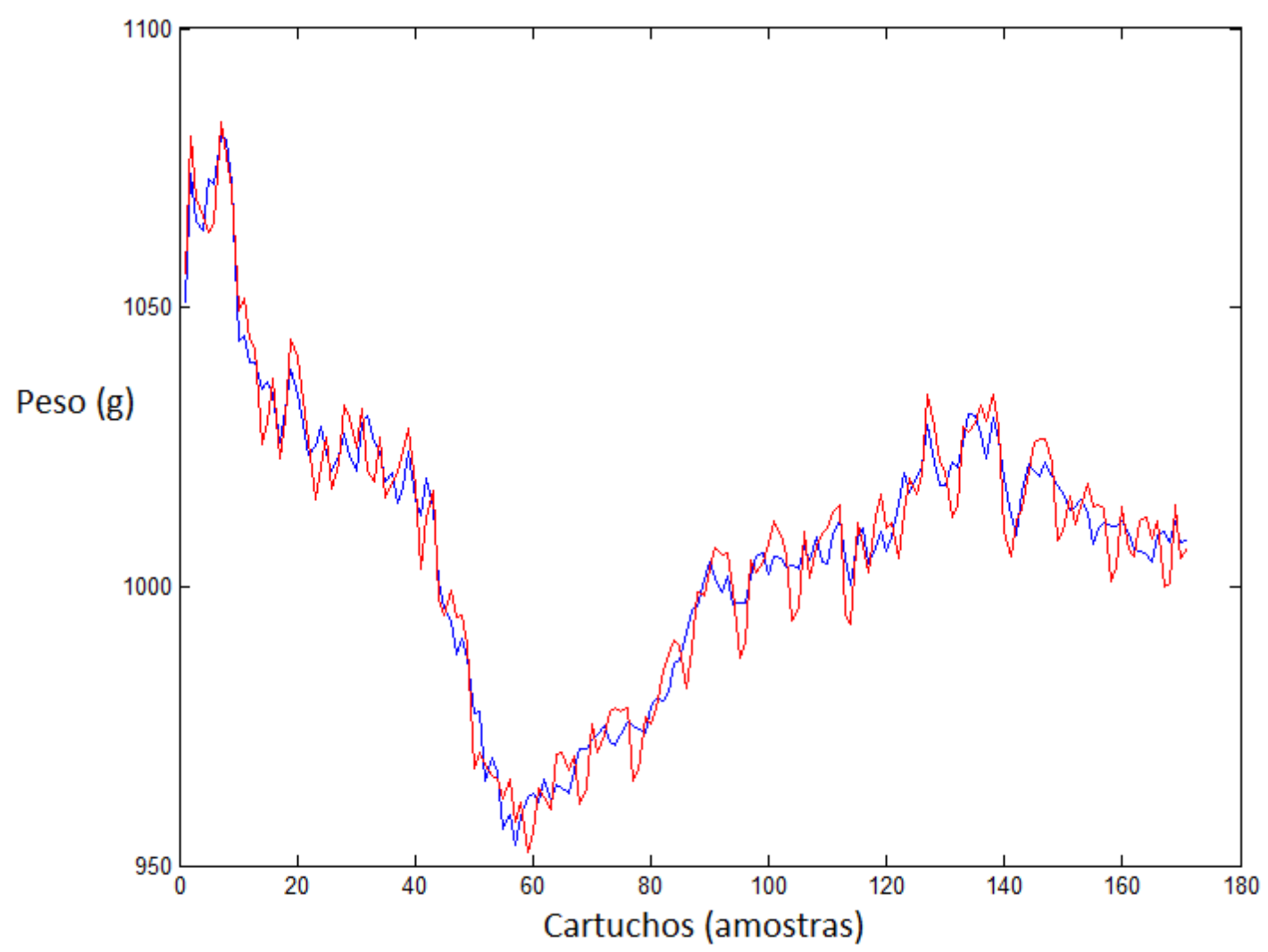

Figura 20- Gráfico comparando o peso com e sem variação das canecas.

O comando enviado pelo controlador afeta a média de altura das nove canecas, a qual é a altura do disco. Para modelar essa diferença entre as canecas, foi necessário 
converter a diferença de peso em diferença de altura, pois fisicamente é isso que acontece na prática. Isso foi realizado de acordo com a Equação (7).

$$
\mu_{\text {altura,dif }}(i)=\frac{\mu_{\text {pes }, \text { dif }}(i)}{\mu_{\text {densidade }} \cdot A_{\text {caneca }}}
$$

O valor da média de densidade foi assumido $\mu_{\text {densidade }}=500 \mathrm{~g} / \mathrm{L}$, uma vez que esse é o objetivo de densidade da fábrica em questão e a média da área das canecas $A_{c a n e c a}=$ $0,01239 \mathrm{~m}^{2}$. Portanto, um valor constante para cada caneca foi adicionado à altura do disco para modelar a real diferença entre elas, que é $\mu_{\text {altura,dif }}(i), i=1$ a 9.

Além desse desvio padrão devido à altura das canecas $\sigma_{\text {caneca }}$, o desvio padrão de curto prazo restante dos pesos dos cartuchos (calculado a cada nove cartuchos) é devido à soma de cinco outras variáveis aleatórias: o ruído da densidade local (cartucho a cartucho) calculado na subseção 3.3.3, o ruído devido à checkweigher calculado na subseção 3.3.1, o ruído devido à variação de cola aplicada na aba dos cartuchos, o ruído devido à variação de peso dos cartuchos vazios e o ruído devido à não uniformidade do processo de enchimento. As últimas três são explicadas a seguir.

Foram realizados dois testes diferentes para quantificar os desvios padrão gerados pela cola aplicada e pelos cartuchos vazios. Para determinar a variabilidade dos cartuchos vazios, cem deles foram numerados e pesados na balança de precisão, já previamente descrita na subseção 3.3.1. Baseado nesses valores, o desvio padrão foi calculado e é mostrado a seguir.

$$
\sigma_{\text {cartuchovazio }}=0,1 \mathrm{~g}
$$

O mesmo lote de cartuchos numerados foi colocado na máquina de embalagem. A máquina foi rodada sem encher os cartuchos com detergente em pó, mas fazendo aplicação de cola. Então os cartuchos foram novamente pesados com a mesma balança de precisão e os pesos com cola foram individualmente subtraídos dos pesos do respectivo cartucho vazio, calculando-se assim o peso da cola aplicada. O desvio padrão da aplicação de cola foi calculado e é mostrado a seguir. 
$\sigma_{\text {cola }}=0,2 \mathrm{~g}$

Os dois desvios padrão anteriores foram descartados, por terem uma influência desprezível no desvio padrão total de curto prazo. As médias dessas variáveis também foram desprezadas, porque elas são compensadas pelo fator de off-set dos ajustes da checkweigher.

Adicionalmente, existe uma variável aleatória que deriva das canecas, que é uma consequência do processo de enchimento não uniforme. Isso acontece porque o desenho do raspador permite que o detergente em pó vindo do silo, encha as canecas, sem nenhum espaço para o ar sair das mesmas. O que acontece no final é que o ar sai das canecas principalmente pelo topo, contra a direção de enchimento do pó, gerando um enchimento turbulento e não uniforme. Algumas vezes é possível ver claramente algumas bolhas de ar saindo entre a massa de pó que está enchendo as canecas.

Foi realizado um experimento para determinar essa variabilidade e foi feito um cálculo posterior na subseção 3.3.3 para validar o valor encontrado no experimento. Uma corrida com quinhentos cartuchos foi realizada, com o raspador normal e as canecas fixadas em 2 litros, registrando-se os pesos com a checkweigher e posteriormente pesando-os na balança de precisão. Em seguida, uma nova corrida foi feita com as mesmas condições, exceto pelo raspador, o qual foi modificado para eliminar o fenômeno de ar, de uma forma que o ar saía da caneca por uma metade do topo da mesma e o detergente em pó entrava pela outra metade. Vale ressaltar que na segunda corrida foi usado o mesmo detergente em pó dos quinhentos cartuchos, o qual foi cuidadosamente colocado no funil acima do conjunto de canecas, na mesma sequência na qual foi embalado no primeiro teste.

Dessa forma, como os dados desse teste foram obtidos com a balança de precisão, a variação da checkweigher estava automaticamente eliminada e através dos dados de variação das canecas obtidos anteriormente nessa mesma subseção, seus efeitos foram eliminados em ambas as situações (raspador antigo e novo). A eliminação desses dois fatores ajuda a minimizar os possíveis erros e imprecisões dos testes. 
Assim se calculou o desvio padrão local dos pesos de 9 em 9 pacotes nas duas situações do teste (raspador antigo e novo, respectivamente). Para isso, a cada conjunto de 9 cartuchos calculou-se o desvio padrão, e no final, calculou-se a média de todos os 55 valores encontrados. É importante notar que com a eliminação da influência das canecas e da checkweigher, esse desvio padrão é impactado pelas variabilidades restantes do sistema, as quais são o enchimento não uniforme, a variabilidade local de densidade e o impacto da variação de densidade de médio prazo no desvio de 9 em 9 pacotes, sendo essas duas últimas explicadas na subseção 3.3.3.

Tendo o desvio padrão local para as duas situações do teste, se obteve o desvio padrão devido ao enchimento não uniforme, uma vez que no segundo caso ele foi eliminado. Ou seja, na segunda situação o desvio padrão local calculado foi menor que o da primeira situação, e essa diferença calculada pela Equação (8) é justamente o desvio padrão almejado.

$\sigma_{\text {primeira }}^{2}=\sigma_{\text {segunda }}^{2}+\sigma_{\text {enchimento }}^{2}$

Esse experimento foi realizado três vezes, para se eliminar outras variabilidades do sistema, como uma possível variação de desvio padrão de densidade de curto e médio prazo a cada amostragem de quinhentos cartuchos, ou ainda variação entre as duas situações do teste, mesmo utilizando-se as mesmas condições de contorno. Dessa forma, foi obtido o desvio padrão do enchimento não uniforme três vezes, não se observando uma variação significativa entre eles, e por fim calculou-se a média do mesmo, que é mostrada a seguir.

$\sigma_{\text {enchimento }}=1,1 \mathrm{~g}$

Foi identificado também, através dos dados desse experimento, que a distribuição estatística da variabilidade pelo enchimento não uniforme pode ser aproximada por uma curva gaussiana. Isso foi concluído, pois a distribuição da diferença de pesos locais em relação à média local (9 pacotes) tem uma distribuição gaussiana, como pode ser visto na Figura 21. Essa diferença tem influência da variação de densidade local, que também tem distribuição gaussiana, como mostrada na subseção 3.3 .3 e 
da variação de enchimento. Dessa forma, como a variação total é gaussiana e uma de suas componentes também o é, obrigatoriamente a segunda componente, a variação de enchimento, precisa ser também. Intuitivamente já se poderia esperar isso, uma vez que essa variação de enchimento é devida ao enchimento turbulento, que normalmente gera variações gaussianas, pois existem inúmeras variáveis físicas influenciando o processo.

Se fosse um sistema com o somatório de muitas variáveis aleatórias independentes (maior que 10), não necessariamente essa conclusão seria verdade, pois se poderia ter componentes não gaussianas e a variável total ser gaussiana (Cymbalista; Neto, 1974).

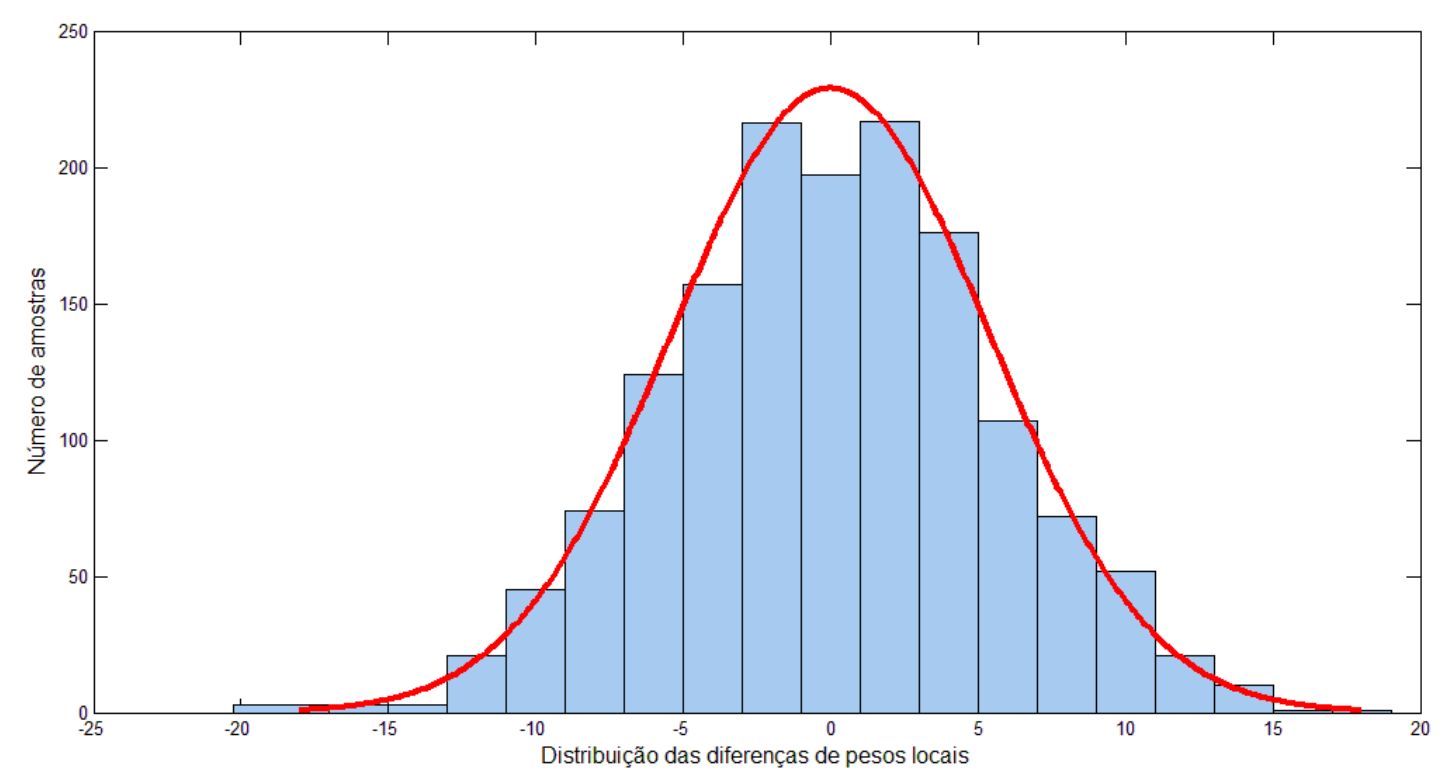

Figura 21- Histograma da distribuição das diferenças de pesos locais do teste de enchimento.

Portanto, o modelo do conjunto de canecas foi dividido também em duas partes: uma determinística e outra estocástica. A parte determinística adiciona ou subtrai de cada caneca um valor constante da altura média das canecas (altura do disco), como previamente explicado. O cálculo utilizado para essa parte do modelo é mostrado na Equação (9).

$\operatorname{peso}(i)=\left[\frac{\mu_{\text {pesodif }}(i)}{\mu_{\text {densidade }} \cdot A_{\text {caneca }}}+\right.$ Alturacaneca $] \cdot A_{\text {caneca }} \cdot$ densidade 
onde:

Altura caneca = Altura média do conjunto de canecas (altura do disco),

Densidade $=$ valor de densidade determinado pelo gerador de densidade descrito na subseção 3.3.3.

A parte determinística do modelo total do conjunto de canecas foi dividida em nove módulos, que simulam cada caneca individualmente. A entrada do módulo é a saída do gerador de densidade do detergente em pó e a altura média do conjunto determinada pelo controlador descrito na subseção 3.3.4. A saída de cada módulo é o peso liberado por cada caneca.

A parte estocástica do modelo, correspondendo às variações aleatórias de peso liberado por cada caneca, adiciona um ruído branco gaussiano de média zero e desvio padrão 1,1g ao peso calculado na Equação (9). O diagrama de blocos do modelo total é mostrado na Figura 22.

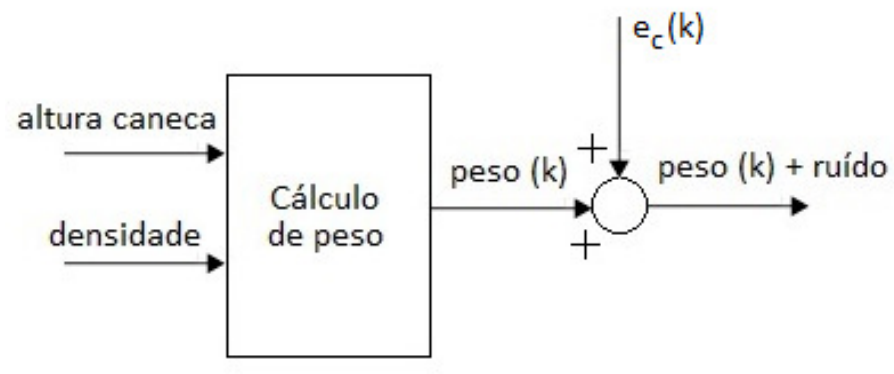

Figura 22- Diagrama em blocos do conjunto de canecas.

São mostrados nas Figura 23 e 24, respectivamente, os modelos usados no Simulink para o conjunto de canecas e para cada caneca individualmente. 


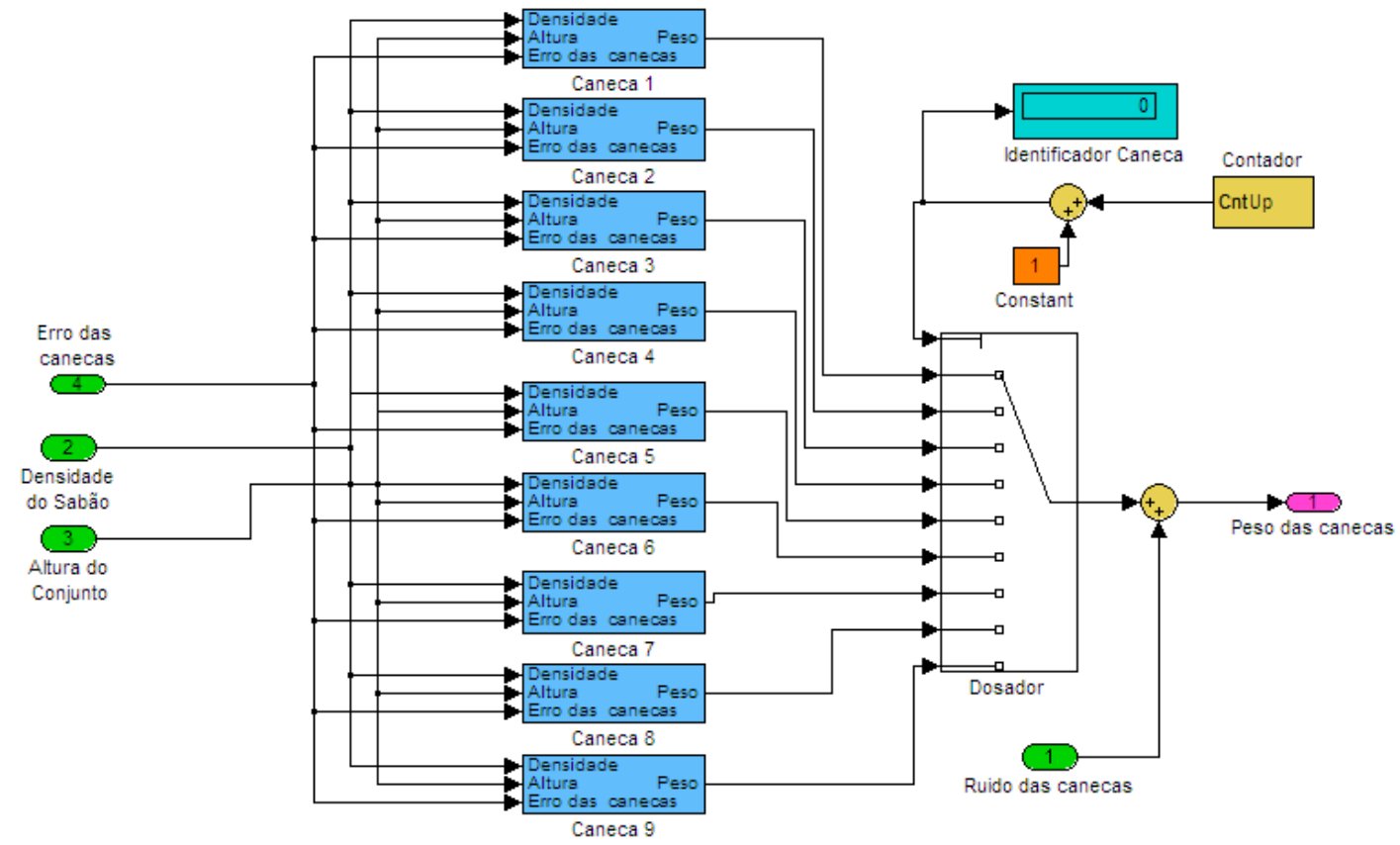

Figura 23- Modelo do conjunto de canecas.

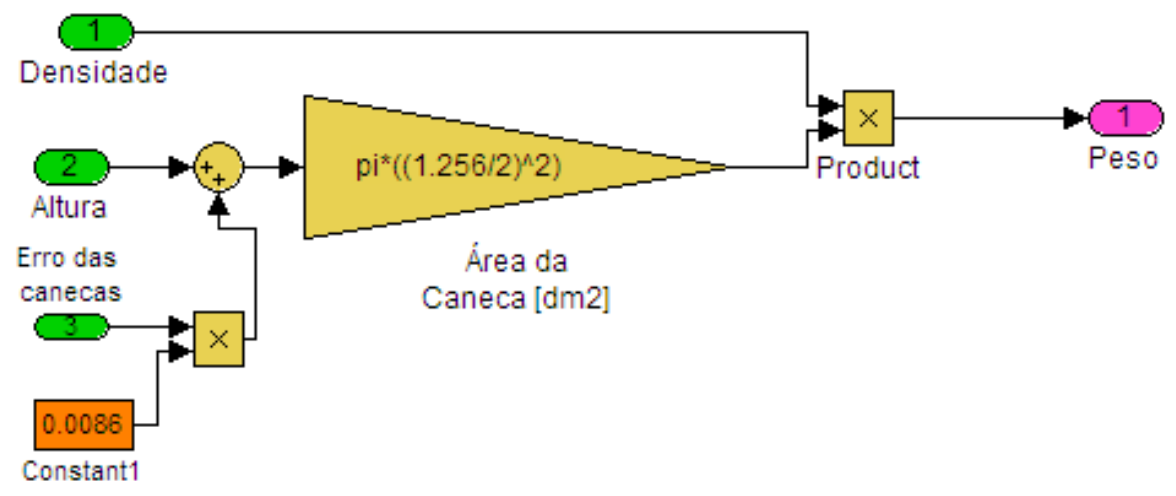

Figura 24- Modelo de uma caneca.

\subsubsection{BLOCO GERADOR DE DENSIDADE}

O detergente em pó tem uma grande variação de densidade, devido à mistura de pó com granulometrias diferentes, compactação de grânulos, variação da densidade de cada grânulo, diferente fluidez, segregação, dentre outras (Ennis, 2010).

Para reproduzir essas perturbações, foram feitas medições de densidade na planta, incluindo medidas nos buggies e nos cartuchos, e coleta de dados de peso de produção normal. Para realizar tais medições o procedimento padrão definido pelo 
INMETRO foi empregado, o que da maior confiabilidade aos dados obtidos. A Figura 25 mostra um período de variação de densidade.

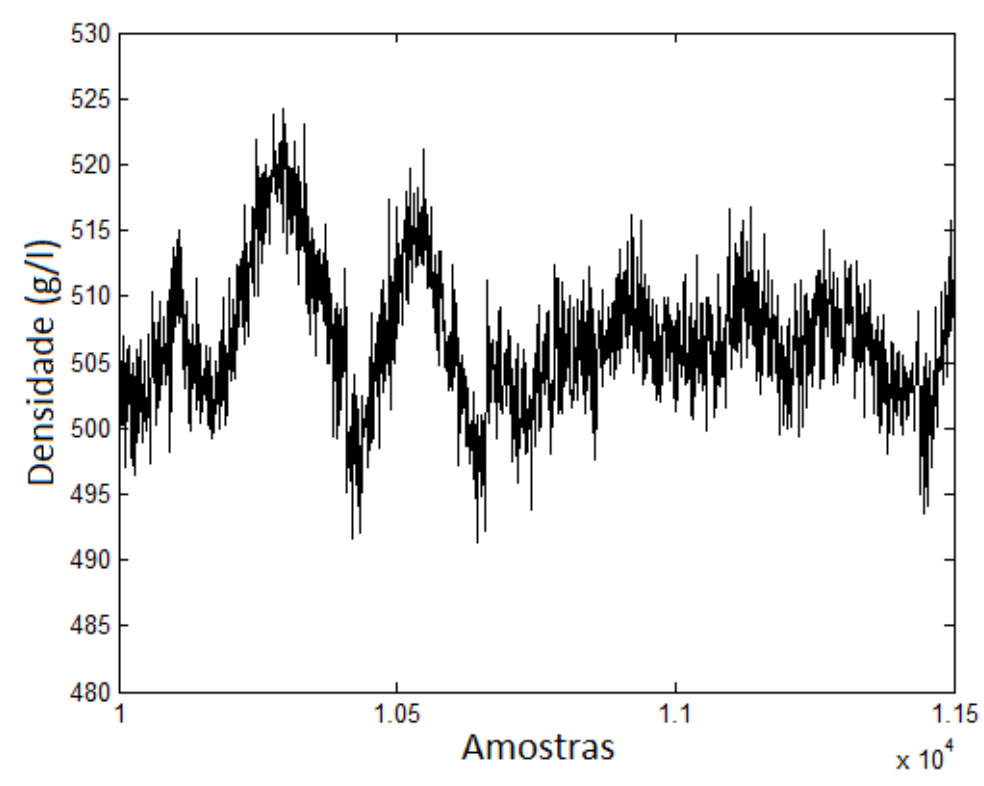

Figura 25- Variação de densidade nos cartuchos.

Depois da análise dos dados, pode-se concluir que a densidade comporta-se conforme descrito a seguir: o conteúdo de cada buggy tem uma densidade média diferente, a densidade de uma sequência de cartuchos apresenta oscilações que são próximas de curvas senoidais, triangulares e rampas, com diferentes períodos e picos, além de um ruído aditivo branco gaussiano de cartucho a cartucho. Resumindo, os três tipos de variações observados foram:

- Variação de curto prazo de cartucho a cartucho, sendo aleatória;

- Variações de médio prazo, sendo oscilações na ordem de 50 a 1500 cartuchos;

- Variações de longo prazo, demonstrada pela variação da média de densidade de buggies consecutivos.

As conclusões vêm das medições e estudos apresentados em detalhe a seguir, primeiramente de forma qualitativa e então de forma quantitativa.

Foi verificado que o conteúdo de cada buggy tem uma densidade média diferente, porque o detergente em pó produzido pela unidade de fabricação tem uma variabilidade com um período de 3-4 toneladas e o pó vindo dessa unidade é 
alimentado em buggies de 1,7 toneladas, os quais são armazenados de forma aleatória no piso de buggies. Esse processo realmente cria rampas rápidas e variações abruptas, porque o silo acima do conjunto de canecas é enchido por uma sequência de buggies aleatórios, cada um com uma diferente densidade média. Cada vez que o conteúdo de um buggy é terminado e o conjunto de canecas recebe o material em pó de outro buggy, uma brusca variação de densidade média pode ocorrer.

Existe uma segunda variação que acontece em médio prazo (50 a 1500 cartuchos). Foi notado que as amostras de densidade retiradas do topo e do fundo de um buggy apresentavam densidades diferentes, confirmando que existe uma variação dentro do mesmo buggy, criadas pelo processo de fabricação. Além disso, foi observado através da Figura 25, que a sequência de cartuchos apresenta oscilações, com uma frequência que pode ocorrer devido à compactação e segregação do material particulado, criadas durante o processo de fluxo de pó dos buggies até as canecas. Portanto, esses dois fenômenos contribuem para a variação de médio prazo.

Finalmente, existem perturbações de alta frequência, as quais atuam como um ruído branco aditivo gaussiano de cartucho a cartucho, somados às variações de médio e longo prazo. O desvio padrão desse ruído depende de muitos fatores, como a umidade do pó fabricado e do ambiente, uma vez que o material é extremamente higroscópico, uniformidade da granulometria do detergente em pó, sistema contínuo de pós-adição no processo de fabricação, dentre outras.

Depois de fazer a análise qualitativa, que dá uma explicação geral da perturbação de densidade, uma análise quantitativa foi realizada, a qual é descrita a seguir para cada um dos três tipos de variação. 


\subsubsection{Variação de densidade de curto prazo}

O primeiro teste quantitativo foi avaliar o desvio padrão da variação de densidade de curto prazo. O teste realizado para obter esse valor consistiu em fixar as canecas em um volume médio de dois litros, desligar o controlador e observar o gráfico de pesos on line, até se ter uma sequência de pesos de pelo menos trinta cartuchos, sem ter uma variação significativa da média deslizante do peso de nove cartuchos. Quando isso acontecia, separava-se a sequência de cartuchos da linha de produção. Foram separadas dez amostragens de pelo menos trinta cartuchos nessas condições.

Para cada uma dessas amostragens foi medida a densidade de todos os cartuchos na mesma sequência em que eles foram produzidos e foi calculado o desvio padrão dessas densidades, o que representa a variabilidade de curto prazo da densidade, uma vez que nessa sequência não existia nenhuma variação de médio e longo prazo. Depois desse processo, calculou-se a média dos dez desvios padrão encontrados, obtendo-se o valor de:

$\sigma_{\text {densidadeCP }}=2,54 \mathrm{~g} / \mathrm{L}$

A variação desses dez desvios padrão não foi muito significativa, mostrando que claramente se poderia representar a variação de densidade de curto prazo como um ruído branco gaussiano aditivo de média zero e com um único valor de desvio padrão, sendo esse a média dos dez valores calculados $\left(\sigma_{\text {densidadeCP }}=2,54 \mathrm{~g} / \mathrm{L}\right)$. Considerouse ruído branco gaussiano, uma vez que a distribuição de probabilidades se aproximava muito de uma distribuição normal e a variação é claramente não auto correlacionada, ou seja, aleatória. A Figura 26 mostra um exemplo de uma dessas sequências de densidade, que ocorreu com aproximadamente 100 cartuchos, bem como a Figura 27 mostra o histograma da diferença da densidade de curto prazo em relação à média. 


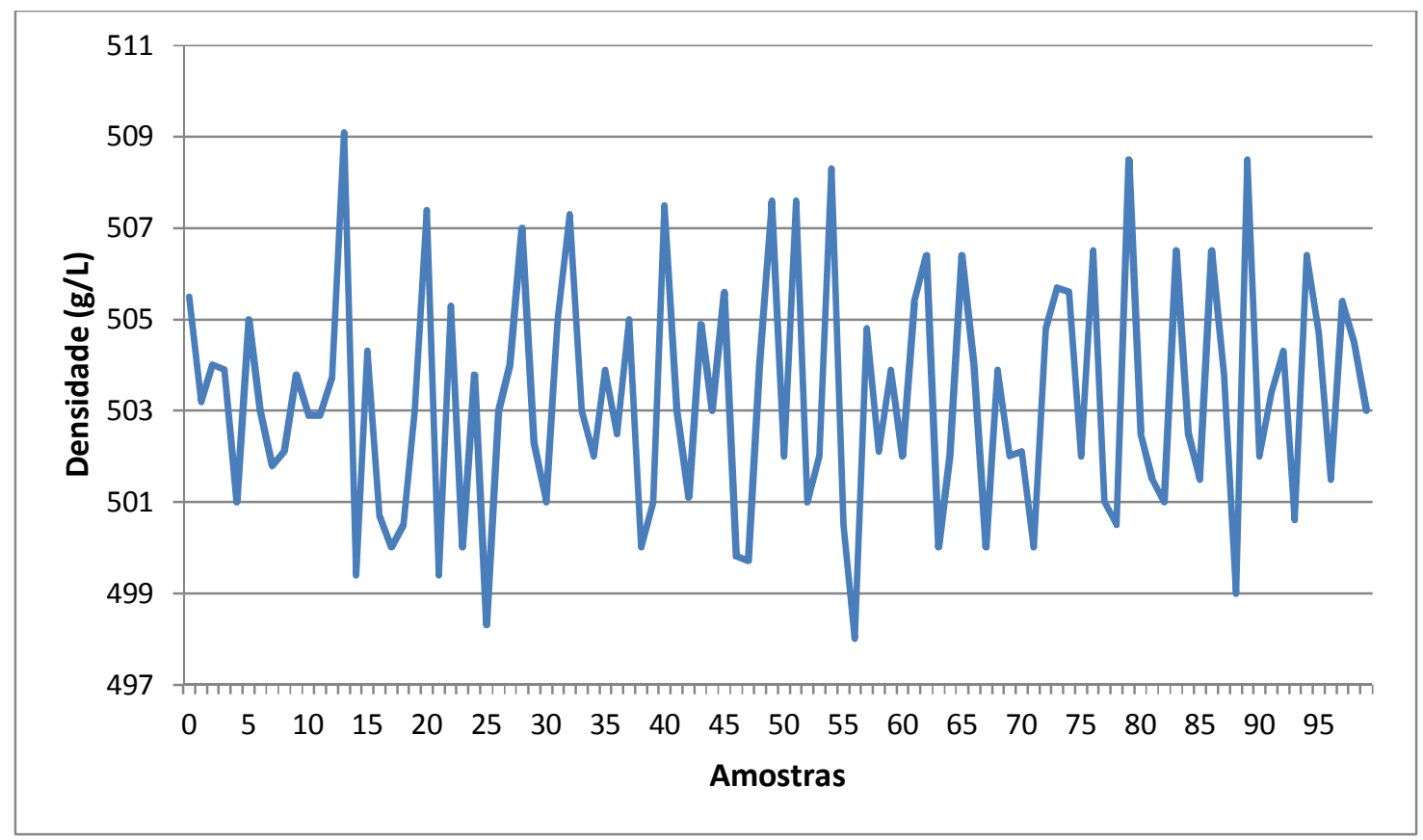

Figura 26- Gráfico de variação de densidade de curto prazo.

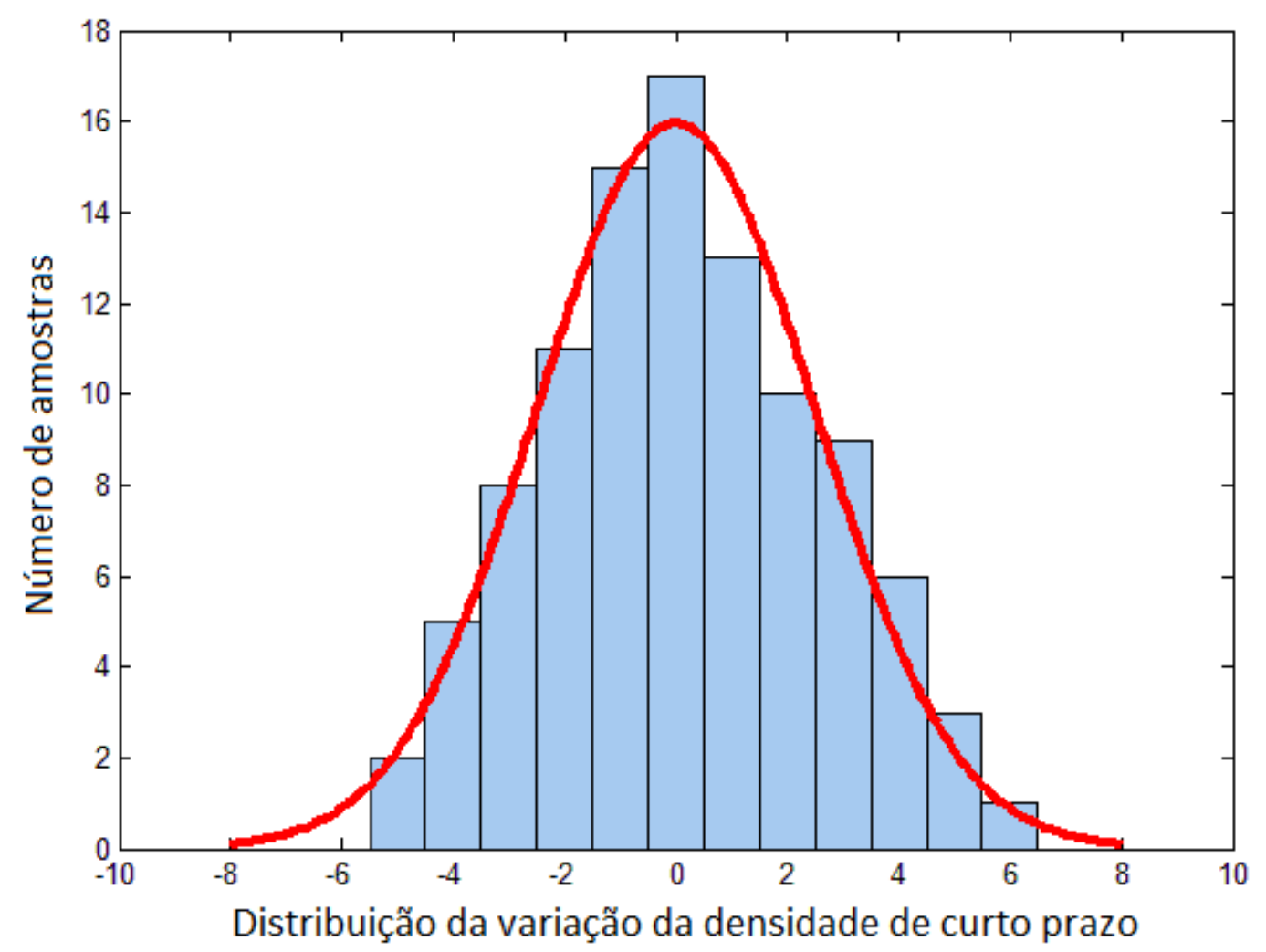

Figura 27 - Histograma da variação da densidade de curto prazo - passo de $1 \mathrm{~g}$.

Como forma de validar o desvio padrão de densidade de curto prazo, o desvio padrão devido à não uniformidade de enchimento, o desvio da checkweigher e o desvio das 
canecas, a seguinte atividade foi realizada. Coletaram-se trinta mil dados de peso sequenciais de uma produção normal (2 horas e 45 minutos de produção). Tais dados foram medidos pela checkweigher de uma das enchedoras com o controlador desligado e as canecas fixas em dois litros. Durante essa produção o controlador não atuava e os pesos estavam diretamente impactados pelas perturbações e variabilidade do sistema, como as variações de densidade, variações das canecas, imprecisão da checkweighere imprecisão de enchimento. Vale ressaltar que uma das enchedoras operava com o controlador desligado por alguns problemas técnicos e de capacitação das pessoas, o que facilitou os testes mencionados neste item e no item 3.3.3.3.

Com os dados de peso dessa produção inteira foi possível calcular a densidade média, uma vez que o valor médio da variação das canecas, da imprecisão da checkweigher e do enchimento são zero e consequentemente, calculando-se a média geral dos pesos e dividindo-se pelo volume médio das canecas, que era de dois litros, obtémse a média de densidade. Esse valor foi de $\mu_{\text {cartons }}=500,5 \mathrm{~g} / \mathrm{L}$.

Com esses dados observados da produção normal, também foi possível calcular o desvio padrão de curto prazo dos pesos. Para isso, se calculou a média dos pesos para todos os momentos em que a média dos cartuchos não alterava de nove em nove pacotes, correspondendo aos momentos em que não existe variação de densidade de médio prazo, que é explicado no item 3.3.3.3. Nesses trinta mil pesos existiram oito momentos em que essa situação ocorreu, com aproximadamente trinta cartuchos em sequência, gerando aproximadamente 250 cartuchos nessas condições. Para cada momento se subtraiu o valor individual de peso das respectivas médias calculadas e, em seguida calculou-se os desvios padrão dessas diferenças para os oito momentos e, por fim, a média desses oito desvios, resultando em $\sigma_{\text {peso, } 9}$ $=7,99 \mathrm{~g}$. Nota-se que não existiu uma diferença significativa entre os oito desvios calculados, mostrando que nesse momento, somente as variabilidades de curto prazo estavam acontecendo.

Então, pode-se dizer que esse é o desvio padrão total de curto prazo, pois ele envolve todas as variabilidades de curto prazo. Ao mesmo tempo, esse mesmo valor pode ser 
obtido através da fórmula mostrada na Equação (10), uma vez que todas variáveis são independentes.

$$
\sigma_{\text {peso, },}=\sqrt{\sigma_{\text {caneca }}^{2}+\sigma_{\text {enchimento }}^{2}+\sigma_{\text {checkweigh er }}^{2}+\text { volume }^{2} \cdot \sigma_{\text {densidadeC } P}^{2}}
$$

Anteriormente, obteve-se a partir de testes ou observações do processo, os valores de todas as variáveis do lado direito da Equação (10), os quais são: $\sigma_{\text {checkweigler }}=1,81 \mathrm{~g}$, $\sigma_{\text {caneca }}=5,65 \mathrm{~g}, \sigma_{\text {enchimento }}=1,1 \mathrm{~g}$ e $\sigma_{\text {densidadeCP }}=2,54 \mathrm{~g} / \mathrm{L}$. Substituindo-se esses valores na Equação (10), obtém-se o valor $\sigma_{\text {peso, },}=7,88 \mathrm{~g}$, que representa um erro de $1,4 \%$ do resultado obtido através da amostragem de trinta mil pesos.

Realizou-se outro cálculo, a fim de validar os desvios padrão encontrados individualmente. Para isso, se calculou a média dos pesos com uma janela deslizante de nove cartuchos, que corresponde a um ciclo das canecas, para as mesmas oito sequências de pacotes. E para cada média deslizante calculada se subtraiu os valores individuais dos respectivos nove cartuchos, e assim calculou-se o respectivo desvio padrão para cada janela, gerando-se 96 valores de desvio. Por fim, calculou-se a média de todos os desvios padrão gerados, obtendo-se o valor de $\sigma_{\text {weight, } 9}=7,95 \mathrm{~g}$, 0 que representa um erro de $0,8 \%$ com relação ao resultado obtido com o cálculo das componentes individuais, podendo-se novamente validar os valores encontrados individualmente.

Esses dois processos de cálculo validam os valores de desvio padrão das componentes de curto prazo encontrados individualmente e reforça que os métodos utilizados foram adequados, uma vez que os valores individuais e o total foram conseguidos através de testes diferentes e dados de entrada distintos.

\subsubsection{Variação de densidade de longo prazo}

Para esse ponto, a preocupação foi entender como o processo de alimentação da máquina de embalagem afeta as variações de densidade, uma vez que se sabe que 
as densidades médias dos buggies são diferentes. Como mencionado anteriormente, o detergente em pó é produzido e armazenado nos bugies, que são aleatoriamente estocados em sua área de armazenagem, a qual se localiza acima da área de embalagem. Portanto, ocorre uma mistura de sequência de partes da produção, que mais tarde alimentam as máquinas de embalagem de forma aleatória, também através das duas aberturas de alimentação do silo, como mostrado na Figura 28. Essa forma de alimentação significa que se pode alimentar o silo com dois buggies ao mesmo tempo.

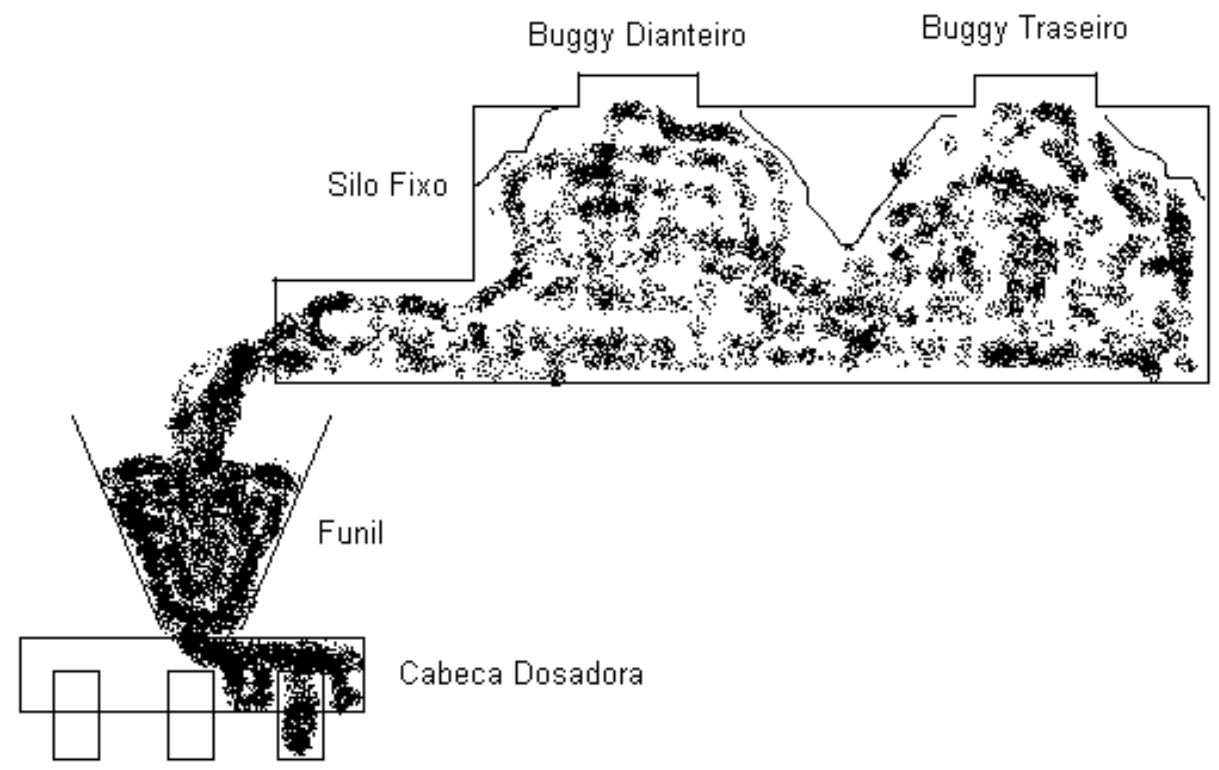

Figura 28- Alimentação do silo.

Portanto, o enchimento do silo consiste na alternância aleatória de partes da produção do material em pó, com cada buggy apresentando uma média de densidade com oscilações de médio prazo em torno da mesma. Tais oscilações de médio prazo são detalhadamente descritas no item 3.3.3.3.

Outro fato importante é a maneira como essa alternância acontece em função do fluxo de pó no silo. Um estudo foi realizado para entender essa alternância e se notou que o detergente em pó vindo da parte de trás do silo (mais distante da parte de alimentação do conjunto de canecas) somente é dosado quando o pó da parte frontal termina. Isto é, o material em pó da parte de trás funciona como um buffer adicional, 
para evitar falta de material em pó na máquina embaladora, dando mais tempo para o operador de buggies abastecer outro buggy.

Em média, um buggy traseiro é substituído a cada três buggies frontais e o tempo de esvaziamento do buggy frontal é de aproximadamente oito minutos, uma vez que cada buggy tem $1540 \mathrm{~kg}$ e isso é suficiente para embalar em torno de 1517 cartuchos, considerando um sobrepeso de cerca de $15 \mathrm{~g} /$ cartucho.

Para modelar as trocas de buggies, um teste foi realizado, no qual a densidade de 150 buggies foi medida (10 amostras por buggy), incluindo buggies usados na produção dos trinta mil cartuchos. O resultado da média e desvio padrão da densidade média de cada buggy foi:

$\mu_{\text {buggy }}=501 \mathrm{~g} / \mathrm{L} \quad$ e $\quad \sigma_{\text {buggy }}=5,7 \mathrm{~g} / \mathrm{L}$

Portanto, uma variável aleatória foi criada para simular a densidade média dos buggies. A função densidade de probabilidade usada para modelar essa variável foi uma gaussiana, que é a curva que mais se aproxima dos dados de densidade média dos buggies, o que já era de se esperar, uma vez que existem diversas variáveis que impactam no resultado de densidade do material em pó produzido. A Figura 29 mostra o histograma da densidade dos buggies. 


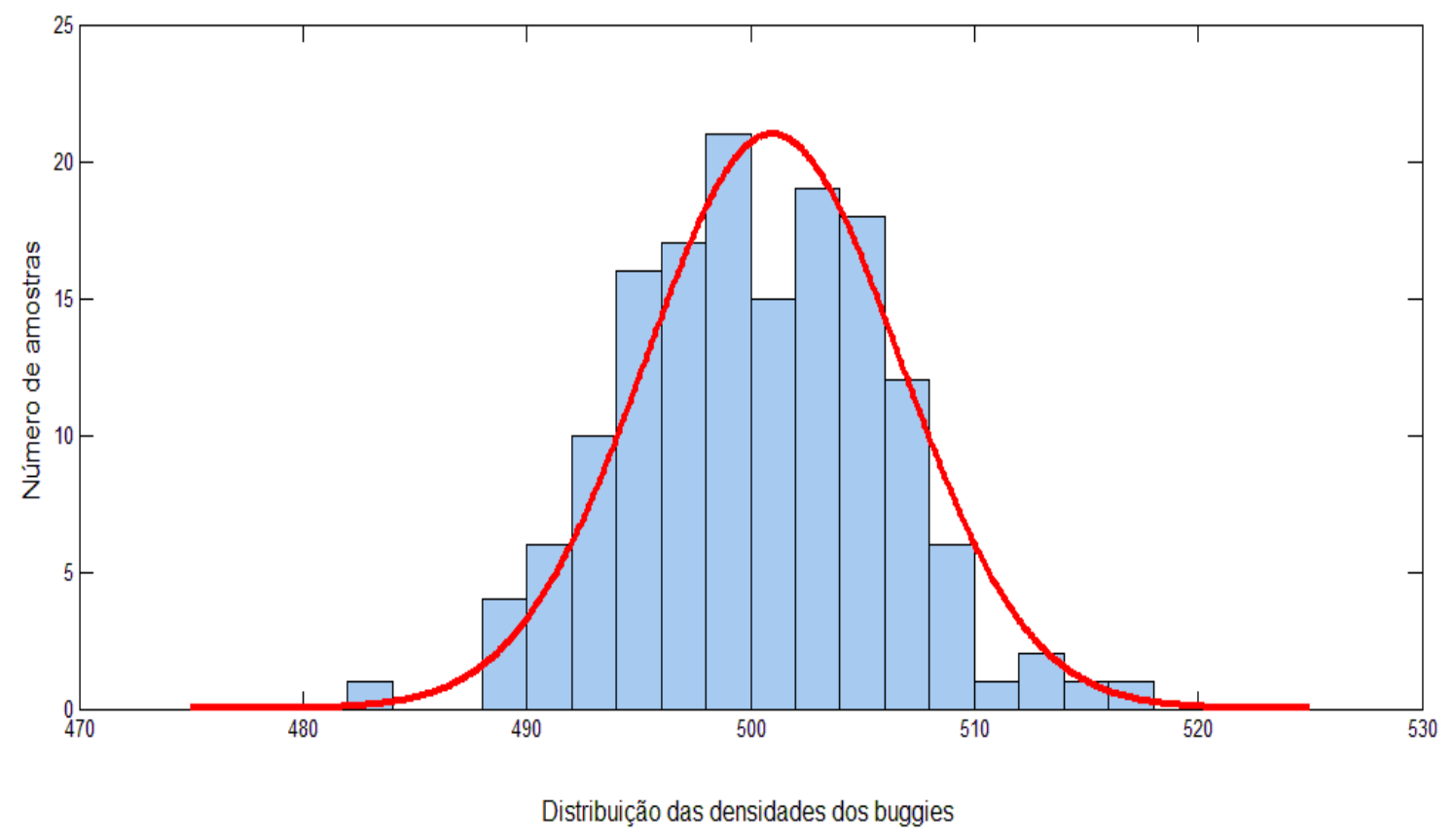

Figura 29- Histograma da densidade dos buggies - passo de $2 \mathrm{~g}$.

Outro teste foi realizado para entender e quantificar como acontece a velocidade de variação de densidade da troca de buggies. Por trinta trocas de buggies, os dados de peso antes, durante e depois da troca foram analisados. Foi observado que em média a velocidade de variação da densidade é de $0,6 \mathrm{~g} / \mathrm{L} /$ cartucho.

Então, para modelar as variações de longo prazo, foi colocada uma constante com valor $\mu_{\text {buggy }}$, foram inseridos dois geradores de variável aleatória gaussiana com média igual a zero e desvio padrão igual a $\sigma_{\text {buggy }}$ somados à constante, representando os dois buggies que alimentam o silo e implementada uma lógica que executa a rampa de transição de troca dos mesmos.

\subsubsection{Variação de densidade de médio prazo}

A proposta aqui é definir como a densidade varia em médio prazo (50 a 1500 cartuchos). Para isso, utilizaram-se inicialmente os mesmos dados da produção de trinta mil cartuchos usados no item 3.3.3.1, fazendo-se um estudo estatístico dos mesmos. Como o controlador estava desligado, as variações de médio prazo dos pesos representam as variações de densidade de médio prazo somente multiplicadas 
por dois, uma vez que esse era o volume médio do conjunto de canecas. Embora esses dados contenham as variabilidades de curto prazo, discutidas no item 3.3.3.1, elas não interferem na análise de médio prazo, uma vez que os métodos utilizados para identificar tais variações filtram as oscilações de curto prazo.

Esse item é seguramente o que ofereceu maior grau de dificuldade em todo o estudo, mas ao mesmo tempo o que mostra o maior diferencial deste trabalho, uma vez que as perturbações de médio prazo seriam extremamente complicadas ou até mesmo impossíveis de serem determinadas pelos princípios primários ou por experimentos, e mesmo que encontradas soluções para isso, certamente envolveria tempos e custos não compatíveis com o objetivo do trabalho. A análise realizada levou dois meses com quatro pessoas, tornando o trabalho possível e viável financeiramente.

Além da análise gráfica básica, foi avaliada também a densidade média com janela deslizante de nove cartuchos. O mesmo estudo se repetiu para uma janela de 50 cartuchos. Essa manipulação de dados foi necessária para filtrar em quase 100\% todas as variações de curto prazo. Toda essa análise também se repetiu exaustivamente para mais aproximadamente cento e cinquenta conjuntos de trinta mil cartuchos, sendo um total de mais de quatro milhões e meio de pesos analisados, o que é bem representativo para gerar uma modelagem estocástica neste caso. As seguintes propriedades foram observadas durante a análise, considerando-se as mesmas como sendo os processos estocásticos necessários para fazer a modelagem:

- Forma de oscilação de densidade (senoidal, triangular e rampa);

- Porcentagem de ocorrência de cada oscilação no tempo observado;

- Amplitude e/ou inclinação de cada forma de onda. Com esses dados calculouse a amplitude média, os seus desvios padrão e verificou-se a distribuição dos valores dessas amplitudes ou inclinações; e

- Período das formas de oscilação. Com esses dados calculou-se o período médio, os seus desvios padrão e verificou-se a distribuição dos valores desses períodos. 
- Número de períodos que a oscilação ocorre (tempo de ocorrência). Calculouse o número médio, o desvio padrão e qual a distribuição. Aplicado somente para alguns tipos de oscilação.

Além da observação gráfica, a análise também utilizou algumas técnicas de análise gráfica, como cálculo do espectro de frequência do sinal, através da transformada $\mathrm{Ze}$ substituição da variável complexa por $\mathrm{e}^{\mathrm{jw}}$ (equivalente à transformada de Fourrier de tempo discreto) e um programa específico feito em "Visual Basic" do Microsoft Excel para, através das médias deslizantes de nove cartuchos, verificar se alguma sequência de dados se aproximava das formas de onda pesquisadas, embora tenha sido de baixa ajuda, uma vez que o somatório das variabilidades em paralelo dificultava a identificação de ondas através do programa automático. A ideia por trás dessas análises foi tentar criar um modelo estocástico para descrever essas variações de densidade, baseado nas cinco variáveis mencionadas.

$A$ análise de frequência da transformada $Z$ ajudou a identificar as frequências de variação, deixando claro que existia uma variação de nove em nove cartuchos, embora essa seja uma variação de curto prazo e já estudada, uma variação de cem em cem cartuchos e uma variação de trezentos em trezentos cartuchos. A Figura 30 mostra uma parte dos dados utilizados. 

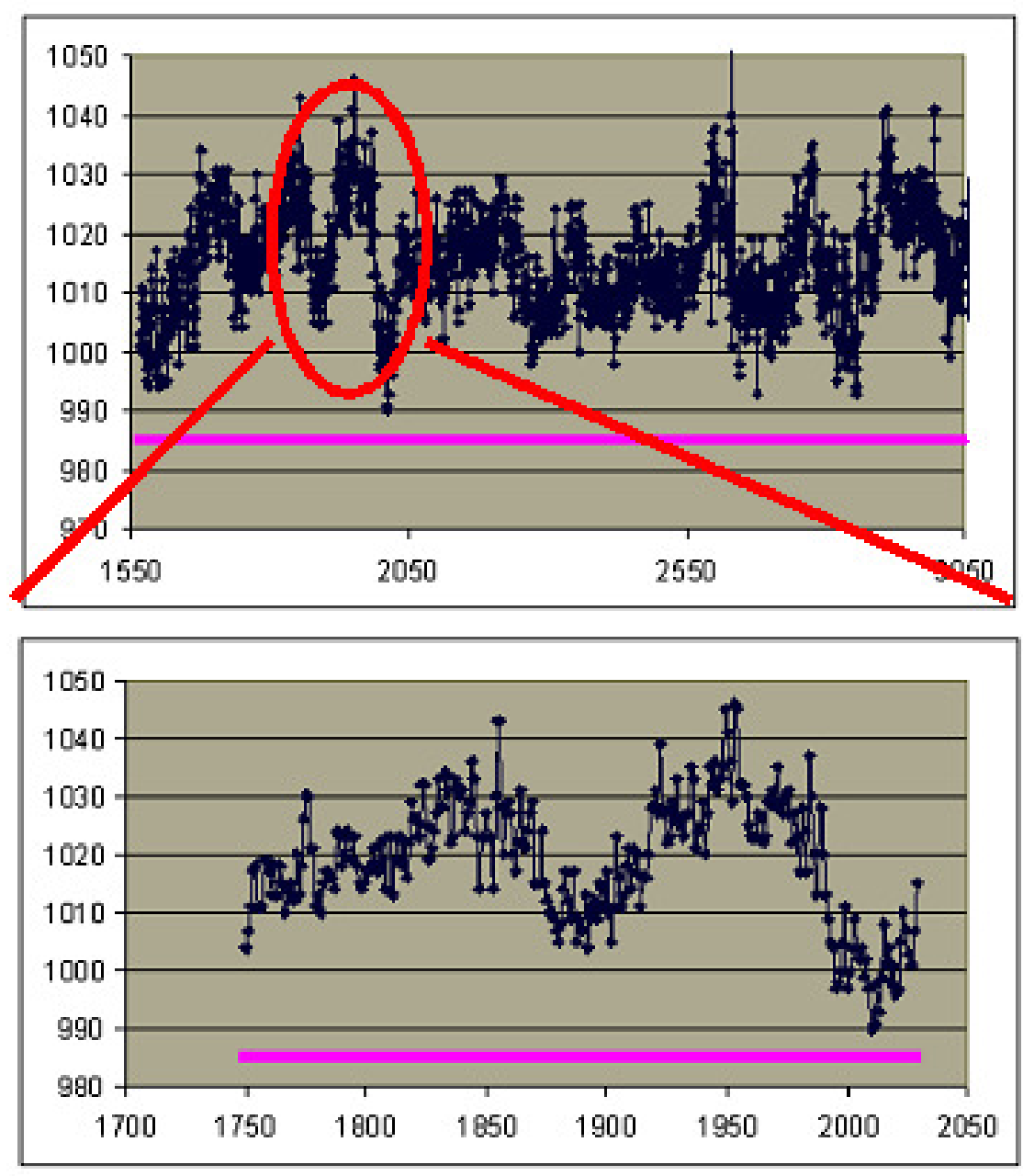

Figura 30- Parte dos dados de pesos coletados - eixo x em amostras e eixo y em $\mathrm{g}$.

Depois de utilizada as duas ferramentas, a maior parte da análise consistiu em observar os gráficos ao longo do tempo. Para cada forma de onda observada foram anotadas as propriedades mencionadas anteriormente, e com esses dados foram feitos os cálculos dos parâmetros de cada uma. Por exemplo, se em uma sequência de trinta mil pesos, que poderia conter cem vezes uma determinada forma de onda (período de trezentos cartuchos), ela apareceu por vinte vezes, sua porcentagem de ocorrência foi de $20 \%$. Para cada uma dessas vinte vezes anotou-se os valores de amplitude e período de ocorrência e com esses 20 valores, calculou-se a média, desvio padrão e verificou-se a distribuição desses valores. No final de toda a análise, as porcentagens, médias, desvios e distribuições dos processos estocásticos observados foram calculados, levando-se em conta todos os 150 conjuntos de trinta mil pesos. 
A seguir são mostradas as formas de oscilação que foram identificadas depois de fazer a análise de dados. Nesse momento suas causas raízes são desconhecidas, somente sabendo-se a região de todo processo que as gera. Portanto, pode parecer um tanto subjetivo, mas essa é justamente a intenção, modelando essas perturbações pelas suas estatísticas sem conhecer suas causas primárias.

- seno de longo período e ondas triangulares devido ao processo de fabricação;

- seno de período curto devido à variação do nível de pó no funil em cima da cabeça dosadora, o qual é enchido e esvaziado a cada 36 segundos;

- rampa lenta decrescente, em torno de 900 a 1500 cartuchos, devido à compactação e segregação do pó no silo principal e nos buggies principalmente;

- rampa brusca de duração curta, em torno de 45 a 55 cartuchos, acontecendo a cada 200 a 250 cartuchos, por determinados períodos; e

- alguns períodos bem pequenos sem oscilação.

, que As observações indicaram que em geral, essas formas de oscilação ocorrem em paralelo, uma vez que elas aparentam ter causas diferentes e não correlacionadas, exceto para o seno de período longo e a onda triangular, os quais são uma variação da mesma causa e portanto não ocorrem em paralelo, ocorrendo ou a primeira ou a segunda. A Figura 31 mostra a autocorrelação de um grupo de trinta mil pesos, demonstrando que o sinal só é autocorrelacionado até 60 pesos à frente ou para trás. Mais do que isso o nível de correlação cai significativamente.
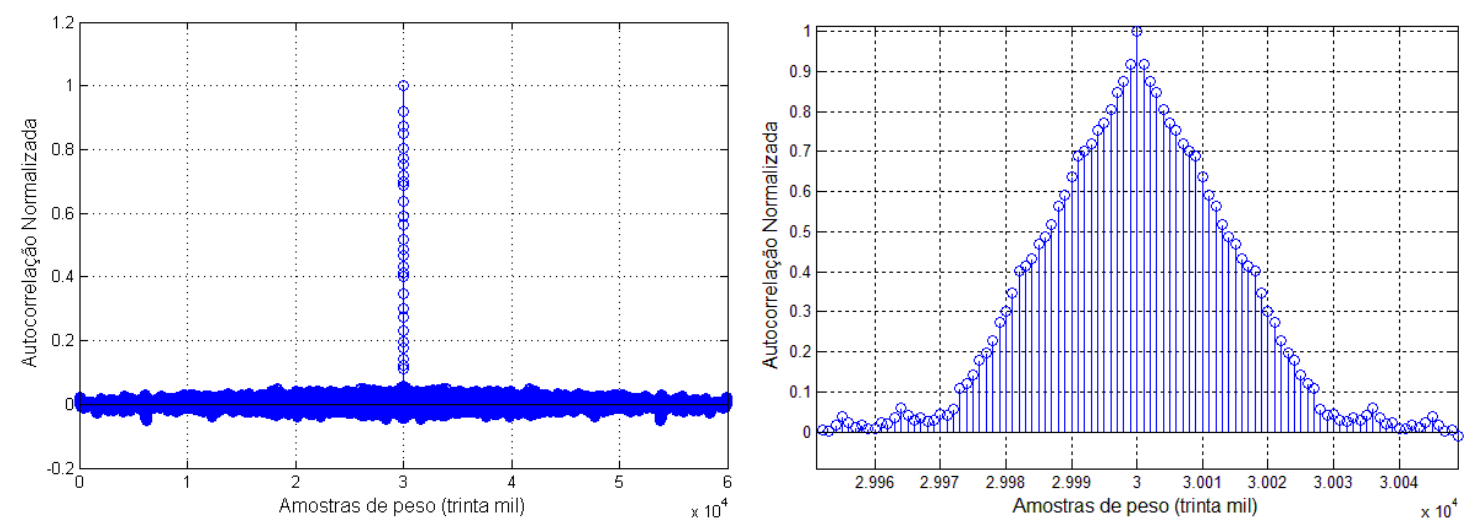

Figura 31- Autocorrelação de trinta mil pesos - ampliação à direita. 
O resultado da Figura 31 já é um indicativo de que as formas de oscilação encontradas não têm uma forte correlação entre elas e que cada oscilação não tem uma forte correlação com ela mesma ao longo do tempo. A Figura 32 mostra a correlação cruzada entre as quatro formas de oscilação, considerando que o seno longo e a onda triangular tem a mesma origem.
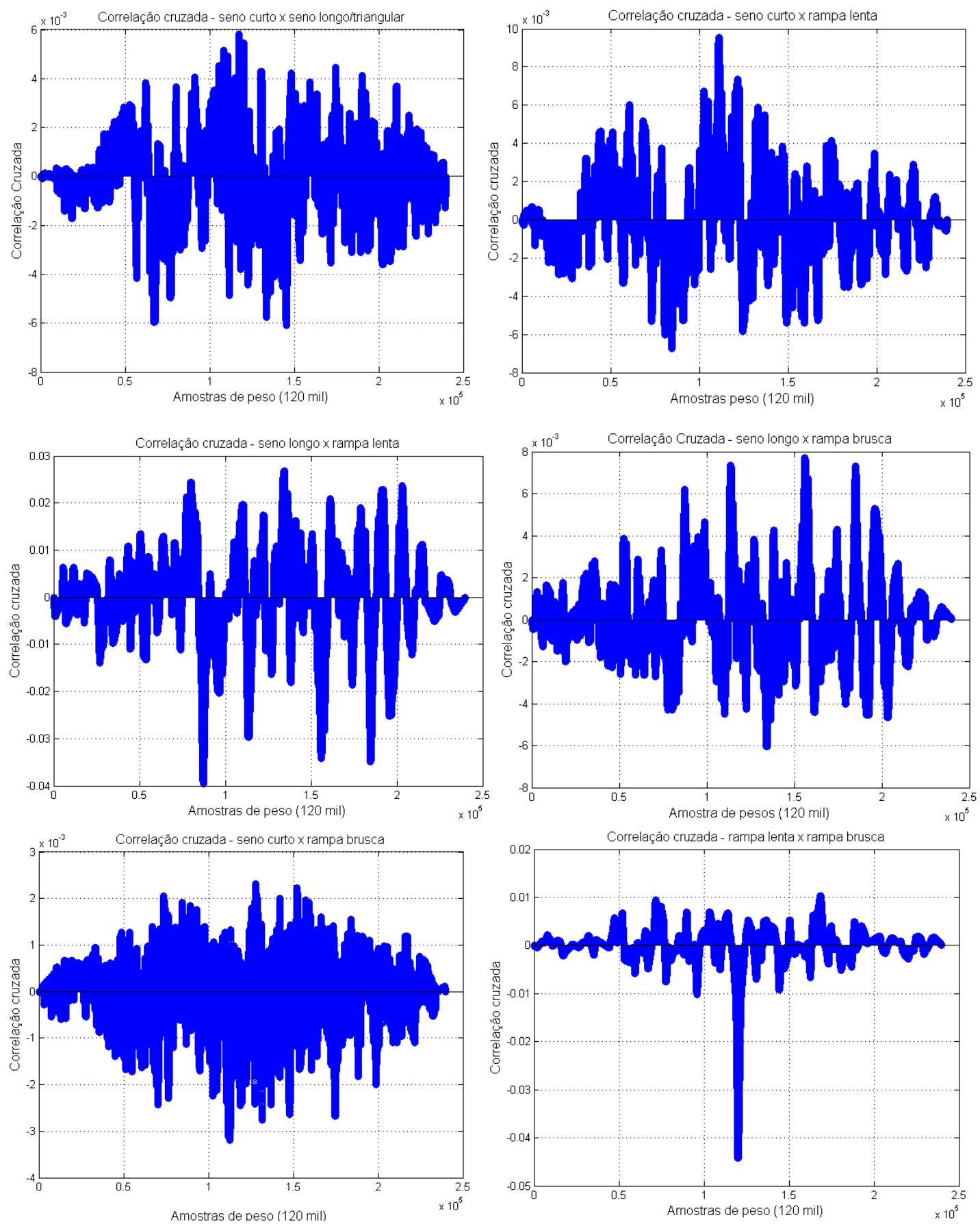

Figura 32 - Gráficos das correlações cruzadas normalizadas das formas de oscilação encontradas. 
Para realizar tal cálculo, as oscilações individuais foram geradas no Matlab, de acordo com os parâmetros encontrados na análise de três sequências de trinta mil cartuchos, ou seja, foi registrado o momento de ocorrência, a amplitude ou velocidade de variação, o período de oscilação e o tempo de oscilação.

Como se pode notar nos gráficos da Figura 32, os valores de correlação cruzada normalizada são bem baixos, demonstrando que existe uma fraca correlação entre as ocorrências das formas de onda. Isso demonstra que o modelo estocástico poderia ser feito individualmente para cada forma de oscilação, considerando que elas ocorrem em paralelo. As Figura 33, 34 , 35 e 36 mostram as autocorrelações das formas de onda encontradas, utilizando os mesmos dados gerados para calcular as correlações cruzadas da Figura 32.
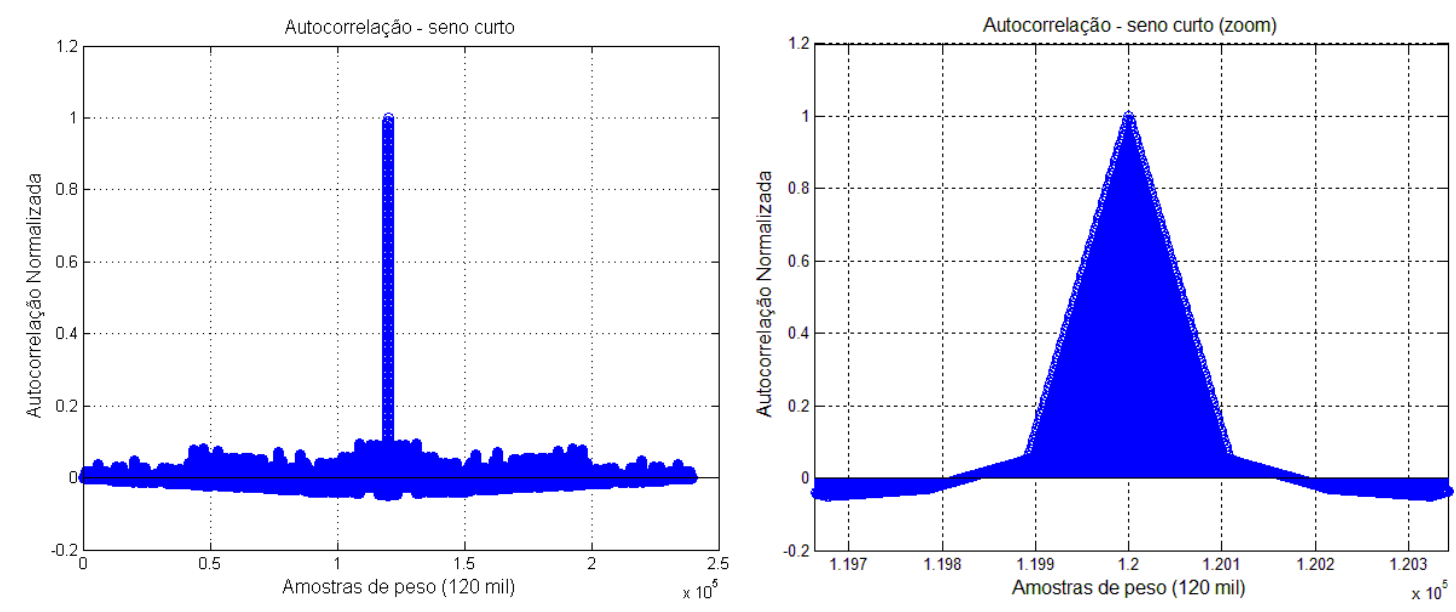

Figura 33 - Autocorrelação das oscilações de seno curto. 

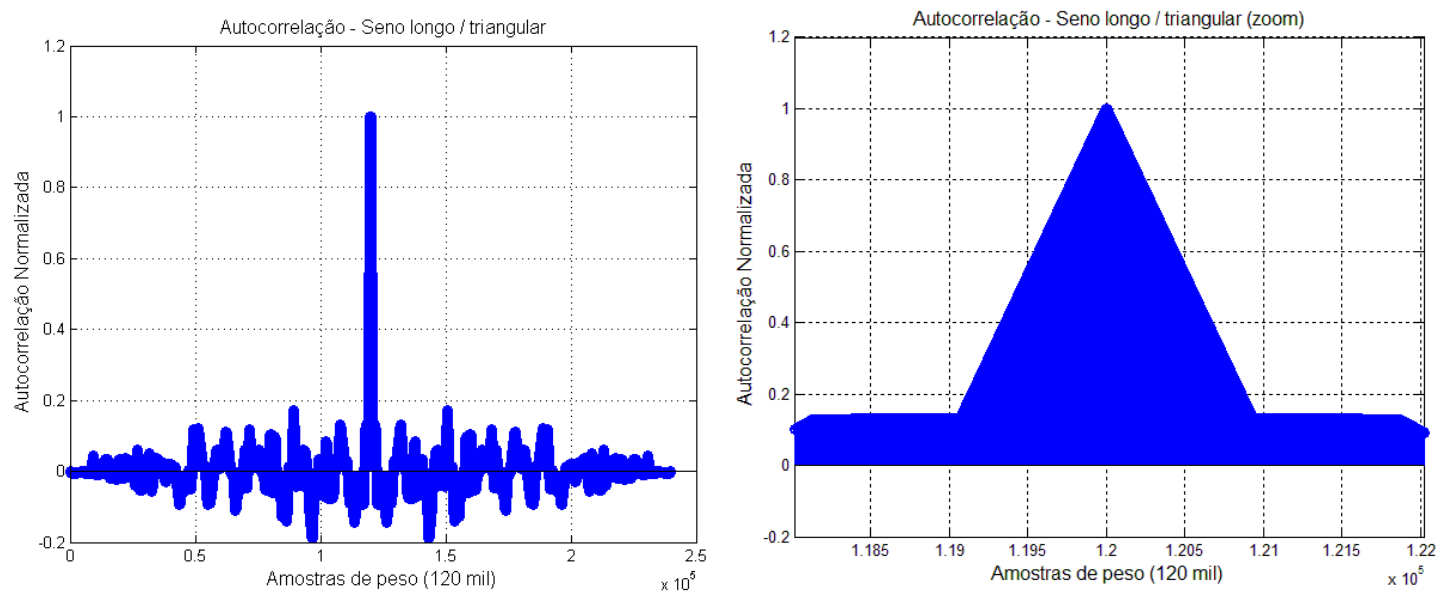

Figura 34- Autocorrelação das oscilações de seno longo / triangular.
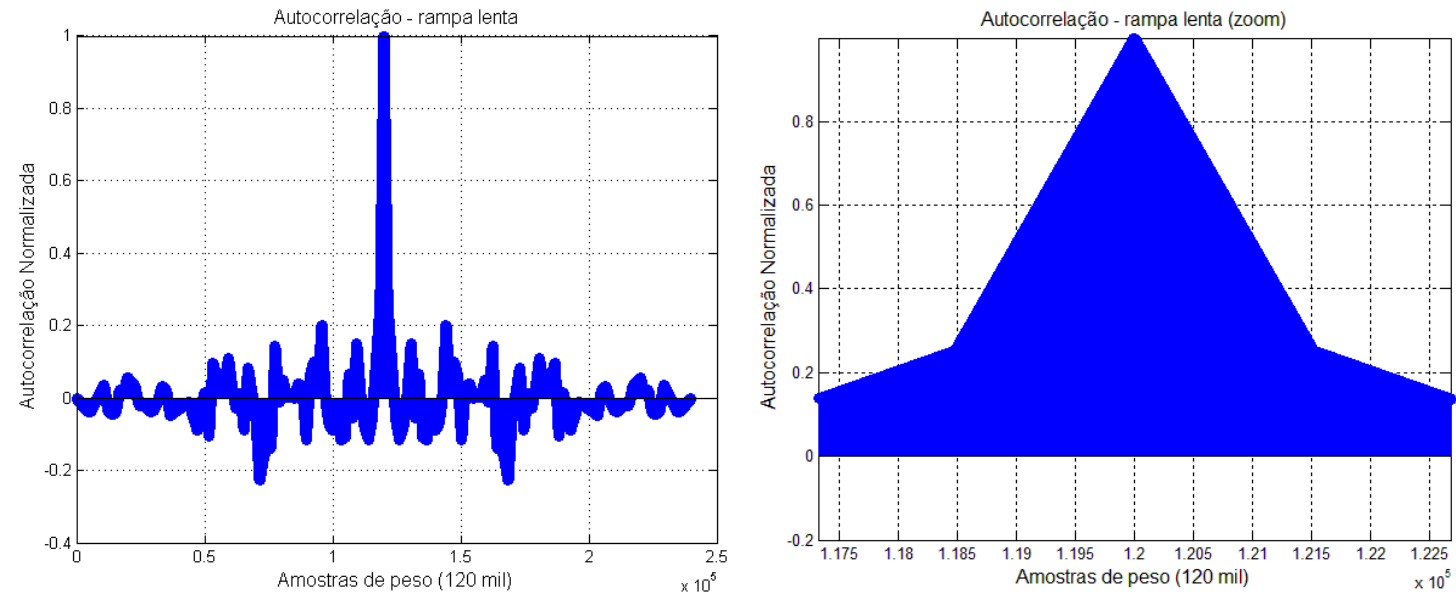

Figura 35 - Autocorrelação das oscilações de rampa lenta.
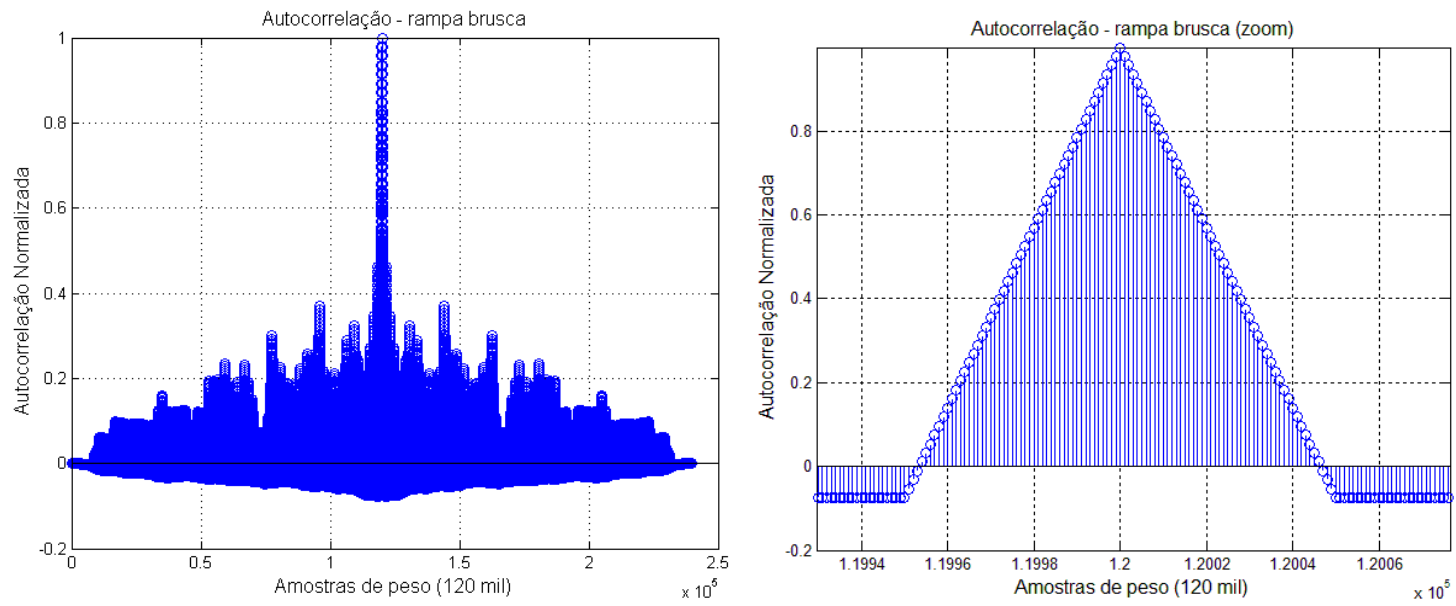

Figura 36- Autocorrelação das oscilações de rampa brusca. 
As autocorrelações das ocorrências das oscilações indicam que elas são processos estocásticos com fraca correlação entre uma ocorrência e as seguintes. Além disso, a ampliação aplicada nos gráficos mostra que a janela com correlação mais forte é justamente o dobro do tempo de ocorrência de cada oscilação, indicando que os processos de ocorrência são aproximadamente binomiais, sendo cada período um "sorteio" de Bernoulli com probabilidade de sucesso que pode ser modelada pela porcentagem de ocorrência observada.

Embora não se saibam as causas raízes de cada oscilação, existe uma boa ideia de onde elas são geradas e fisicamente seriam realmente processos sem relações fortes uns com os outros, e cada um individualmente é afetado por tantas variáveis, que realmente pode haver uma fraca correlação entre suas ocorrências. Dessa forma, as análises de correlação reforçam as hipóteses físico-químico estudadas.

Observações adicionais identificaram também que as rampas bruscas acontecem em torno de 5,5\% do tempo total, as quais aumentavam consideravelmente a variação e a velocidade de variação nesse período. Fazendo uma análise um pouco mais detalhada, identificou-se que esses períodos correspondiam aos momentos em que o buggy traseiro alimenta a máquina e como mencionado anteriormente, elas aconteciam com intervalos mais ou menos de 200 a 250 cartuchos, o que corresponde a $22 \%$ do tempo de dosagem do buggy traseiro. Observou-se também que as rampas lentas ocorriam em aproximadamente $71 \%$ do tempo total e somente nos momentos em que o buggy dianteiro alimentava a máquina, ou seja, praticamente durante toda a alimentação desse buggy, uma vez que o buggy dianteiro alimenta a máquina em $75 \%$ do tempo.

As rampas lentas, embora ocorram durante $71 \%$ do tempo, têm um impacto bem menor no sobrepeso do que as rampas abruptas, uma vez que o controlador tem velocidade suficiente para compensar a maioria das rampas lentas, enquanto não tem velocidade para compensar a maioria das rampas abruptas.

Dessa forma, com as observações e análise de dados, pode-se chegar às seguintes formas de modelagem para cada forma de oscilação: 
Seno curto - cada período de ocorrência é um "sorteio" de Bernoulli com probabilidade de sucesso igual à porcentagem de ocorrências práticas, formando ao longo do tempo um processo binomial. Cada "sorteio" seleciona ou não a ocorrência da oscilação e tal oscilação é composta por dois processos estocásticos: a amplitude e o período/frequência. Para cada um dos dois casos definiu-se a média, o desvio padrão e a forma de distribuição. Neste caso, como a porcentagem de ocorrência é bem alta, o tempo de ocorrência foi sempre considerado como um período completo, ou seja, a cada novo período um novo "sorteio" é realizado.

Seno longo / triangular - a cada tempo de ocorrência, o qual é aproximadamente múltiplo do período, um "sorteio" de Bernoulli é realizado com probabilidade igual à porcentagem de ocorrências práticas, formando também um processo binomial. Da mesma forma que para o seno curto, cada "sorteio" seleciona ou não a ocorrência da oscilação, existindo neste caso, três processos estocásticos da mesma: a amplitude, o período/frequência e o tempo de ocorrência. Isto foi considerado neste caso, pois normalmente quando a oscilação ocorre, ela levava três períodos para terminar.

Rampa lenta - essa oscilação ocorre para todo início de buggy frontal, ocorrendo por um determinado tempo e com uma determinada inclinação, os quais são processos estocásticos com média, desvio padrão e distribuição definidas pelos dados práticos. Como são três buggies frontais para um traseiro, a porcentagem de ocorrência é um pouco menor que $75 \%$. Pelos estudos e análise de dados realizadas, não se perderia precisão significativa do modelo, fazendo essa rampa aparecer também como um processo binomial sem características determinísticas, com probabilidade de sucesso igual à porcentagem de ocorrência, uma vez que as outras ondas já ocorrem em paralelo de qualquer forma, formando uma sobreposição aleatória de oscilações. Ou seja, mesmo com esse fator determinístico, acaba se formando uma sobreposição de ondas aleatórias de qualquer forma, dada a aleatoriedade das outras e a aleatoriedade do abastecimento dos buggies.

Rampa brusca - essa forma de perturbação ocorre sempre que é dosado um buggy traseiro. Ela ocorre por aproximadamente 50 pacotes, estabilizando a média de densidade por aproximadamente mais 200-250 pacotes, ocorrendo novamente no sentido contrário por mais 50 pacotes e assim sucessivamente até acabar o produto 
vindo do buggy traseiro. Os processos estocásticos avaliados a cada surgimento dessa oscilação são a inclinação de variação, o tempo de atuação e o período para começar outro ciclo. Para esse caso também não se perderia muita precisão do modelo, caso se considerasse essa oscilação ocorrendo como um processo binomial, da mesma forma que o mencionado para a rampa lenta. A única ressalva para os dois casos é que seria mais adequado que elas não ocorressem juntas, pois isso não ocorre na prática, embora tal fato não tivesse um impacto significativo, pois ora o processo teria uma variação mais agressiva, quando as duas inclinações tivessem a mesma direção, ora seria mais brando, quando as oscilações tivessem sentidos opostos.

É interessante notar que esse modelamento estocástico não usa nem o conceito no qual uma realização estocástica inteira (forma de onda) é selecionada, e nem o conceito no qual uma sequência de variáveis aleatórias é ordenada no tempo, mas sim os dois ao mesmo tempo. A variável aleatória é o processo binomial, no qual a cada ciclo um "sorteio" aleatório é executado com determinada probabilidade de sucesso, mas ao invés de ser "sorteado" um número, é "sorteada" uma forma de onda completa com processos aleatórios presentes (período, amplitude / inclinação e tempo de ocorrência), a qual ocorre no tempo por um ciclo do processo.

Existem alguns fatores que não foram considerados no modelamento, mas sem impactos significativos, como é visto na validação do simulador no capítulo 4 . Esses fatores são:

- Na prática as oscilações algumas vezes não terminavam no final de um período perfeito, mas como nesses casos a frequência de ocorrência é muito alta (seno curto), o impacto de não considerar é baixo;

- Nas observações de dados, notou-se que durante uma oscilação os parâmetros estocásticos observados tinham um certo grau de variação, por exemplo uma amplitude de um seno longo poderia ser diferente de um período para outro. Como essas variações não eram muito grandes, foram desprezadas, uma vez que sua implementação e cálculo trariam uma complexidade muito grande. 
Assim, a Tabela 4 mostra os resultados desse estudo, considerando-se que as rampas lentas ocorrem somente com o buggy dianteiro e as rampas bruscas somente com o buggy traseiro.

Tabela 4- Resultado da análise estatística das formas de onda.

\begin{tabular}{|c|c|c|c|c|c|c|}
\hline $\begin{array}{c}\text { Processo } \\
\text { estocástico }\end{array}$ & Parâmetros estocásticos & $\begin{array}{l}\text { Seno } \\
\text { Curto }\end{array}$ & $\begin{array}{l}\text { Seno } \\
\text { Longo }\end{array}$ & Triangular & $\begin{array}{c}\text { Rampa } \\
\text { Lenta }\end{array}$ & $\begin{array}{l}\text { Rampa } \\
\text { brusca }\end{array}$ \\
\hline $\begin{array}{l}\text { Porcentagem de } \\
\text { ocorrência }\end{array}$ & $\begin{array}{l}\text { Porcentagem de } \\
\text { ocorrência observada }\end{array}$ & $95 \%$ & $11 \%$ & $9 \%$ & $71 \%$ & $5,5 \%$ \\
\hline \multirow{3}{*}{$\begin{array}{l}\text { Período em cada } \\
\text { forma de } \\
\text { oscilação } \\
\text { periódica }\end{array}$} & Média & 108 & 310 & 310 & 1500 & 225 \\
\hline & Desvio padrão & 12 & 25 & 25 & 25 & 5 \\
\hline & Distribuição estatística & Gaussiana & Gaussiana & Gaussiana & Gaussiana & Gaussiana \\
\hline \multirow{3}{*}{$\begin{array}{l}\text { Tempo de } \\
\text { atuação } \\
\text { (amostras) }\end{array}$} & Média & NA & 930 & 930 & 1200 & 50 \\
\hline & Desvio padrão & NA & 50 & 50 & 100 & 3 \\
\hline & Distribuição estatística & NA & Gaussiana & Gaussiana & Uniforme & Gaussiana \\
\hline \multirow{3}{*}{$\begin{array}{l}\text { Amplitude média } \\
\text { medida para cada } \\
\text { oscilação }(\mathrm{g} / \mathrm{L})\end{array}$} & Média & 5,4 & 10,1 & NA & NA & NA \\
\hline & Desvio padrão & 1,5 & 2,2 & NA & NA & NA \\
\hline & Distribuição estatística & Gaussiana & Gaussiana & NA & NA & NA \\
\hline \multirow{3}{*}{$\begin{array}{l}\text { Inclinação média } \\
\text { cada oscilação } \\
\text { (g/L/cartucho) }\end{array}$} & Média & NA & NA & 0,06 & 0,012 & 0,3 \\
\hline & Desvio padrão & NA & NA & 0,016 & 0,003 & 0,1 \\
\hline & Distribuição estatística & NA & NA & Gaussiana & Gaussiana & Gaussiana \\
\hline
\end{tabular}

NA - não aplicável

É interessante notar que a probabilidade de ocorrer períodos sem oscilação é de $1 \%$, considerando que isso vai acontecer somente quando nenhuma das ondas ocorre. $A$ rampa lenta inicia quando um buggy dianteiro começa a alimentação e termina em um intervalo de 900 a 1500 cartuchos, com uma média de 1200.

O desvio padrão da densidade total foi calculado, eliminando-se a influência da imprecisão da checkweigher, a variação das canecas e o enchimento não uniforme, resultando em $\sigma_{\text {densidade,total }}=8,7 \mathrm{~g} / \mathrm{L}$. O desvio padrão dos buggies calculado no item 3.3.3.2 é $\sigma_{\text {buggy }}=5,7 \mathrm{~g} / \mathrm{L}$ e o desvio padrão de densidade de curto prazo calculado no item 3.3.3.1 é $\sigma_{\text {densidadeC }}=2,54 \mathrm{~g} / \mathrm{L}$. Para calcular o desvio padrão da variação de densidade de médio prazo, a Equação (11) foi usada.

$\sigma_{\text {densidade,total }}=\sqrt{\sigma_{\text {buggy }}^{2}+\sigma_{\text {densidade } M P}^{2}+\sigma_{\text {densidade CP }}^{2}}$

O resultado é:

$\sigma_{\text {densidadeMP }}=6,06 \mathrm{~g} / \mathrm{L}$ 
Para confirmar esse resultado e consequentemente que a Equação (11) foi propriamente definida, foi calculado o desvio padrão dos dados de densidade média com janela deslizante de nove, eliminando-se o efeito das variações abruptas geradas pelas trocas de buggy. E como usou-se as médias da janela deslizante, automaticamente os efeitos da variabilidade local foram praticamente eliminados, restando somente os efeitos das variações de médio prazo. O valor encontrado foi de $6,3 \mathrm{~g} / \mathrm{L}$, o qual é bem próximo do valor calculado anteriormente e ligeiramente superior, como era esperado, uma vez que ainda existia um pequeno resíduo de variabilidade local (curto prazo), como consequência da média deslizante de nove cartuchos.

Para simular as variações de densidade de médio prazo, ondas senoidais, triangulares e rampas com diferentes períodos e amplitudes foram aplicadas, com seus respectivos valores de desvio padrão para as distribuições de densidade de probabilidade de cada um dos casos mencionados anteriormente. Além disso, as rampas lentas e bruscas foram aplicadas somente para os buggies dianteiros e traseiros respectivamente, de acordo com a realidade encontrada, descrita previamente neste item.

Como o desvio padrão dos buggies (longo prazo) mostrado no item 3.3.3.2 e o desvio de densidade local são determinados com um grau de precisão muito maior que o desvio padrão da variação de médio prazo, para o qual é mais difícil obter-se um modelo estocástico, foi incluído no simulador um fator de ajuste que multiplica a saída do bloco gerador de densidade de médio prazo, de forma a possibilitar um ajuste fino no desvio padrão desse bloco, e consequentemente atingir o desvio padrão total de densidade igual a 8,7 g/L, como calculado anteriormente. Esse fator de ajuste deve ser muito próximo a 1 se o modelo do gerador de densidade de médio prazo representar bem a realidade, e de fato esse fator durante as simulações foi de 1,02, para obter a variação total esperada. 


\subsubsection{Modelo completo do gerador de densidade}

A Figura 37 mostra o modelo do gerador de densidade.

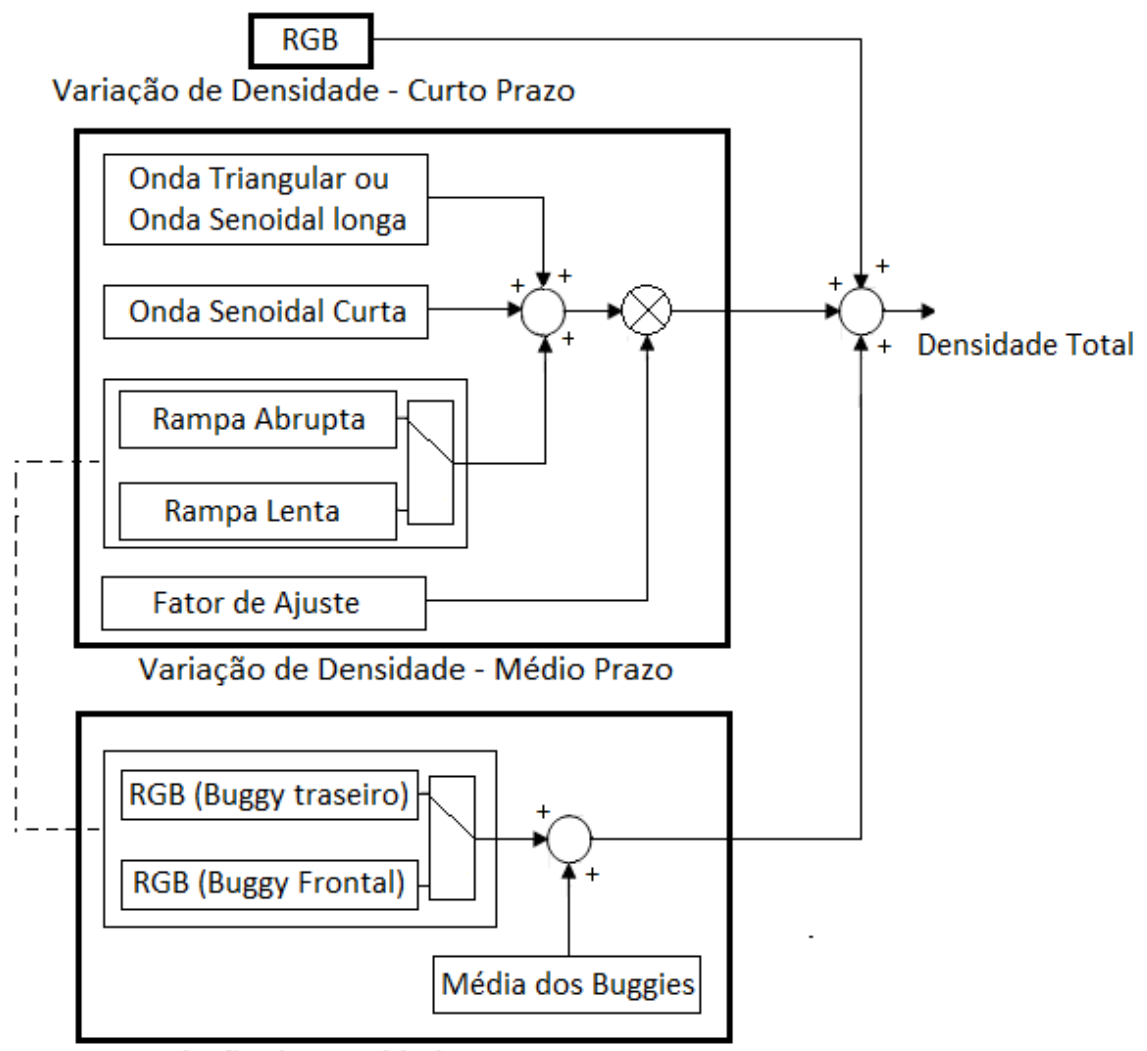

Variação de Densidade - Longo Prazo

Figura 37- Modelo do bloco gerador de densidade.

Como se pode notar na Figura 37, o gerador de densidade, o qual corresponde à principal fonte de perturbação, é um modelo com uma parte determinística e outra estocástica, da mesma forma que os modelos do conjunto de canecas e checkweigher foram representados. A única diferença é que a parte estocástica dos primeiros modelos era somente uma variável aleatória, que foi determinada através de alguns testes induzidos, enquanto no caso do gerador de densidade ela é a combinação de alguns processos estocásticos e foi determinada a partir da observação do processo normal de embalagem.

No gerador de densidade, a parte estocástica consiste na soma de três variáveis aleatórias: a variação de curto prazo, a variação de densidade dos buggies e a parte 
estocástica das ondas senoidais, triangulares e em rampa da variação de médio prazo. A parte determinística é composta pelo bloco que multiplica a saída do bloco gerador de médio prazo e a seleção da rampa abrupta ou lenta, de acordo com o buggy que alimenta a máquina.

Embora os dados levantados no item 3.3.3.3 sejam referentes aos 4,5 milhões de pesos observados, calculou-se também os dados de média e desvio padrão de densidade para cada grupo de trinta mil cartuchos, obtendo-se resultados que variaram em torno de 3 a 4\% para a média, e em torno de 0,7\% para a diferença de variabilidade, os quais são diferenças pequenas. Como a média não tem muita importância e sim a variabilidade, considerou-se que o modelo descrito anteriormente é aplicável para a maioria das produções do mesmo produto dessa fábrica. Somente em produções em que algo esteja fora do normal, é que se pode ter alguma variação significativa em relação ao modelo criado, mas esses são pontos que ocorrem com uma frequência muito baixa e então, para efeitos de avaliação de melhorias, podem ser desprezados.

O mesmo estudo foi realizado também para outras marcas de detergente em pó e foi observado que as oscilações e formas de onda são as mesmas, apenas amplificadas ou reduzidas, devido a diferentes características do detergente. Então, para simular outros produtos, usa-se o próprio fator de ajuste para compensar as variações de médio prazo e, se necessário, ajustam-se os parâmetros de média e desvio das variáveis aleatórias das oscilações de curto e longo prazo. As Figura 38, 39 e 40 mostram o modelo implementado no Simulink. 


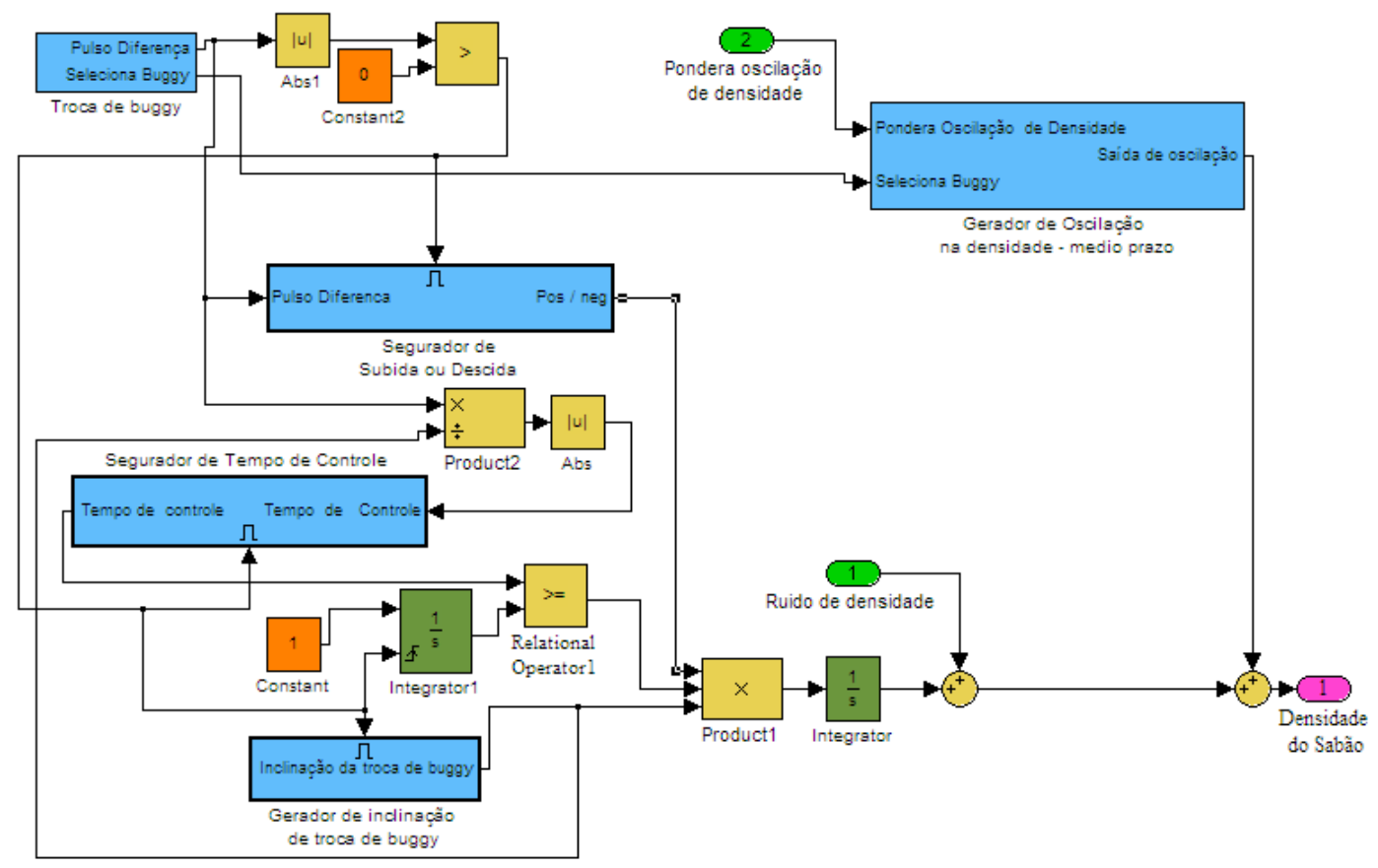

Figura 38- Gerador de densidade no Simulink.

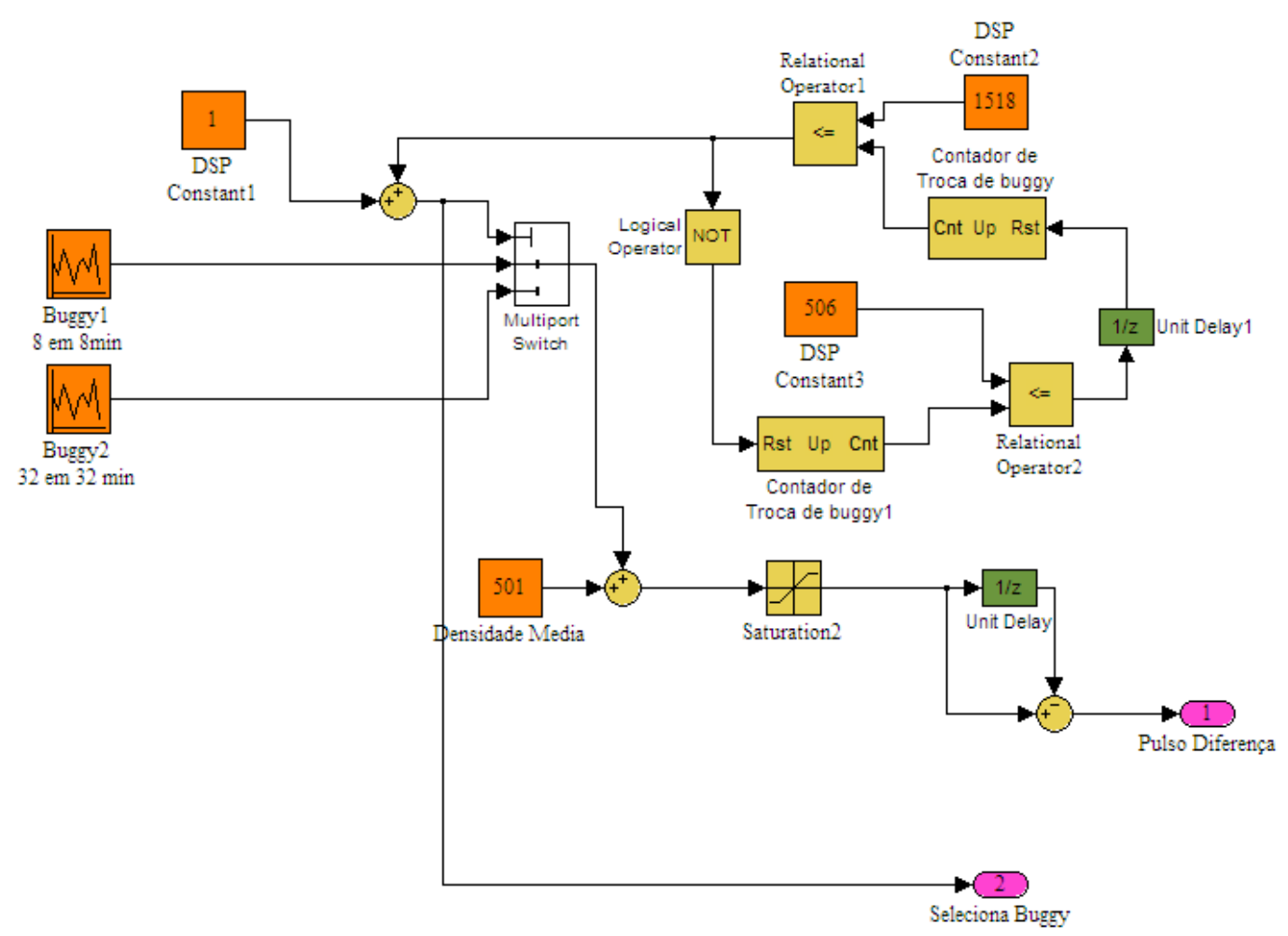

Figura 39- Gerador de densidade média dos buggies. 


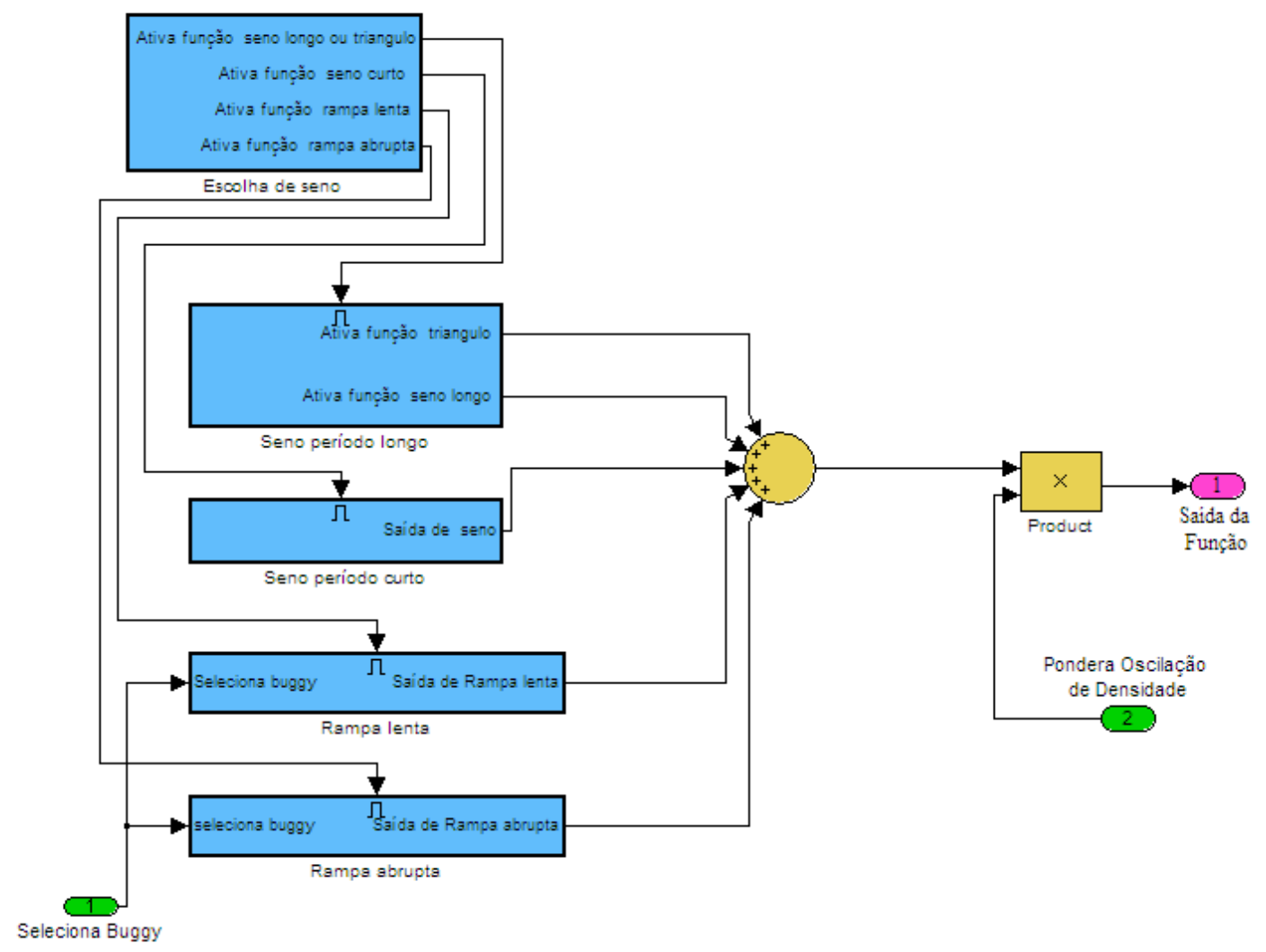

Figura 40- Gerador de densidade de médio prazo.

Como forma de validação do bloco gerador de densidade, o simulador foi rodado e o desvio padrão e média de densidade foram calculados, obtendo-se respectivamente $8,75 \mathrm{~g} / \mathrm{L}$ e $501,8 \mathrm{~g} / \mathrm{L}$, o que representa um erro de $0,6 \%$ e $0,3 \%$, respectivamente, em relação aos valores encontrados na análise de dados.

\subsubsection{Alternativa para modelo completo de gerador de densidade}

Inicialmente, o bloco gerador de densidade foi criado a partir de uma corrida de oito horas de produção. A ideia foi coletar todos os dados de peso dessa corrida, transformá-los em dados de densidade e colocar essa sequência de dados no simulador, para sempre realizar as simulações considerando essa perturbação. É uma boa ideia e a forma mais simples de fazer o modelo, embora gere algumas limitações, como somente poder atuar na amplitude geral do modelo, sem poder fazer alterações em uma das três partes que geram oscilações, ou seja, as simulações somente 
poderiam ser feitas reduzindo-se o desvio padrão total da densidade, mas não alterando partes da oscilação ou mesmo alterando a velocidade de variação.

Para gerar esse modelo foi feita uma corrida de oito horas (86400 cartuchos) com o controlador desligado e as canecas fixas com uma média de dois litros. Todos os dados de peso foram registrados pela checkweigher e colocados em uma planilha de Excel. Mas esses dados de peso estão contaminados com a influência do conjunto de canecas e com a imprecisão da checkweigher. Portanto, a primeira atividade foi filtrar esses dados o máximo possível. Assim, a parte determinística da variação das canecas foi facilmente eliminada, subtraindo-se de cada dado de peso o respectivo valor de erro médio de cada caneca, definido na subseção 3.3.2. Já os dados de variação devidos à não uniformidade de enchimento e imprecisão da checkweigher são mais difíceis de serem filtrados, pois são ruídos aleatórios gaussianos, que estão somados ao ruído gaussiano local de densidade. Subtrair dos dados duas variáveis aleatórias gaussianas de mesma média e desvio padrão do enchimento e checkweigher, não é solução, pois isso na verdade aumentaria ainda mais o desvio padrão total.

Foram utilizados dois métodos para filtrar esses dois ruídos, que não fazem parte da variação de densidade. Para o primeiro inicialmente se dividiu todos os dados de peso por dois litros, gerando os dados de densidade que ainda continuavam com a influência do enchimento e checkweigher, os quais aumentavam de forma irreal o desvio padrão local de densidade desses dados. Então para eliminar esses ruídos, calculou-se a média deslizante da densidade, usando uma janela de nove pacotes para todos os dados. Assim, os ruídos locais eram praticamente todos filtrados, restando somente a variação de médio e longo prazo da densidade, e ainda um pequeno resíduo do ruído local. Esse resíduo era gaussiano com desvio padrão igual ao total desvio padrão local desses dados, dividido pela raiz quadrada de nove. Isso ocorre, uma vez que o desvio padrão da média da amostragem de uma população é igual ao desvio da população dividido pela raiz quadrada do número de amostras. Isso pode ser aplicado porque as variáveis são independentes. No final, essa média funciona como um filtro passa baixa e como para uma média de nove cartuchos a frequência de variação não é alta, o ganho é praticamente 1, não necessitando-se 
fazer nenhum ajuste depois do filtro para acertar a amplitude das variações de médio e longo prazo.

Então, o desvio padrão total local calculado desses dados de densidade antes do cálculo da média deslizante foi $2,78 \mathrm{~g} / \mathrm{L}$, que está de acordo com a fórmula da Equação (10), a qual resultaria depois de multiplicar por dois litros, em um desvio total local de peso de 5,56g, considerando que o efeito do conjunto de canecas foi eliminado e portanto sua influência é nula. Assim, depois de calcular a média móvel, o desvio padrão local restante foi de 0,93 g/L. Sabe-se do item 3.3.3.1, que o desvio padrão local da densidade é $2,54 \mathrm{~g} / \mathrm{L}$, portanto somou-se ao resultado da média deslizante um ruído branco aditivo gaussiano com desvio padrão igual a 2,36 g/L, de forma que o desvio padrão local resultasse em 2,54g/L, que é o desvio somente da variação de densidade local.

Dessa forma, o resultado de dados obtidos depois dessa sequência de cálculos seria o modelo de dados de densidade a ser colocado no simulador. Uma validação foi feita, medindo-se na prática 2000 densidades em sequência e comparando-se a média e o desvio padrão da densidade e dos pesos dos respectivos cartuchos, com as mesmas variáveis dos dados de densidade e peso gerados pelo simulador. O erro foi de $1 \%$ e 0,9\% para os dados de média e desvio de densidade, respectivamente, e 0,8\% e 0,7\% para os dados de média e desvio de peso.

A segunda forma foi considerar que as influências de enchimento e da checkweigher já estavam representadas dentro do bloco de densidade, eliminando as mesmas dos seus respectivos blocos. O problema dessa segunda forma é que limita ainda mais os graus de liberdade do simulador, uma vez que não se pode simular, por exemplo, melhorias na checkweigher ou no enchimento.

Para os dois casos anteriores se implementou no simulador um bloco com uma sequência de números e a cada ciclo de simulação ele reproduz os mesmos.

Ainda existiria uma terceira possibilidade que não foi explorada. Poder-se-ia tentar encontrar um modelo para perturbação de densidade, através da técnica de Identificação de Sistemas conhecida por ARIMA (Samoradnitsky, Taqqu, 1994, \& 
Harvey, AC. 1990). Para isso passar-se-ia um ruído branco gaussiano por um filtro ou função de transferência, para os quais se deveria determinar o grau dos polinômios do denominador e numerador, seus respectivos coeficientes, e o grau de integração, de forma a obter na saída uma perturbação similar à realidade. Nesse caso também não seria possível separar as diferentes causas da variabilidade de médio prazo, além de ser duvidosa a possibilidade de encontrar um modelo que representasse com um mínimo de precisão, a realidade das perturbações aleatórias e descorrelacionadas.

No final foi utilizado o gerador de densidade mostrado no item 3.3.3.4, pois ele tem mais flexibilidade de alterar pontos importantes do processo, que os outros dois métodos não possuem, possibilitando qualificar e quantificar mais opções de melhorias.

\subsubsection{BLOCO DO CONTROLADOR}

O sistema de controle de peso é volumétrico, uma vez que ele tem por objetivo manter

o peso dos cartuchos no valor desejado, enchendo certo volume variável de detergente em pó. O volume tem que ser variável, porque a densidade do material varia ao longo do tempo. A Figura 4 mostra o diagrama de malha fechada do sistema de pesagem, que facilita muito o entendimento desta subseção.

Antes de explicar este módulo é necessário um dicionário de dados para melhor familiarização com as variáveis e palavras específicas.

- Tempo Morto (amostras) - é o atraso dos pacotes (intervalo entre encher e pesar o mesmo pacote);

- Média Desejada (g) - é a média ajustada na entrada do controlador, para que este tente manter a média dos pacotes no valor desejado;

- Falha de Controle (g) - é o parâmetro de zona morta do controlador. Se a média dos pacotes medidos estiver diferente da média desejada por um valor dentro da margem definida pela falha de controle, o controlador não envia um pulso para corrigir a altura das canecas. 
- Número de amostras - Número ajustado no controlador, que determina de quantos em quantos pacotes a média para controle é calculada;

- Velocidade do Motor ( $a_{m}$, graus/s) - é a velocidade que o motor gira;

- Fator de Controle $\left(C_{f}, \mathrm{~g} / \mathrm{s}\right)$ - fator ajustado na máquina, dado em gramas por segundo, que determina por quanto tempo o motor permanece ligado em uma correção; e

- Ganho de Controle ( $K_{C}$, adim.) - ganho dado ao Fator de Controle para amortizar erros de correção do controlador, devido às variações entre as dinâmicas do controlador e a realidade do processo (ajustável entre 0 e 1).

A inteligência do sistema de pesagem é o controlador, que tem como função manter o peso dos pacotes no valor da média desejada, corrigindo as perturbações causadas pelas variações de densidade. É importante que fique claro que se não houvesse variações da densidade, não seria necessário o uso do controlador, pois para um volume fixo ter-se-ia um peso fixo também, uma vez que as outras perturbações, que são de curto prazo, são ruídos com média zero e a variação determinística das canecas também com média zero. $O$ controlador é implementado em um software que faz também o cálculo da média dos pacotes e subtrai a média calculada da média desejada.

O que o controlador faz é calcular a diferença entre a média desejada e a média calculada a partir de um certo número ajustável de pacotes, e caso essa diferença supere uma falha de controle (também ajustável), é enviado um sinal para a cabeça dosadora, a fim de alterar a altura atual da mesma. O sinal enviado para a cabeça dosadora é um pulso de duração previamente calculada, que ativa o motor que controla a altura das canecas. Esse pulso tem amplitude fixa, causando uma velocidade constante do motor. O tempo é calculado de acordo com as Equações (12), (13) e (14).

$$
\begin{aligned}
& \text { erro }=\text { Set Point }-\bar{W} \\
& \Delta t=\frac{\text { erro }}{C_{f}} K_{c}
\end{aligned}
$$


$C_{f}=\omega_{m} \cdot C_{s} \cdot A_{c} \cdot \bar{d}$

onde erro é a diferença entre a média calculada $(\bar{W})$ usando o número de amostras e a média desejada (set point), $\Delta t$ é o tempo do pulso que o controlador envia para o motor, $C_{f}$ é o fator de controle, $K_{c}$ é o ganho de controle, $a_{m}$ é a velocidade angular do motor, $C_{S}$ é a constante da rosca que transforma velocidade angular em velocidade linear, $A_{c}$ é a área média das canecas e $\bar{d}$ é a densidade média de todos os pacotes em $\mathrm{g} / \mathrm{L}$ (valor constante).

Como se pode perceber, esse é um controlador proporcional e o fator de controle determina a variação de peso nas canecas para um dado tamanho de pulso, como por exemplo, se $C_{f}=14 \mathrm{~g} / \mathrm{s}$, significa que um pulso de 1 segundo causa uma diferença de peso de 14 gramas, se o ganho de controle for igual a um. $O$ fator de controle atualmente usado é $14 \mathrm{~g} / \mathrm{s}$. Dessa forma, a correção de altura visa manter o peso dos pacotes no valor desejado.

Para quantificar essas variáveis, realizaram-se várias medições, como medida da velocidade do motor, medida da velocidade linear para determinação de $C_{S}$ e medida da área das canecas. O valor de $C_{S}$ foi determinado de acordo com a Equação (15).

$$
C_{s}=\frac{s_{l}}{\omega_{m}}
$$

Onde $s_{l}$ é a velocidade linear.

A velocidade angular do moto-redutor medida foi de $120 \mathrm{graus} / \mathrm{s}$ e a velocidade linear foi de $0,0226 \mathrm{dm} / \mathrm{s}$. Portanto, $C_{S}=0,00018862 \mathrm{dm} / \mathrm{graus}$. Além disso, foi definida a constante de tempo da resposta do motor, através da medição da velocidade com um tacômetro, após aplicação de um degrau. Esse tacômetro era digital com armazenamento de dados que podem ser transferidos ao computador. $\mathrm{O}$ valor encontrado foi de $\tau_{m}=0,2 \mathrm{~s}$. 
Ao realizar uma correção, o controlador espera um determinado número de pacotes (tempo morto - ajustável) para recomeçar o cálculo das médias. Essa espera é devida ao atraso referente à posição da checkweigher, já que não faz sentido utilizar para o cálculo da média pacotes já enchidos, que não foram afetados pelo controle. Esse atraso é extremamente prejudicial para o controlador, já que ele tem que fazer correções dinâmicas devido às variações de densidade, que muitas vezes ocorrem mais rapidamente que o próprio atraso.

Através de vários blocos lógicos, implementou-se no simulador um subsistema chamado de controlador, que desempenha todas as funções identificadas. A seguir, são mostrados, respectivamente, nas Figura 41, 42 e 43, o diagrama de blocos do controlador, a parte macro do controlador implementado em Simulink e os detalhes do sistema que controla a altura das canecas.

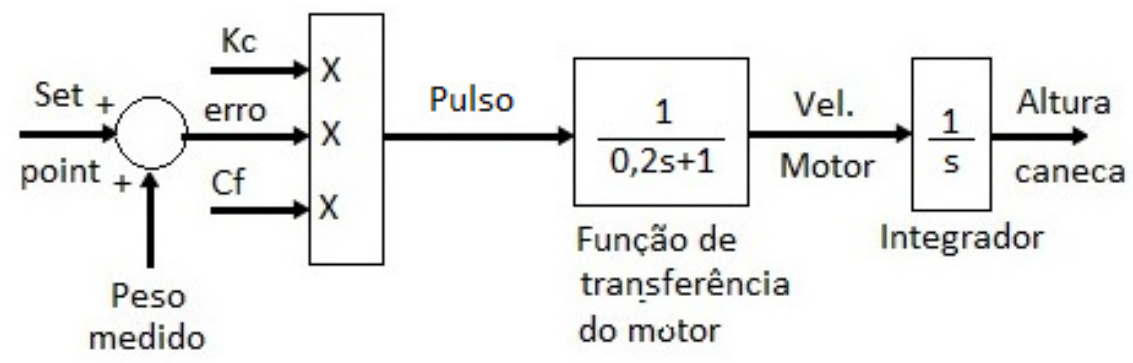

Figura 41- Diagrama de blocos do controlador. 


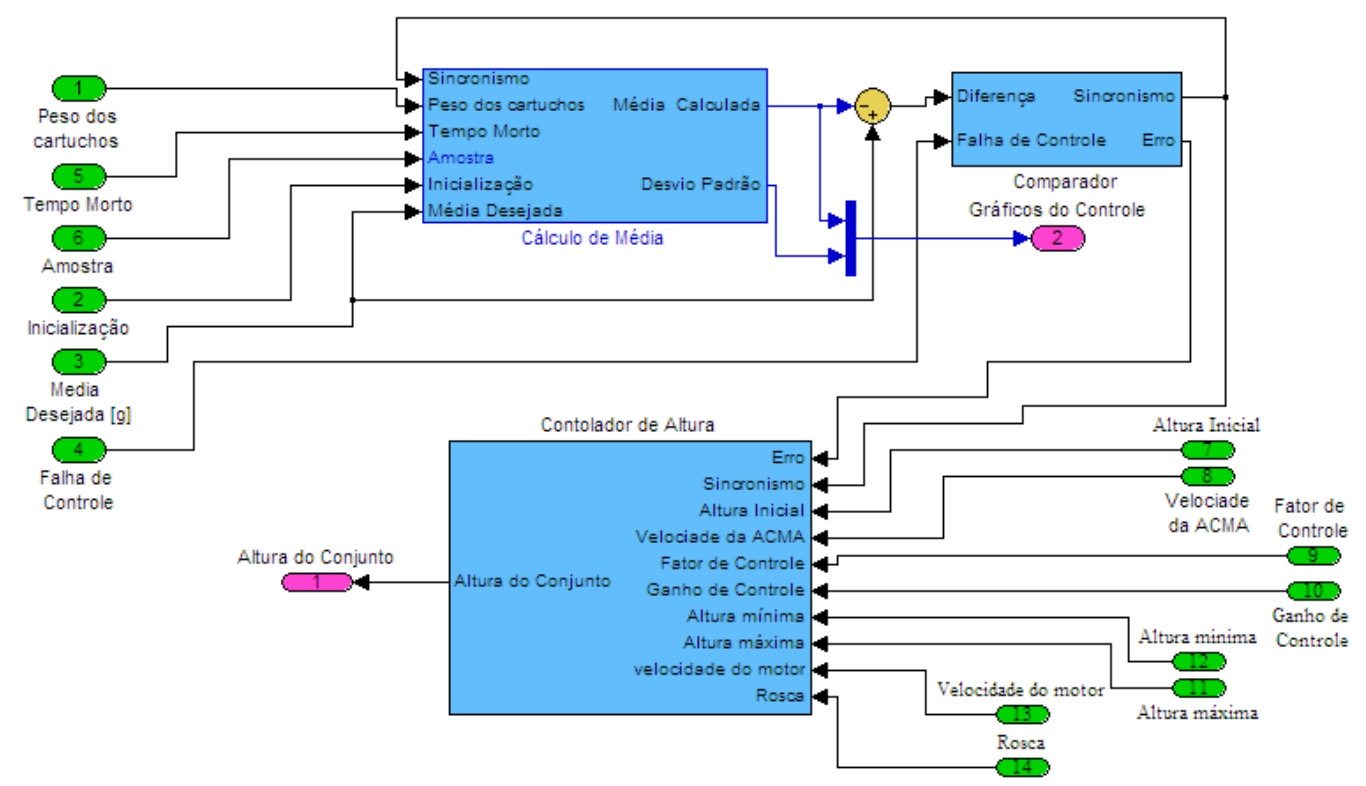

Figura 42- Modelo macro do controlador no Simulink.

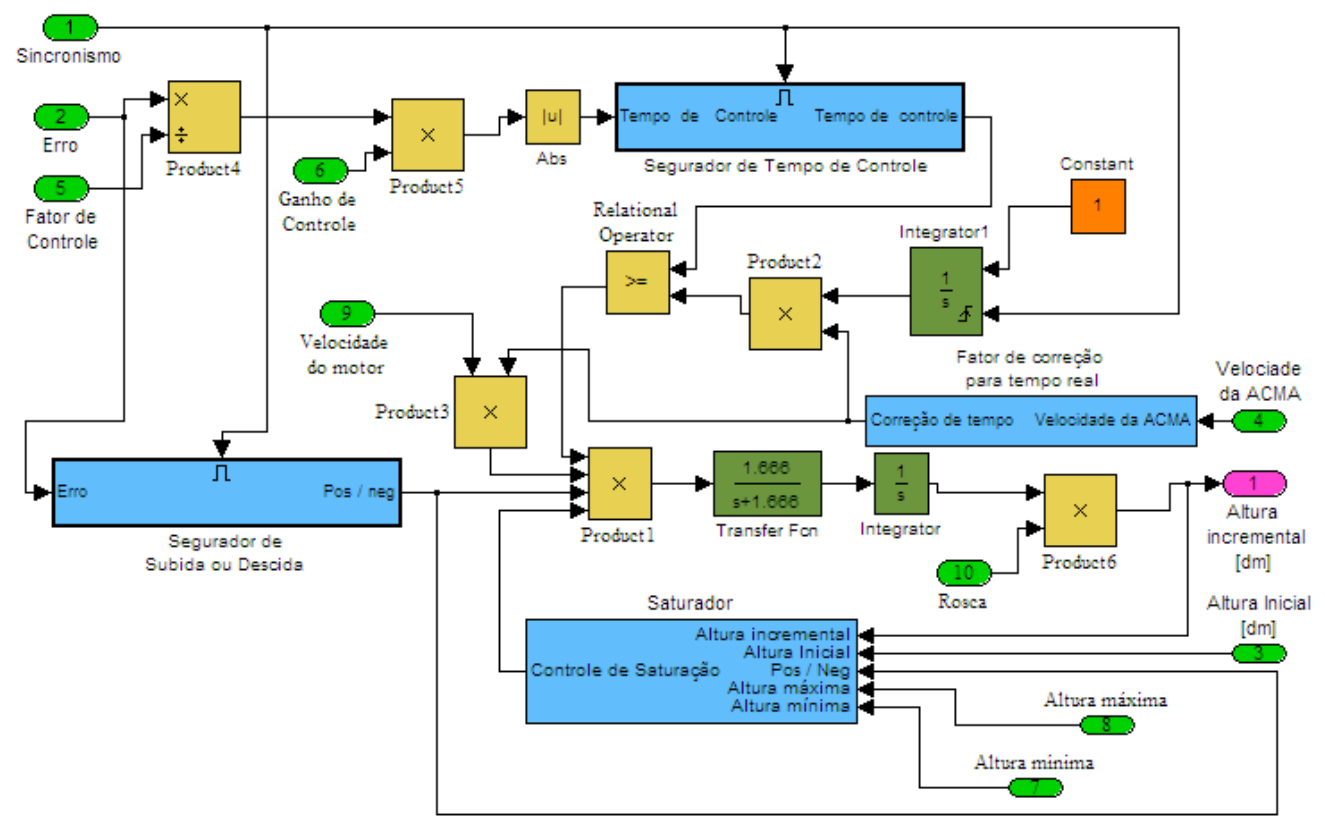

Figura 43- Modelo da parte do controlador e partes físicas que controlam a altura das canecas.

\subsection{BLOCO DE ANÁLISE DE DADOS}

Este bloco calcula todas as variáveis de interesse a serem analisadas como, por exemplo: número total de pacotes produzidos, porcentagem de sobrepeso, porcentagem e número de scraps, desvio padrão dos pesos dos cartuchos, desvio 
padrão da densidade e as perdas monetárias devidas ao sobrepeso e scrap. Além disso, mostra gráficos de pesos, correção do controlador e densidade.

Dentro deste bloco existem os sub-blocos que calculam as variáveis comentadas e um sub-bloco em que elas podem ser visualizadas. A Figura 44 mostra um dos blocos de cálculo e a Figura 45 mostra o sub-bloco de visualização.

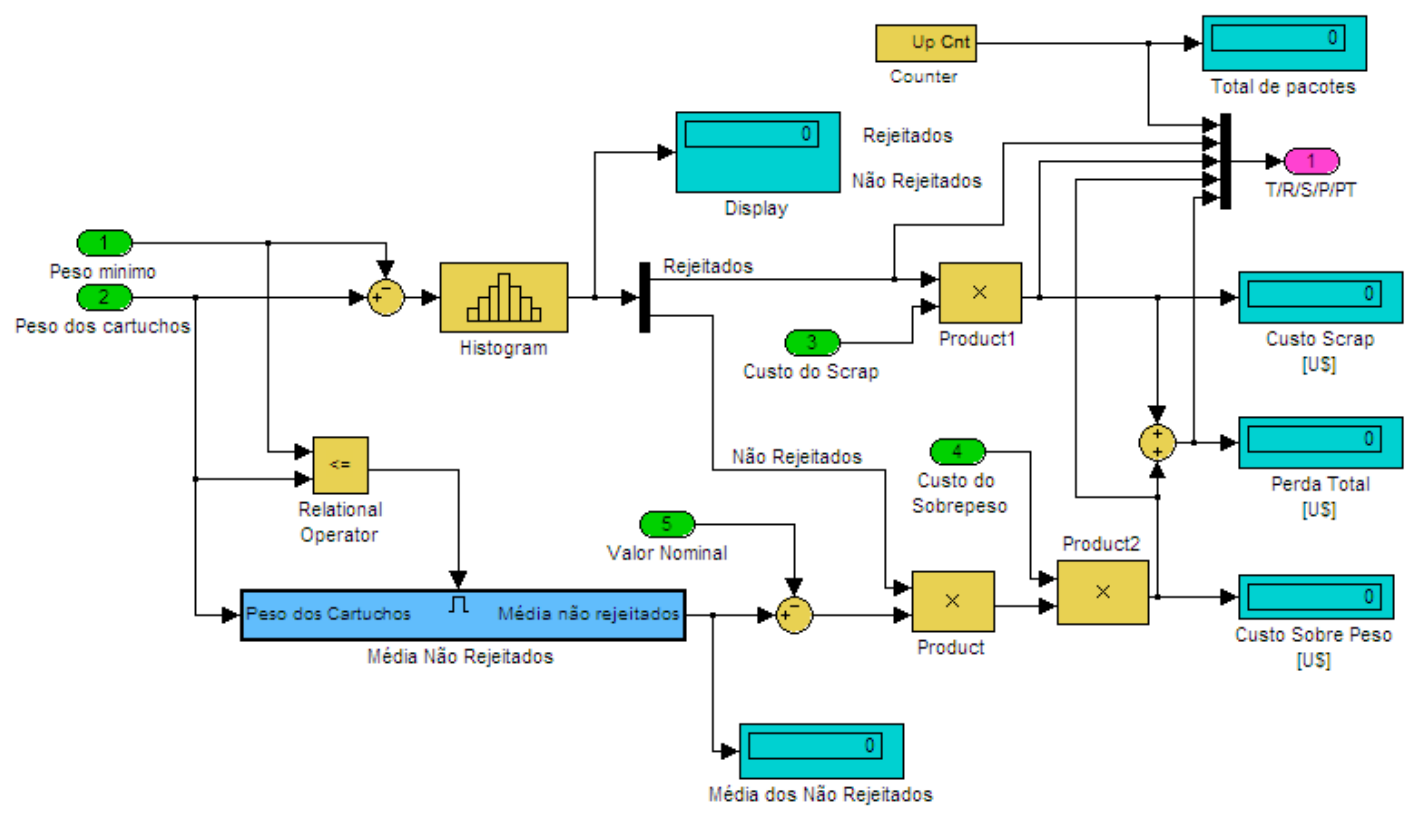

Figura 44- Bloco de cálculo de perdas monetárias. 


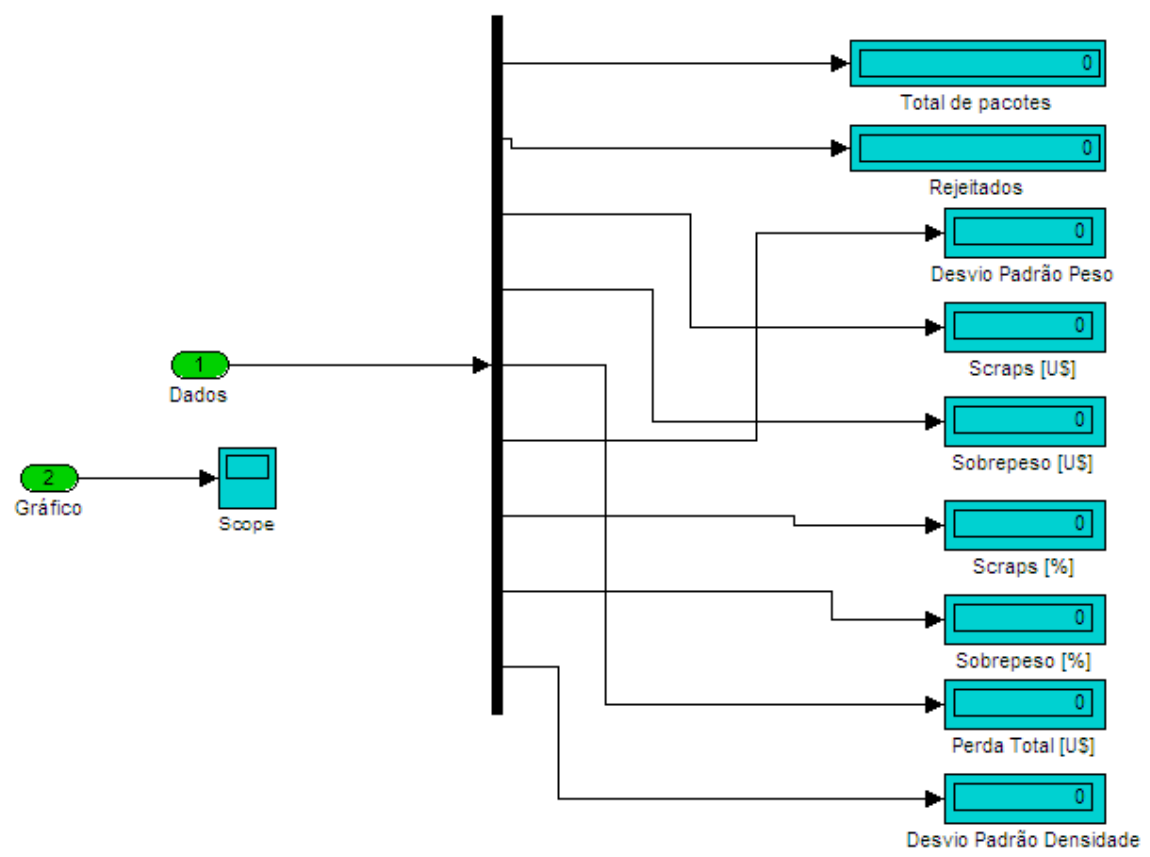

Figura 45- Bloco de visualização das variáveis.

Em uma simulação com 64800 amostras (6 horas de operação de uma máquina), os seguintes resultados foram obtidos:

- scrap = 460 cartuchos; $\quad$ - desvio padrão de peso $=13,18$;

- desvio padrão de densidade $=8,8 ; \quad$ - perda por scrap = US\$92,00;

- perda por sobrepeso = US\$589,00; - percentagem de scrap $=0,71 \%$;

- percentagem de sobrepeso $=1,83 \%$; - perda total $=$ US $\$ 681,00$.

Então, para identificar e quantificar as perdas monetárias, várias características podem ser alteradas no simulador:

- Parâmetros - no módulo dos parâmetros do modelo, diferentes parâmetros podem ser alterados. Parâmetros do controlador como tempo morto, média desejada ou número de amostras podem ser testados para otimizar os ajustes atuais. Adicionalmente, parâmetros de custo de scrap podem ser modificados para simular uma mudança de preço de matéria prima, ou mesmo o fator de diferença de altura das canecas pode ser reduzido para simular uma melhora dessa variação. Finalmente, o fator que controla as oscilações de densidade de médio prazo pode 
ser alterado para simular uma melhora no processo de fabricação ou controle de nível de pó no silo.

- Nova Lógica de Controle - uma nova lógica de controle pode ser implementada no simulador, substituindo-se o controlador proporcional ou alguma nova característica pode ser adicionada ao atual.

- Gerador de densidade - mudanças no gerador de densidade podem ser aplicadas para simular redução de trocas de buggies ou variação de médio prazo, para verificar qual seria a respectiva melhora.

- Mudanças físicas no sistema - pode ser simulada uma redução do atraso físico se a checkweigher é posicionada mais perto do conjunto de canecas ou se o motor é substituído por um servomotor, para se ter uma resposta mais rápida e precisa.

Para os quatro pontos anteriores, o simulador pode mostrar no módulo de análise de dados as perdas monetárias, antes e depois de implementar as melhoras. Desta forma, é possível decidir se vale a pena implementá-las. Note que o simulador pode simular muitas das mudanças mencionadas em conjunto e uma vez que o sistema é não linear, o benefício total de um conjunto de melhorias não é simplesmente a soma de todos os benefícios individuais.

A Figura 46 mostra o gráfico mostrando uma parte dos pesos e limites simulados.

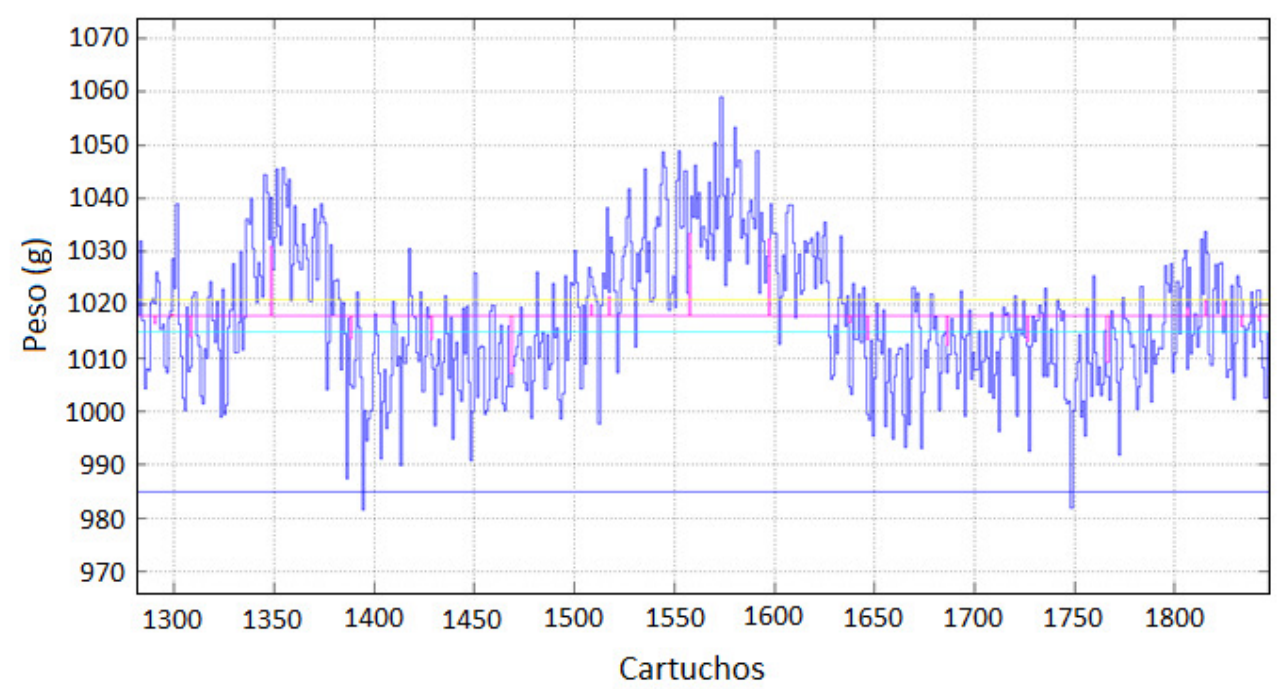

Figura 46- Gráfico dos pesos e das atuações do controlador gerados pelo simulador. 
A Figura 47 mostra os dados de peso em azul e os dados de densidade em verde da simulação de 6 horas de produção (64800 cartuchos).
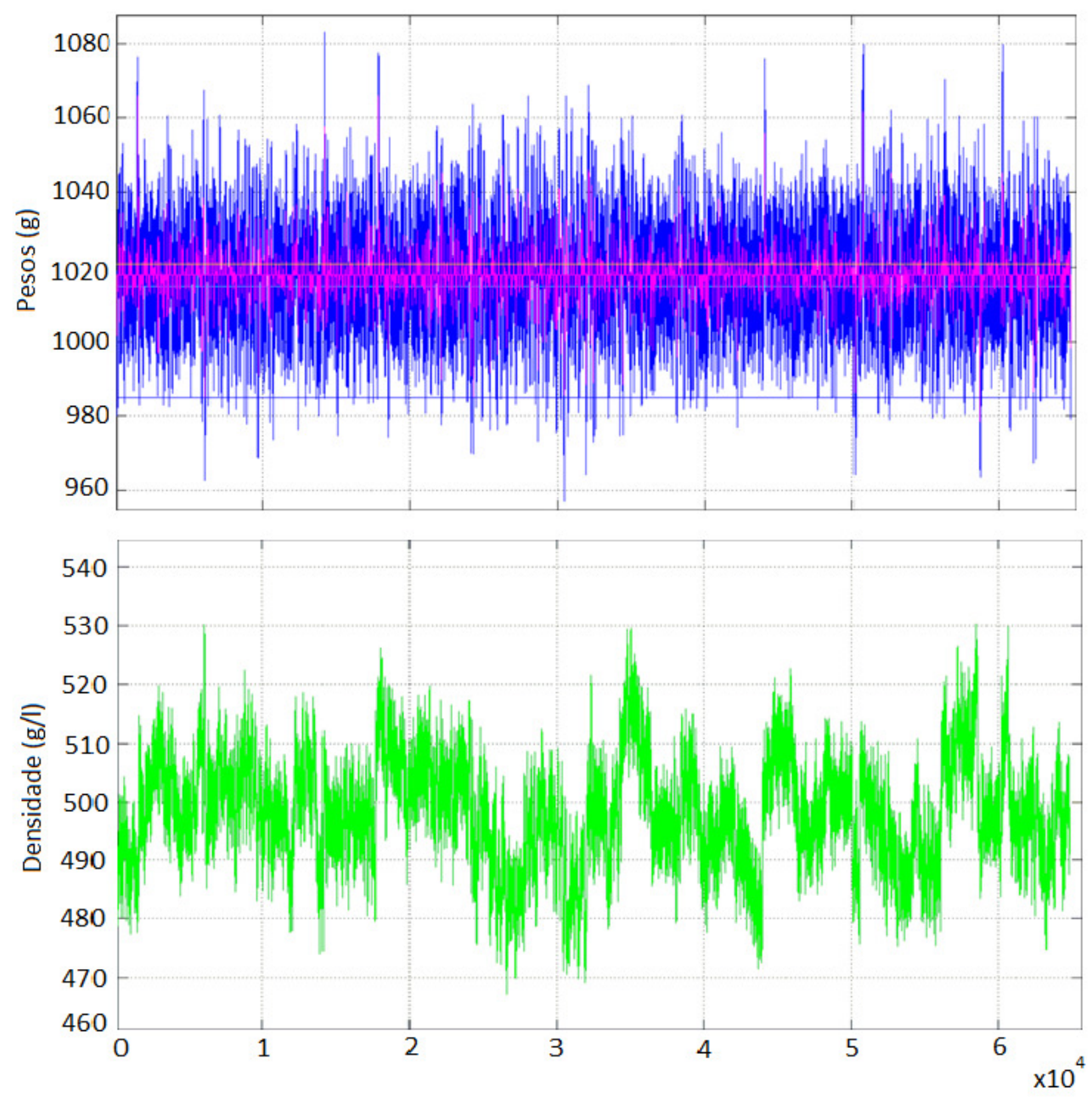

Figura 47- Gráfico de pesos e densidade da simulação de 6 horas. 


\section{VALIDAÇÃO DO SIMULADOR}

A validação foi feita em três passos: o primeiro comparando-se o resultado de saída real e simulada (sobrepeso e rejeitos) para o mesmo nível de variação de entrada (perturbação de densidade), o segundo comparando-se os gráficos com dados de peso real e simulado e o terceiro comparando-se o gráfico da Densidade Espectral de Potência (DEP) dos pesos reais e simulados, para avaliar a velocidade de variação.

No primeiro passo a variável de entrada é o desvio padrão de densidade e as de saída são o sobrepeso e a porcentagem de pacotes rejeitados. A perturbação do sistema normalmente não é a entrada de processos avaliados, mas nesse caso é o que faz sentido, pois é a variável que muda de um produto para outro, enquanto o resto do sistema permanece inalterado. É importante observar que os parâmetros do controlador foram ajustados no simulador exatamente igual aos utilizados na prática.

A Tabela 5 compara a saída real e a simulada para um turno de produção. A entrada considerada foi baseada na produção real de produtos diferentes que têm aqueles números de desvio padrão de densidade e, portanto, os parâmetros de curto, médio e longo prazo do simulador foram ajustados, para fornecer o mesmo nível de entrada, de forma a ser possível uma comparação entre dados reais e simulados. Isso pode ser feito, uma vez que o estudo de variação de densidade foi realizado também para todos os produtos, depois de ter sido feito para o produto inicial, como mencionado na subseção 3.3.3.

Tabela 5- Validação do modelo.

\begin{tabular}{|c|c|c|c|c|c|c|c|}
\hline & & \multicolumn{2}{|c|}{ Real } & \multicolumn{2}{c|}{ Simulado } & \multicolumn{2}{c|}{ Erro } \\
\hline Produto & $\sigma_{\text {dens }}(g / l)$ & Scrap (\%) & $\begin{array}{c}\text { Sobrepeso } \\
(\%)\end{array}$ & Scrap (\%) & $\begin{array}{c}\text { Sobrepeso } \\
(\%)\end{array}$ & Erro de scrap (\%) & $\begin{array}{c}\text { Erro de } \\
\text { sobrepeso (\%) }\end{array}$ \\
\hline Produto 1 & 7,4 & 0,62 & 1,29 & 0,60 & 1,31 & $-3,23$ & 1,55 \\
\hline Produto 2 & 8,4 & 0,64 & 1,49 & 0,65 & 1,53 & 1,56 & 2,68 \\
\hline Produto 3 & 9,2 & 0,71 & 1,77 & 0,71 & 1,78 & 0,0 & 0,57 \\
\hline Produto 4 & 10,5 & 0,76 & 2,05 & 0,75 & 2,01 & $-1,32$ & $-1,95$ \\
\hline Produto 5 & 11,7 & 0,75 & 2,18 & 0,76 & 2,21 & 1,33 & 1,38 \\
\hline
\end{tabular}


Como se pode notar na Tabela 5, para a mesma entrada, foram obtidos valores de saída muito parecidos, com o máximo erro absoluto de 3,23\% em produtos rejeitados (scraps) e 2,68\% em sobrepeso.

No segundo passo compararam-se os gráficos de pesos reais e simulados, como pode ser visto na Figura 48, que é uma ampliação da Figura 47 e cuja intenção é mostrar, que ao longo do tempo, o nível e velocidade de variação de curto e médio prazo são similares.

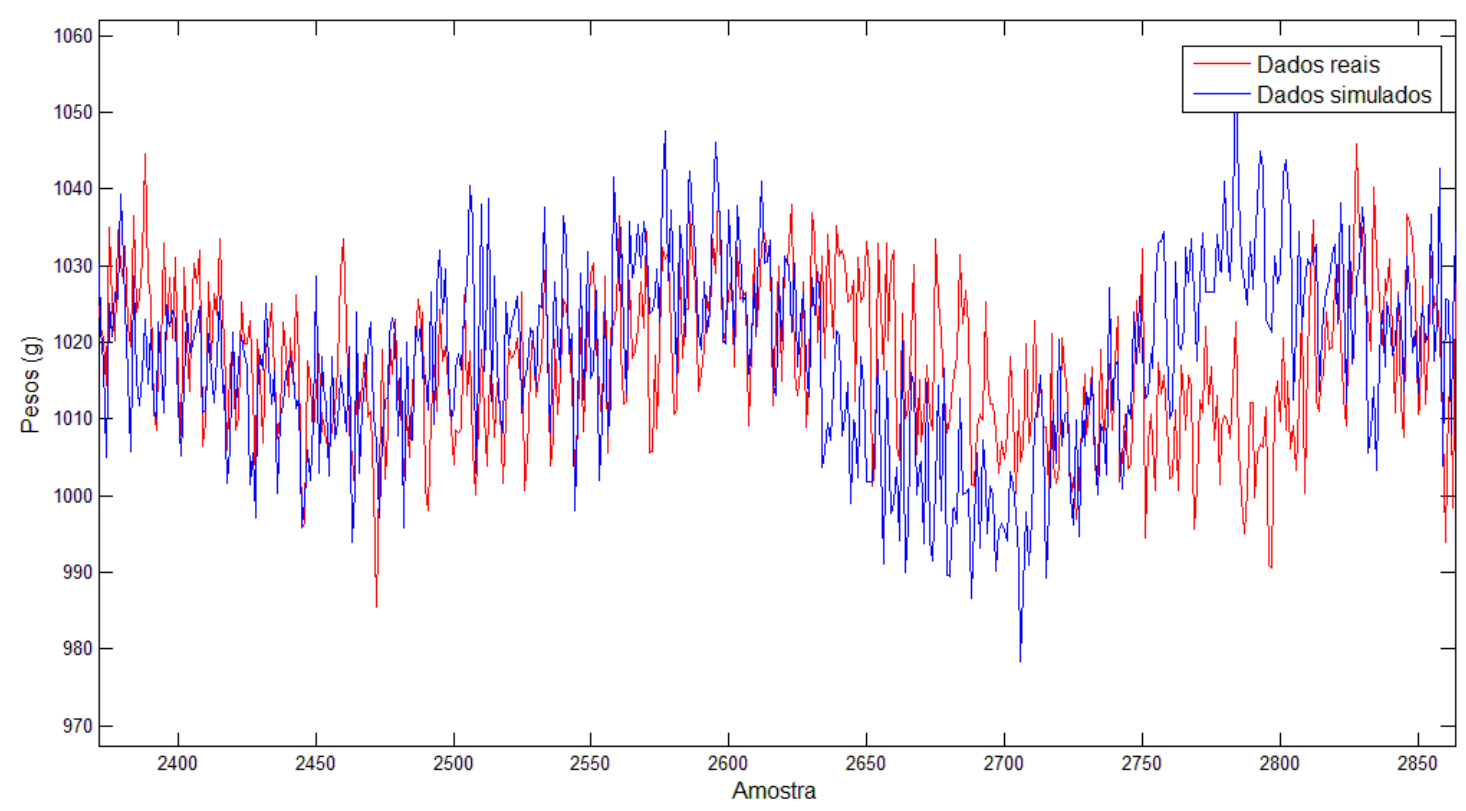

Figura 48- Comparação de pesos reais e simulados.

Esses dois gráficos são somente uma parte pequena de uma produção e de uma simulação e, portanto não representam uma comparação exaustiva. Mas essa comparação na realidade foi feita de forma muito mais detalhada, utilizando-se mais de quatrocentos mil dados, mostrando que as variações de curto, médio e longo prazo são bem similares.

Os gráficos de DEP da Figura 49 mostram que além do nível de variação ser o mesmo, a velocidade de variação é muito similar, também para os dados de peso reais e simulados. Nesses gráficos é bem claro que a maior parte das variações é de baixa 
frequência (variações de médio e longo prazo) e se pode ver algumas raias para algumas frequências específicas.

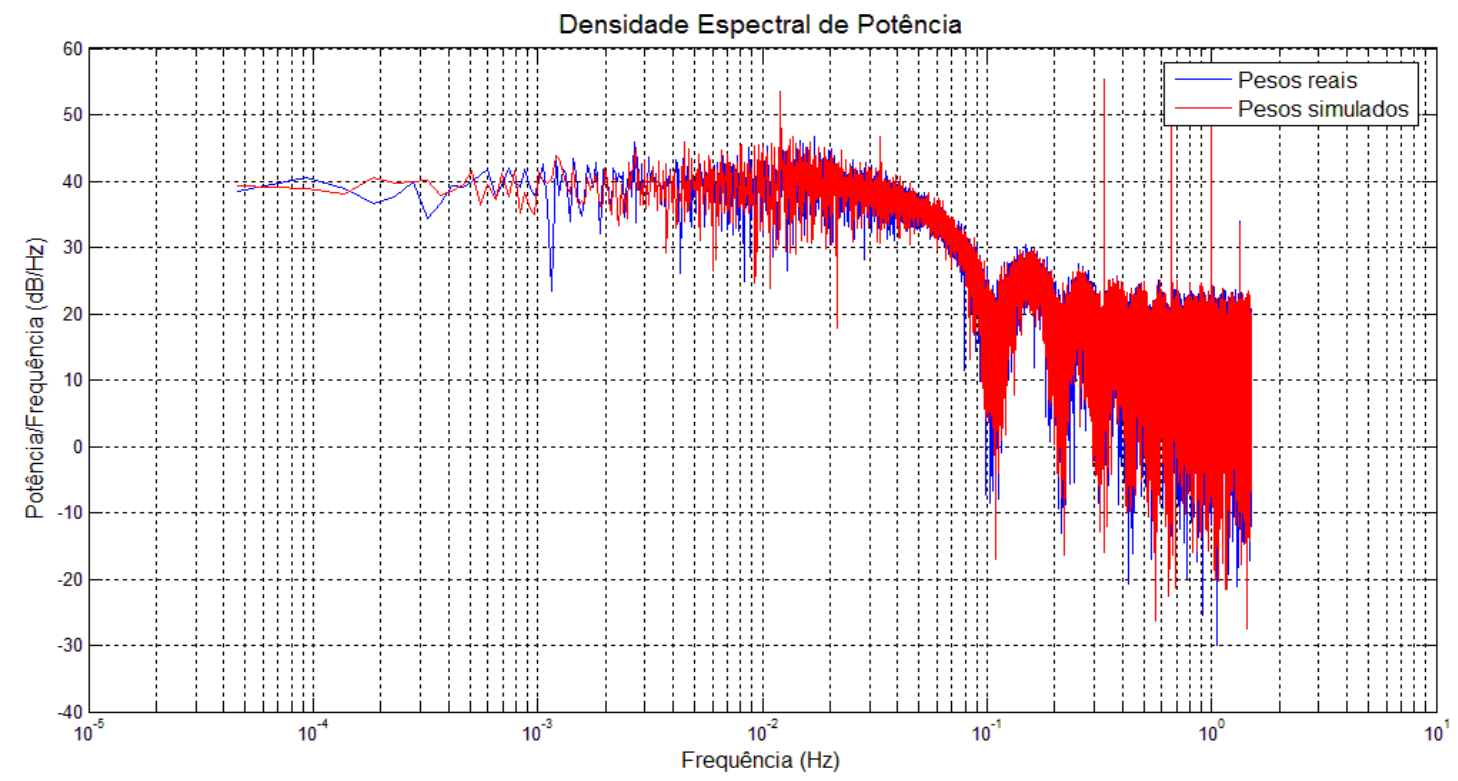

Figura 49- DEP (baseada em FFT unilateral) para os pesos simulados e reais com desvio padrão de densidade de $8,4 \mathrm{~g} / \mathrm{L}$.

Uma ampliação é aplicada nos gráficos da Figura 49 em torno de algumas frequências, gerando as Figura 50 e 51. Pode-se observar nesses gráficos que os valores iniciais da DEP são os mesmos e que as raias mostram variações periódicas, tendo o mesmo nível nas mesmas frequências para os dados simulados e reais. É possível notar um pico em $0,33 \mathrm{~Hz}$, que corresponde à variação das canecas, a qual ocorre a cada 3 segundos, correspondendo a uma volta completa do conjunto de canecas. 


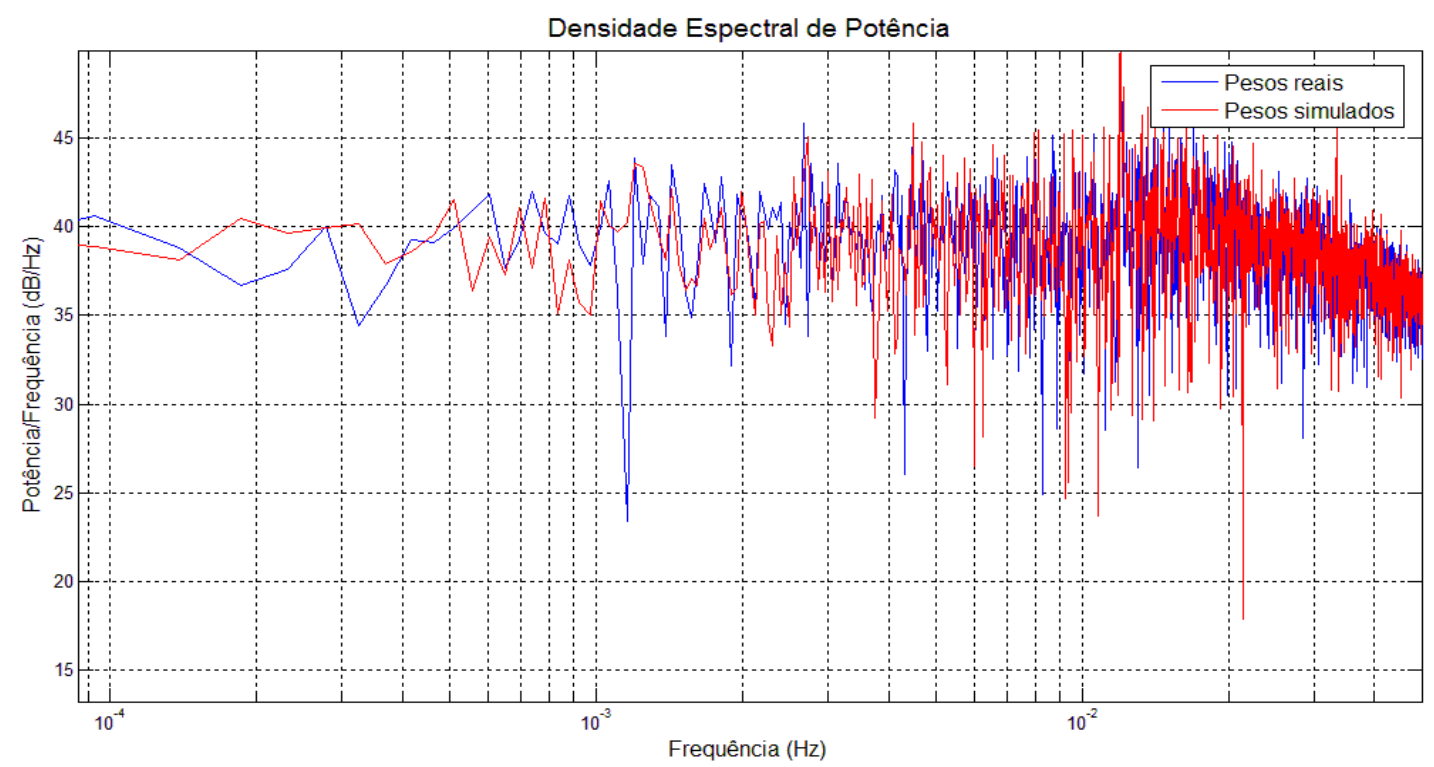

Figura 50- Ampliação em DEP (baseada em FFT Unilateral) de pesos reais e simulados para desvio padrão de densidade de $8,4 \mathrm{~g} / \mathrm{L}$.

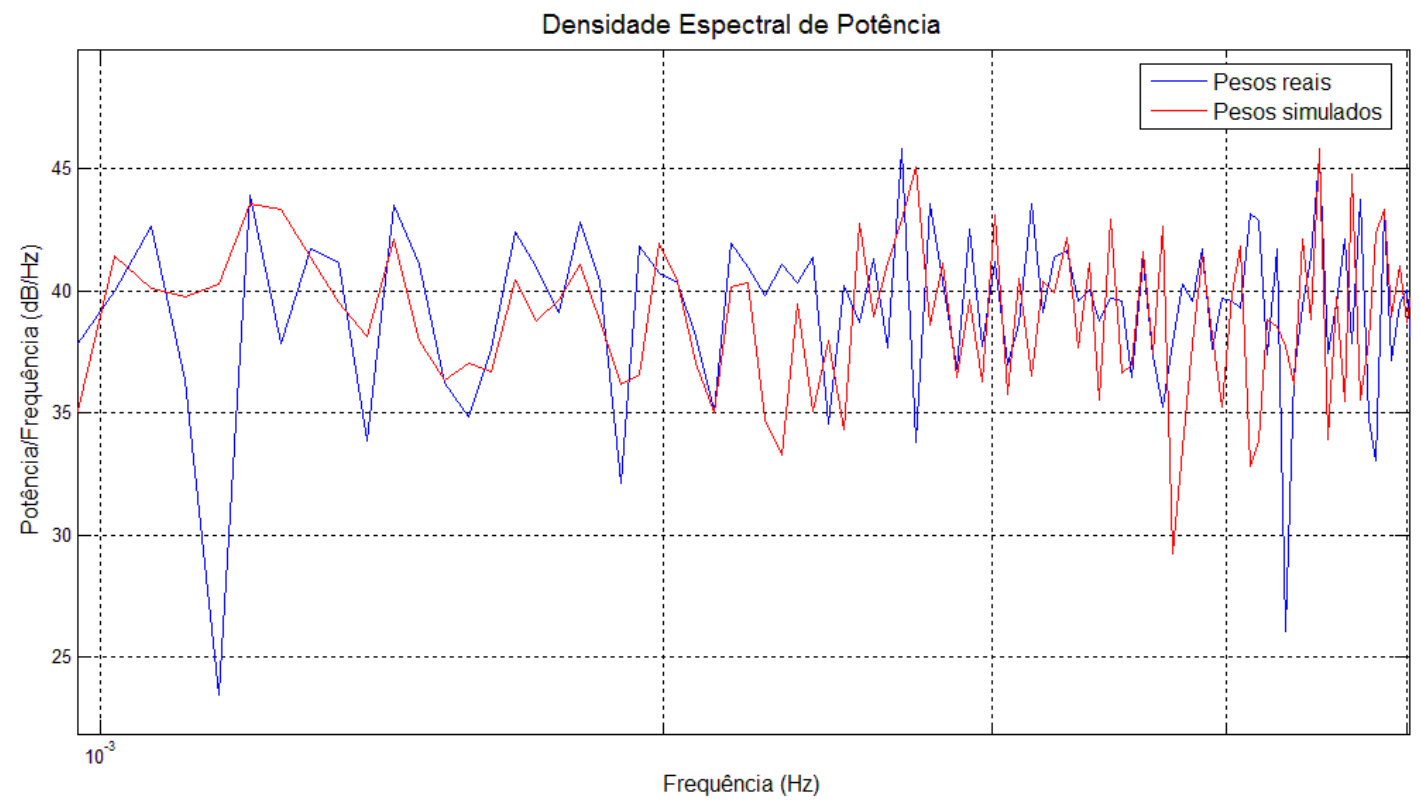

Figura 51- Ampliação em DEP (baseada em FFT Unilateral) de pesos reais e simulados para desvio padrão de densidade de $8,4 \mathrm{~g} / \mathrm{L}$. 


\section{CONCLUSÕES E AVALIAÇÃO DE REAPLICAÇÃO}

\subsection{CONCLUSÕES GERAIS}

Como previsto nos objetivos do trabalho, tem-se um simulador capaz de identificar e quantificar melhorias para o sistema em questão, evitando a necessidade de testes práticos, que muitas vezes são impossíveis, pois eles seriam a própria implementação da melhoria, como no caso de se reduzir o atraso. Assim, o simulador é uma ferramenta para avaliar a viabilidade financeira das melhorias.

O simulador pode:

- manipular parâmetros do sistema de controle;

- reduzir a variabilidade de processo devido às canecas;

- simular melhorias como substituir o motor do conjunto de canecas por um servo;

- eliminar parte da variabilidade de densidade; e

- testar novos tipos de controladores.

Esse conceito está alinhado com o aumento do uso de simuladores no cenário industrial nas últimas três décadas, com o objetivo de se correr menos riscos e se ter menos perdas, uma vez que as mudanças ocorrem em ambiente simulado (Cole; Yount, 1994; Klopfenstein, 1994).

Provou-se também que o simulador modela fielmente o processo em questão, já que os valores de saída das simulações correspondem quase que exatamente aos valores encontrados na prática, alcançando erros menores que 3,5\%, como mostrado no capítulo 4.

\subsection{AVALIAÇÃO DE REAPLICAÇÃO}

Esse simulador pode ser usado para uma infinidade de sistemas de embalagem de material particulado em pó com cartuchos, uma vez que esse tipo de máquina e 
tecnologia são as mais usadas para essa aplicação, devido a sua alta produtividade. Ou seja, muitas outras empresas poderiam usar exatamente o mesmo simulador, somente ajustando os parâmetros de acordo com sua realidade.

\subsection{APRENDIZADOS ADQUIRIDOS AO LONGO DESTE TRABALHO}

Através desse trabalho foi possível aprender técnicas de modelagem de sistemas, verificar como processos estocásticos estão presentes no dia-a-dia, realizar uma profunda análise de dados, utilizar conhecimentos de processamento digital de sinais, fazer análises matemáticas e tudo isso aplicado a um problema prático, que visa uma necessidade do mundo de hoje: a redução de custos de forma inteligente.

Além dos aprendizados acadêmicos, pode-se citar que houve um aprofundamento no conhecimento de sistemas de enchimento de produtos, cujo peso é controlado por volume. Embora este fosse um caso de material particulado em pó, todos os conhecimentos adquiridos podem ser aplicados para qualquer tipo de produto. Não só os conhecimentos, mas o simulador em questão também, claro que com as adaptações necessárias.

Assim, esse conceito pode ser utilizado para outros sistemas de embalagem e pesagem, como produtos líquidos ou pastosos. A empresa em questão está empregando o mesmo conceito para as linhas de shampoo. Outros aprendizados interessantes estão saindo deste trabalho, como o fato de que no caso de frasco com produto líquido, é melhor ter uma checkweigher de final de linha pesando a caixa toda com 12 frascos, do que uma checkweigher pesando os frascos individualmente, uma vez que a imprecisão da checkweigher é grande para produtos de baixo peso (100 a 200g) e a variação da densidade de produtos líquidos é lenta e varia em degraus, a cada batelada produzida.

\subsection{SUGESTÕES PARA TRABALHOS FUTUROS}

A seguir estão algumas perspectivas de continuação deste trabalho: 
- definir lista de possíveis melhorias para o sistema e testá-las no simulador, quantificando seus benefícios para decidir suas respectivas implementações;

- implementar as melhorias na prática e verificar os resultados, confrontando com o esperado no simulador;

- através do simulador, desenvolver propostas inovadoras de tipos de controladores para este tipo de aplicação;

- estudar um controlador PID para o sistema em questão. O controlador normal das checkweighers para essa aplicação é proporcional e talvez usando um algoritmo PID com a média tenha-se um melhor desempenho;

- estudar um tipo de predição para os dados de densidade e peso, de forma a incluir isso como parte do controlador tradicional. Isso pode ser pensado, uma vez que a perturbação de densidade é um sinal correlacionado, dependendo de algumas características do processo de fabricação e fluidez do produto;

- pesquisar alternativas para medidores de densidade, de forma a ele servir como uma pré-medição da perturbação;

- implementar um sistema de pós dosagem depois da checkweigher, de forma que a máquina atual funcionaria como uma dosagem grossa e depois existiria uma dosagem fina com um dosador de rosca; e

- estudar aplicações de pré-pesagem para sistema de embalagem rotatório, de forma que o peso dos pacotes seja pesado antes ou enquanto a dosagem é feita.

Portanto, estudos futuros poderiam abordar outros produtos de material particulado em pó, assim como produtos líquidos e pastosos. 


\section{Referências Bibliográficas}

Åström, K.J. \& Wittenmark, B. Computer-controlled systems - theory and design, $3^{\text {rd }}$ ed. Upper Saddle River, NJ: Prentice Hall, 2000.

Carrasco. J.A. \& Dormido, S. Analysis of the use of industrial control systems in simulators: State of the art and basic guidelines. ISA Transactions, v. 45, n. 2, p. 295312, 2006.

Cole, J.D. \& Yount, K.B. Applications of dynamic simulation to industrial control problems. ISA Transactions, Kingsport, TN, v. 33, n. 1, p. 11-18, 1994.

Cronin, K. A methodology for investigation into alternative packaging methods for column wrapped biscuits. Journal of Food Engineering, Cork, Ireland, v. 39, p. 379387, 1999.

Cronin, K. \& Fitzpatrick, J. \& McCarthy, D. Packaging strategies to counteract weight variability in extruded food products. Journal of Food Engineering, Cork, Ireland, v. 56, p. 353-360, 2003.

Cymbalista, M. \& Neto, P.L.O.C., Probabilidades, $1^{\text {a }}$ edição São Paulo SP: Edgard Blucher, 1974.

Ennis, B.J. Agglomeration Technology: Mechanisms. Chemical Engineering, Feature Report, p. 34-39, 2010. Disponível em: <www.che.com>. Acesso em: 23 julho. 2013.

Harvey, AC., Forecasting,structural time series models and the Kalman filter, $1^{\text {st }}$ ed, Cambridge University Press, 1989.

Klopfenstein, R. Personal computer process loop simulator. ISA Transactions, Bowling Green, OH, v. 33, n. 3, p. 255-274, 1994.

Lathi, B.P. Modern digital and analog communication system, $3^{\text {rd }}$ ed. New York, NY: Oxford University Press, 1998.

Leon-Garcia, A. Probability and Random Process for Electrical Engineering, $2^{\text {nd }}$ ed. Addison-Wesley Publishing Company, Inc., 1994.

Ljung, L. System identification: theory for the user, $2^{\text {nd }}$ ed. Upper Saddle River, NJ: Prentice Hall, 1999.

Ogata, K. Discrete-Time Control System, $2^{\text {nd }}$ ed. Upper Saddle River, NJ: Pretince Hall, 1995.

Oliveira, R.C.R. \& Garcia, C. Simulator for a packing and weighing of granulated powder. ISA Transactions, v. 52, p. 672-683, September, 2013.

Samoradnitsky, G. \& Taqqu, MS. Stable non-gaussian random process: Sthocastic Models with Infinitive Variance, $1^{\text {st }}$ ed. Chapman \& Hall, 1994. 
Sanchez, A. \& Parra, L.F. \& Baird, R. \& Macchietto, S. Hybrid modeling and dynamic simulation of automated batch plants. ISA Transactions, Guadalajara, México, v. 42, n. 3, p. 401-420, 2003 